\title{
ENHANCING RADIOTHERAPY USING ULTRASOUND AND MICOBUBBLES WITH CHEMOTHERAPY
}

\author{
by \\ Firas Almasri \\ B.Sc. Ryerson University, 2011 \\ Toronto, Canada
}

\author{
A thesis \\ presented to Ryerson University \\ in partial fulfillment of the \\ requirements for the degree of \\ Master of Science \\ in the Program of \\ Biomedical Physics
}

Toronto, Ontario, Canada, 2014

(C) Firas Almasri, 2014 


\section{Authour's Declaration}

I hereby declare that I am the sole author of this thesis. This is a true copy of the thesis, including any required final revisions as accepted by my examiners.

I authorize Ryerson University to lend this thesis to other institutions or individuals for the purpose of scholarly research.

I further authorize Ryerson University to reproduce this thesis by photocopying or by other means, in total or in part, at the request of other institutions or individuals for the purpose of scholarly research.

I understand that my thesis may be made electronically available to the public.

Firas Almasri 


\begin{abstract}
Enhancing Radiotherapy using Ultrasound and Microbubbles with Chemotherapy
\end{abstract}

\author{
Firas Almasri \\ Master of Science, Biomedical Physics
}

Ryerson University, 2014.

The application of ultrasound and microbubble (USmb) has been shown to enhance chemotherapy and radiotherapy (XRT) both in vivo and in vitro. The hypothesis guiding this research is that the combination of ultrasound and microbubbles with chemotherapy (Taxotere TXT) improves treatment response of radiotherapy of in vitro prostate (PC3) cancer cells. USmb synergistically decreased cell viability when combined with $\mathrm{TXT}_{2 \mathrm{~h}}+\mathrm{XRT}$ and XRT. Cell viability with the combined treatment $\left(\mathrm{TXT}_{2 \mathrm{~h}}+\mathrm{USmb}+\mathrm{XRT}=2 \%\right)$ decreased by $\sim 28$-folds, $\sim 19$ folds and $~ 11$-folds compared to XRT alone (57\%), $\mathrm{TXT}_{2 \mathrm{~h}}+\mathrm{XRT}(37 \%)$ and USmb+XRT (22\%), respectively. Cell viability with USmb+XRT (22\%) decreased by $\sim 2.5$ folds compared to XRT alone. Effectiveness of the combined treatment depended on chemotherapy dose and treatment duration as well as microbubble concentration. The therapeutic application of USmb may enhance cancer cell death by chemotherapy and radiotherapy and reduce their toxic side effects. 


\section{Acknowledgments}

This thesis not just a typing work, it is a great milestone working with my advisor Prof. Raffi Karshafian, I would like to express my sincere gratitude to my advisor Prof. Raffi Karshafian for the continuous support of my Master study and research, for his patience, motivation, enthusiasm, and immense knowledge. His guidance and advices helped me in all the time of research and writing of this thesis. I could not have imagined having a better advisor and mentor for my Master study.

Besides my advisor, I would like to thank the rest of my thesis committee members Dr. Michael Kolios, Dr. Devika Chithrani, Dr. Greg Czarnota and Dr. Shun Wong for their encouragement and insightful comments. I would also like thank my fellow lab mates Narbeh Edjiu, Amanda Tran and Anoja Giles who have provided support during early mornings and long nights of failed and successful experiments

Finally, I would like to thank my family. They were always there cheering me up and stood by me through the good times and bad. 


\section{Dedication}

Mom, Dad, brother \& my beautiful sisters 


\section{TABLE OF CONTENTS}

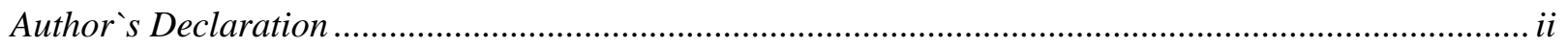

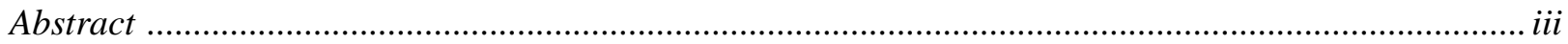

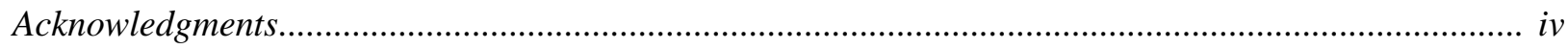

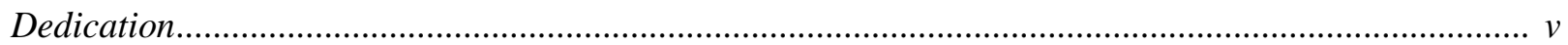

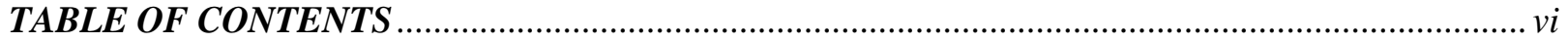

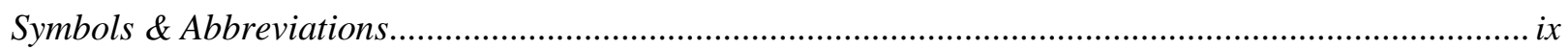

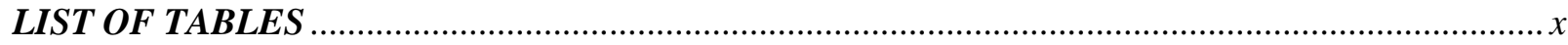

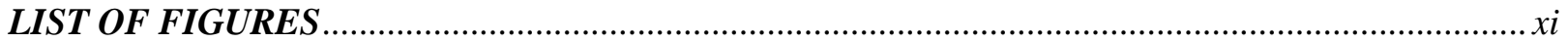

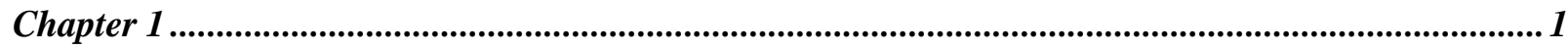

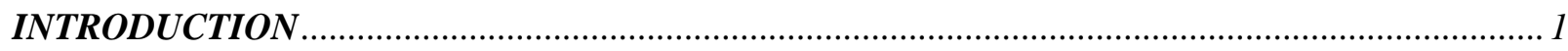

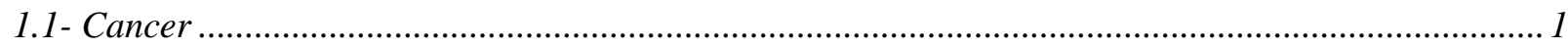

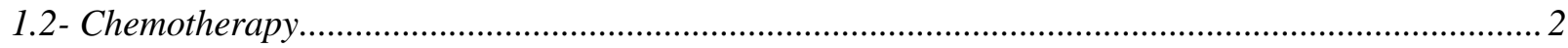

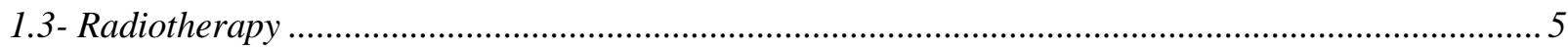

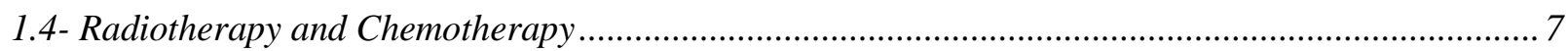

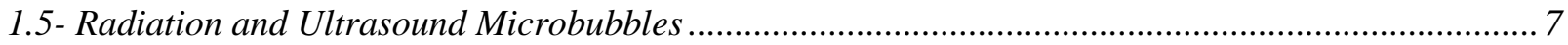

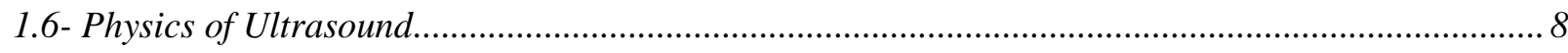

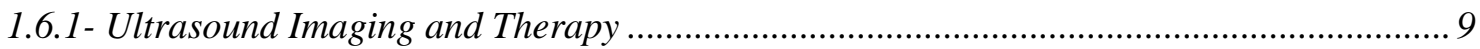

1.6.2-Ultrasound Microbubble Imaging and Therapy .............................................................. 9

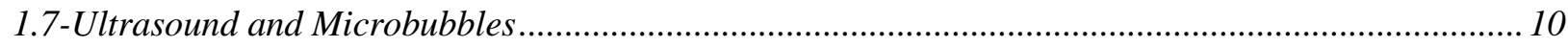

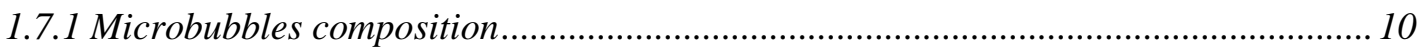

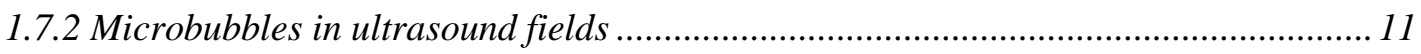




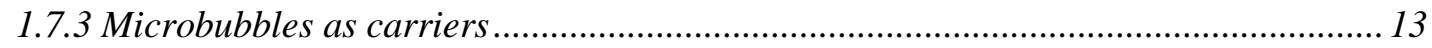

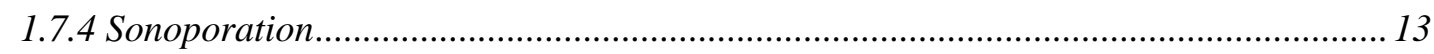

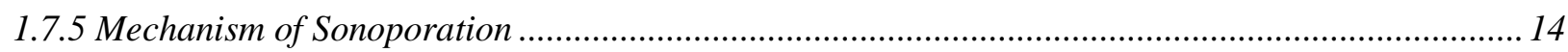

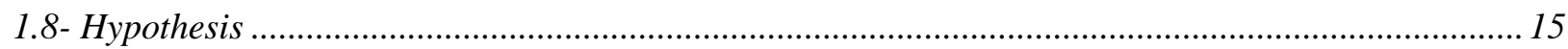

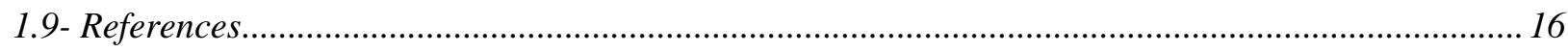

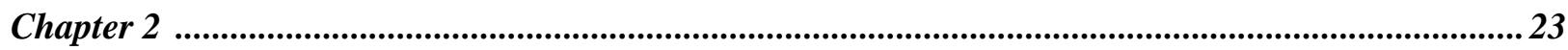

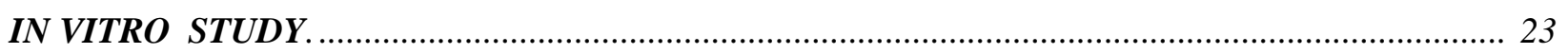

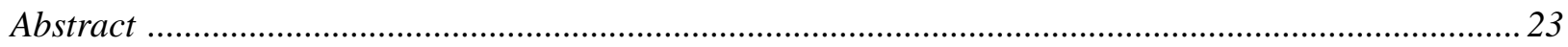

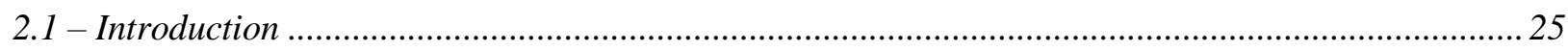

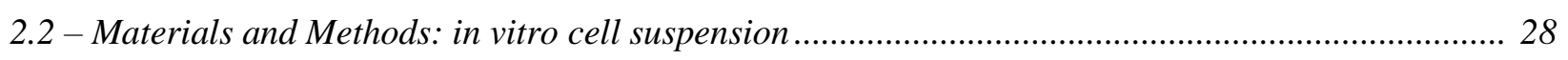

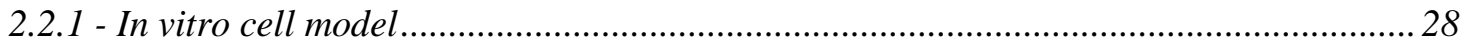

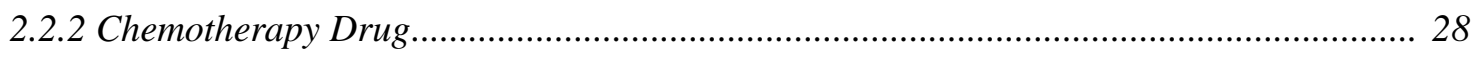

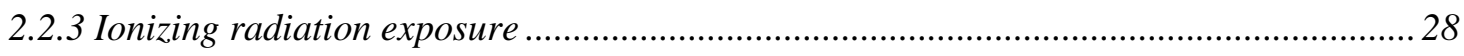

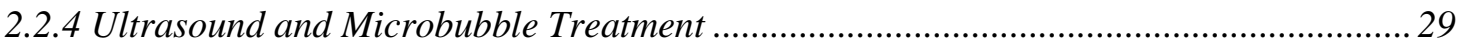

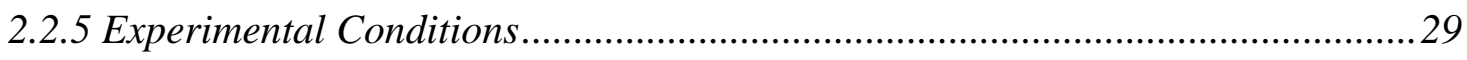

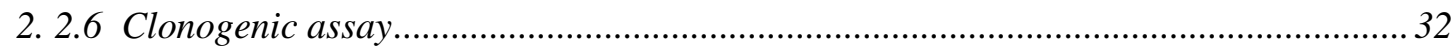

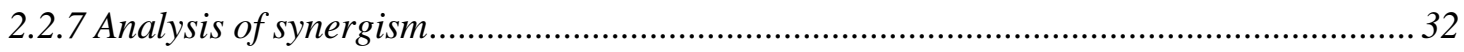

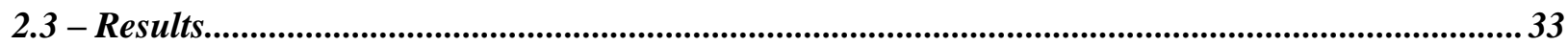

2.3.1 Chemotherapy duration and Combined Treatment ................................................................. 33

2.3.2 Study of Synergism for combined treatments at different Chemotherapy durations........................ 36

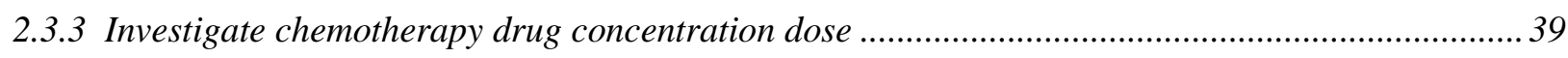

2.3.4 Study of Synergism for combined treatments in the chemotherapy dose ....................................... 41 


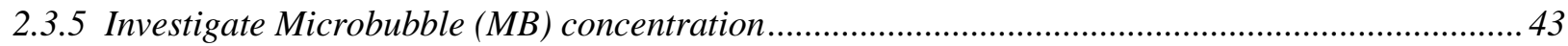

2.3.6 Study of Synergism for combined treatments in the Microbubble concentration ............................ 46

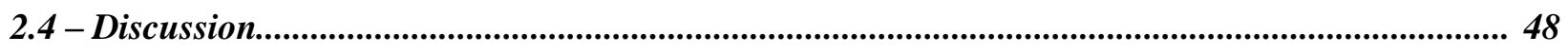

2.4.1 Taxotere concentration and duration, Microbubble concentration............................................... 48

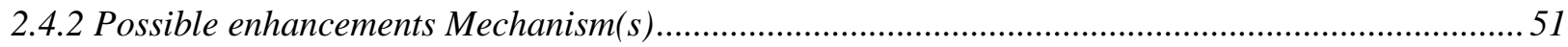

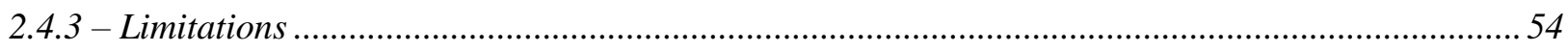

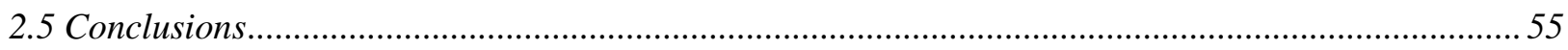

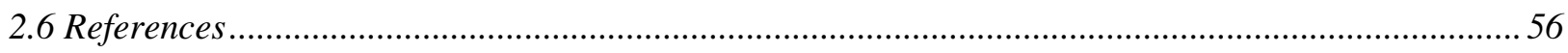

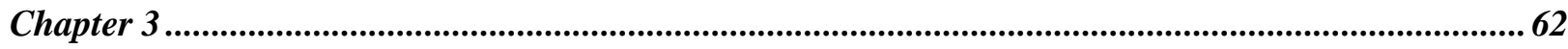

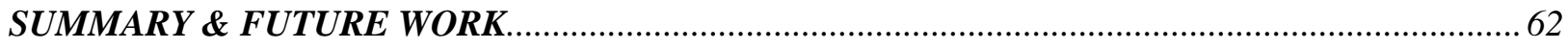

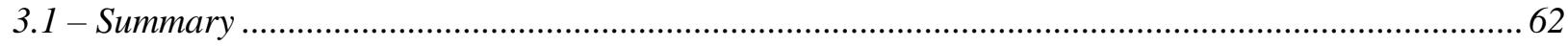

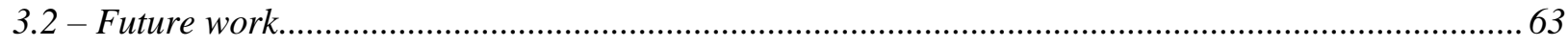

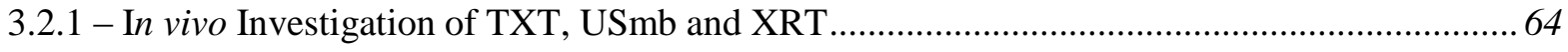

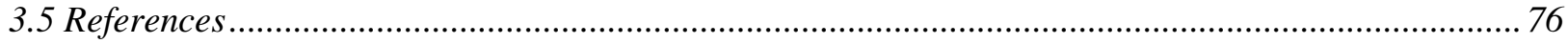




\section{Symbols and Abbreviations}

TXT - Taxotere ${ }^{\circledR}$ chemotherapeutic drug

XRT - irradiation

DNA - deoxyribonucleic acid

EPR effect - enhanced penetration and retention effect

H\&E - hematoxylin and eosin

MI - mechanical index

MV - megavolt

Nmol- Nanomole

PEG - polyethylene glycol

SCID - severe combined immunodeficient

UCA - ultrasound contrast agents

USmb - ultrasound and microbubbles

VA - calculated additive viability

VC - combined experimental viability 


\section{LIST OF TABLES}

Table 2.1: Experimental conditions of TXT duration experiment.............................................31

Table 2.2: Experimental conditions of TXT concentration experiment ..................................31

Table 2.3: Experimental conditions of microbubblue concentration experiment........................31 


\section{LIST OF FIGURES}

Figure 1.1: Schematic diagram of ultrasound and microbubble induced sonoporation where a microbubbles are placed in an ultrasound field, the microbubbles undergo oscillation causing the phenomenon known as sonoporation allows macromolecules to enter the intracellular matrix (Reprinted from Karshafian et al., 2009)................................................. 15

Figure 2.1: A schematic diagram of the ultrasound exposure apparatus. Cells are placed within the chamber and exposed to set acoustic conditions (Reprinted from Karshafian et al., 2009)...29

Figure 2.2: (a) PC3 clonogenic viability exposed to $0.1 \mathrm{nmol} / \mathrm{ml}$ TXT at two different treatment exposure times ( 5 minutes blue bars $\& 2 \mathrm{hr}$ red bars) cell viability was normalized to the control. USmb fixed at $0.5 \mathrm{MHz}$ frequency pulses with $580 \mathrm{kPa}$ negative peak pressure and $2 \%(\mathrm{v} / \mathrm{v})$ microbubbles, and a $160 \mathrm{kVp} 2 \mathrm{~Gy}$ single radiation dose and their combinations are shown (b) Represents the viability ratio were samples normalized to zero nmo/ml TXT for each combined treatment. These samples were centrifuged, removing TXT within the sample before irradiation and plating in dishes. $\mathrm{N}=24$ from 4 independent experiments, the asterisks signify the statistically significantP $<0.05$

Figure 2.3: The calculated additive effect $\left(\mathrm{V}_{\mathrm{A}}\right)$ of TXT, USmb, and XRT compared to cell viability $\left(\mathrm{V}_{\mathrm{C}}\right.$ ) for (a) 5 minutes TXT and (b) Two hr TXT. The asterisks identify the treatments

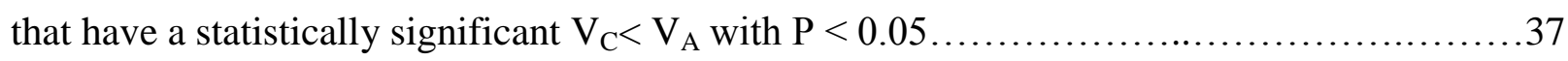

Figure 2.4: (a) The calculated additive effect $\left(\mathrm{V}_{\mathrm{A}}\right)$ of different permutations of $\mathrm{TXT}+\mathrm{USmb}+\mathrm{XRT} 5$ minutes \& $2 \mathrm{hr}$ exposure time. (b) Experimental cell viability $\left(\mathrm{V}_{\mathrm{C}}\right)$ for $\mathrm{TXT}+\mathrm{USmb}+\mathrm{XRT}$. The asterisks identify the treatments that have a statistically significant $\mathrm{V}_{\mathrm{C}}<$

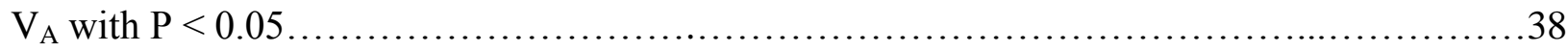

Figure 2.5: (a) PC3 clonogenic viability exposed to a different TXT concentrations $(0.001,0.01$, $0.1 \mathrm{nmo} / \mathrm{ml}$ ) at $2 \mathrm{hr}$ treatment exposure cell viability, fixed $2 \%(\mathrm{v} / \mathrm{v})$ microbubbles, and $160 \mathrm{kVp}$ 2Gy single radiation dose and their combinations, cell viability was normalized to the control. 
cell viability was normalized to the control. USmb fixed at $0.5 \mathrm{MHz}$ frequency pulses with $580 \mathrm{kPa}$ negative peak pressure. (b) Represents the viability ratio were samples normalized to zero $\mathrm{nmol} / \mathrm{ml}$ TXT for each combined treatment. These samples were centrifuged, removing TXT within the sample before irradiation and plating in dishes. $\mathrm{N}=24$ from three independent experiments. . .40

Figure 2.6: (a) The calculated additive effect $\left(\mathrm{V}_{\mathrm{A}}\right)$ compared to the experimental cell viability $\left(\mathrm{V}_{\mathrm{C}}\right)$ in Fig2.4 (a) for the different treatment combination at $(0.001,0.001,0.1 \mathrm{nmol} / \mathrm{ml}) \mathrm{TXT}$ doses. The asterisks identify the treatments that have a statistically significant $\mathrm{V}_{\mathrm{C}}<\mathrm{V}_{\mathrm{A}}$ with $\mathrm{P}<$ 0.05

Figure 2.7: (a) PC3 clonogenic viability exposed to a different MB concentrations $(0.1,0.5,1,2$ $\%(\mathrm{v} / \mathrm{v}))$ microbubbles concentrations, and fixed $2 \mathrm{hr}$ TXT treatment exposure and and a $160 \mathrm{kVp} 2 \mathrm{~Gy}$ single radiation dose and their combinations, cell viability was normalized to the control. USmb fixed at $0.5 \mathrm{MHz}$ frequency pulses with $580 \mathrm{kPa}$ negative peak pressure (b) represents the viability ratio were samples normalized to zero $\mathrm{nmol} / \mathrm{ml}$ TXT for each combined treatment. These samples were centrifuged, removing TXT within the sample before irradiation and plating in dishes. $\mathrm{N}=24$ from three independent experiments. . .44

Figure 2.8: Cell viability at (Zero \%) MB With different treatment combination .... .45

Figure 2.9: (a) The calculated additive effect $\left(\mathrm{V}_{\mathrm{A}}\right)$ compared to the experimental cell viability $\left(\mathrm{V}_{\mathrm{C}}\right)$ in Fig2.9 (a) for the different treatment combination at $(0.1,0.5,1,2 \%(\mathrm{v} / \mathrm{v}))$ microbubbles concentrations. The asterisks identify the treatments that have a statistically significant $V_{C}<V_{A}$. (b) The calculated additive effect $\left(\mathrm{V}_{\mathrm{A}}\right)$ of different permutations of $\mathrm{TXT}+\mathrm{USmb}+\mathrm{XRT}$ a statistically significant $\mathrm{V}_{\mathrm{C}}<\mathrm{V}_{\mathrm{A}}$ with $\mathrm{P}<0.05$.

Figure 3.1: Representative Tunel, hematoxylin and eosin (H\&E), and CD31 stains for the untreated control, USmb $350 \mathrm{kpa}$, USmb $580 \mathrm{kPa}$, USmb $350 \mathrm{kPa}+$ USmb $580 \mathrm{kPa}$, TXT, XRT, TXT+USmb $580 \mathrm{kPa}$, TXT+ USmb 350 +USmb580 kPa, USmb 350+USmb580 kPa +XRT, 
TXT +XRT, TXT+USmb580 kPa +XRT, and TXT+USmb 350nUSmb580 kPa +XRT. Images were taken at $1 \mathrm{x}$ magnification with a light microscope .69

Figure 3.2: Tunel- positive apoptotic cells exposed to different treatments conditions. Four animals per condition were used to calculate the means and SD of the Tunel- postive cells. Significant difference between the TXT+USmb350 kPa+USmb580kPa+XRT and any other treatment condition $\mathrm{P}<0.05$ .72

Figure 3.3: High frequency ultrasound imaging for the PC3 tumour. The RF readings obtained are the difference in the backscatter pre and post treatment for all the conditions. $\mathrm{N}=4$ for each condition. The bars represent $\mathrm{SD}$ . .73

Figure 3.4:Growth delay curve of tumour growth post treatments normalized with untreated control $(\mathrm{n}=4)$. All microbubble treatments were done with $2.5 \%(\mathrm{v} / \mathrm{v})$, with a TXT dose of 1.25 $\mathrm{mg} / \mathrm{ml}$ and 8 Gy $\mathrm{X}$-ray radiation .74

Figure 3.5: Survival proportions: Survival curves for tumour mice $n=4$. Control (the green line), treated by XRT only (the blue line) and treated by TXT following XRT treatment (the red line). Injection of MB and treated with US (350 kPa) with delays of 5 minutes for the next US (580 $\mathrm{kPa}$ ) MB treatment following by XRT (the grey line). The combination of all three treatments are represented by the black line. .75 


\section{Chapter 1 INTRODUCTION}

\subsection{Cancer}

Cancer is a group of different diseases characterized by abnormal, uncontrolled cell growth and in most cases tumour forming (Datta 2004). In contrast, normal healthy cells grow, divide and undergo programmed cell death appropriately due to their unaltered genetic make-up. Mutations of the DNA of cells may occur as a result of naturally occurring mutations (spontaneous mutation, aging, errors in DNA repair, and replication by-pass), carcinogens (tobacco, dietary factors, obesity) or inherited gene mutations. Upon DNA damage, healthy cells either repair damage or initiate apoptosis; mutated cells surpass advances of cell death and form new tumor cells with the same alterations (Friedberg et al. 2006). A cell is only deemed cancerous or malignant when it has the potential to metastasize by invading other tissues. An accumulation of many different gene mutations such as those that block p53 (tumor suppressor gene) or upregulate bcl-2 (proto-oncogene) is required to cause malignancy. Genes usually targeted in 
cancerous mutations are proto-oncogenes, tumor suppressor genes and DNA repair genes (Bunz 2008). The response of different types of cancers varies with treatments due to their acquired ability to resist treatment through examples such as membrane proteins that block entry or push out agents and enzymes that metabolize the drug (Bates 2009). Treatment depends on the stage of cancer, the age and health of the individual. Typical treatment options consist of surgery, chemotherapy and radiotherapy where cancers are generally treated with a combination of modalities.

\subsection{Chemotherapy}

Chemotherapy drugs are cytotoxic and consequently inhibit cell division by damaging proteins and DNA, inducing apoptosis. Typically these drugs target labile cells (rapidly dividing cells), a characteristic not only of cancer cells but of healthy cells such as skin, blood and gastrointestinal cells as well as cells within the bone marrow (Barton-Burke et al. 2001). Side effects most common after chemotherapy treatment are hair loss, fatigue, nausea and vomiting. Though the cytotoxic effect is an issue during treatment, the body's healthy cells are capable of efficiently recovering the lost cells from induced damage whereas cancer cells cannot (Mckay \& Schacher, 2009). Patients are treated with chemotherapy in cycles allowing the body time to recuperate between doses.

Most chemotherapy delivery is done by intravenous but there are some that are done orally (Liu et al. 1997). Since the drug travels through the circulatory system it is the most effective treatment for cancers that have invaded other tissues. The dosage of drug is adjusted for the stage and type of cancer but also the toxic effects that it may have on normal cells. The types and the severity of these side effects differ amongst patients therefore affecting the permitted dosage 
(Minev, 2011).

There are many different cytotoxic drugs in the arsenal of cancer treatment that are divided into various categories. The classification of the drug depends on its mode of action, chemical structure and its relationship to other drugs giving physician's insight into type and the dose of drug to treat a specific type of cancer (Skeel \& Khleif 2011).

A specific drug of interest in this project is called taxotere (TXT). TXT exhibits anticancer activity in different cancer cell lines including prostate cancer cells (Gravis et. al 2003). Aside from being able to flow passively across the lipid bi-layer, the majority of its potency stems from the various bio-effects it can inflict on cells. From the physical aspect, papers have shown that TXT will bind to and stabilize microtubules inhibiting their breakdown causing a G2/M stop (cell cycle stop) (Li et al. 2004). Subsequently, TXT also affects the cell from a genetic aspect, up regulating pro-apoptotic genes and down regulating or inhibiting genes associated with transcription or tumour genesis ( $\mathrm{Li}$ et al. 2004). A gene down regulated during TXT treatment is one related to the control of ceramide production, a signalling molecule that causes apoptosis (Bassoy et al. 2012). The dose of TXT required to initiate these responses within the cells depend on the concentration of the drug administered.

However PC-3 cells, are resistant to chemotherapy drugs such as paclitaxel due to a protein transporter called P-glycoprotein 1 found on the cell membrane. It is associated with multidrug resistance and is weakly expressed in normal prostate cells relative to PC-3 cells (Kawai et al. 2000; Bhangal et al. 2000). This suggests that when TXT freely flows across the cell membrane down its concentration gradient, the cell will pump out the drug due to the increased number of channels available. There has been some investigation into attempting to evade the resistance by 
blocking the channel or inhibiting its production (Sparreboom et al. 2003).

Cancer cells also develop resistance through gene amplification where cells contain multiple copies of the same gene (Meng et al., 2004). As a result the administered drug will be unable to inhibit the expression of the whole gene unless a high enough dose is applied. However, this would not be possible because of the toxic effects associated with chemotherapy drugs, therefore limiting the dose administered to the body (Jain, 1996; Eisenbrey et al., 2009). The majority of chemotherapy drugs also induce apoptosis but cancer cells with defects along the apoptotic pathway are capable of becoming resistant to these drugs. Cells that avoid apoptosis through altering its pathway will be unable to undergo cell death.

There are also many other reasons as to why some chemotherapy treatments may remain ineffective regardless of the delivered dose. Higher stages of cancer, wherein the cancer is fast growing and very aggressive, can be difficult to completely eradicate allowing the cancer to linger and rejuvenate (Minev, 2011). Furthermore, there are incidents where the drug is completely effective however its delivery is limited. Chemotherapy drugs have difficulty accessing tumours within the brain due to the protective mechanisms of the blood brain barrier: efflux pumps and reduced permeability to harmful chemicals (Kobiler et al. 2000). Also tumours that grow to bigger sizes have a deficiency in the vasculature throughout the tumour, which obstructs the drug, given that the majority of chemotherapy drugs are introduced through the blood (Shannon et al. 2003).

Chemotherapy drugs can be used to treat a variety of different cancers but it is seldom used alone. Generally therapy consists of a cocktail of multiple types of chemotherapy or chemotherapy combined with other treatment modalities. 


\subsection{Radiation}

Radiotherapy is used as a treatment option for different forms of cancers with the purpose of killing or controlling the growth of cancer cells using particles or waves with high energy (Dritschilo et al. 1979). Ionizing radiation causes the formation of ions in cells by liberating atomic particles within atoms. These chemically reactive ions will then lead to DNA damage and eventually cell death. Photons, neutrons and charged particles, such as protons and electrons, of high enough energy are capable of yielding this type of response (Schulte-Frohlinde et al. 1989). Radiation can damage DNA through both its direct and indirect ionization. The direct damage comes as a result of the high-energy photons with the target structure being DNA of cells (Hall \& Giaccia 2006). In contrast, indirect radiation involves the interaction with molecules within and around the cell, especially water, forming free radicals that interact with targeted structures within cells.

Damage due to ionizing radiation can result in nucleotide bases damages, single strand breaks and double strand breaks. It has been shown that double strand breaks contribute the most to the anti-cancer action of radiation. Cells with point mutations and single strand breaks seem to recover and repair their damage (Han \& Yu 2010). Cancer cells die from radiation treatment because of their inability to overcome the damage to their DNA. As for their increased rate of mitosis, cancer cells are more likely to pass on DNA damage through cell division until the accumulated damage is past the point of recovery (Kharisov et al. 2013).

A specific molecule in question called ceramide, a trigger for apoptosis, appears to heavily influence the outcome of a cell existence (Nikolova-Karakashian et al. 2010). In addition, cells exposed to XRT will also incur DNA damage by breakage and mutation as well as membrane 
damage through the generation of reactive oxygen species (Mishra 2004). XRT seem to directly intensify ceramide levels by the irradiation of membrane-bound acid and neutral sphingomyelinases (Al-Mahrouki et al. 2012).

In cases where a tumour is localized and not yet metastasized, radiotherapy can be used as a curative treatment (Cox \& Ang 2010). Radiotherapy is also used post surgery to prevent any recovery of cancer. Radiotherapy will be used in combination with other modalities such as chemotherapy. Knowing variables such as size, shape, type and location of the tumour are important in effectively carrying out treatment (Brady et al. 2006). 


\subsection{Radiotherapy and Chemotherapy}

Chemotherapy drugs make cancer cells more sensitive to ionizing radiation as it acts as a radiosensitizer. Chemotherapeutic drugs increase apoptosis significantly in tumour cells by blocking cell cycle (Meyn et al. 1993; Coleman et al. 1996). Certain phases of the cell cycle are more sensitive to radiation than others; the G2 phase is more sensitive than both $\mathrm{S}$ and G1 phases. This is due to the lack of repair mechanisms necessary to resolve the DNA damage caused by radiation. Double strand breaks are the most lethal to cells and the repair of these breaks is limited in the $\mathrm{G} 2$ phase.

Chemotherapy agents however have toxic effects of their own and therefore some focus has turned to other agents that are both non-invasive and lack the toxic characteristic of chemotherapy. It has been shown that combined chemotherapy-radiotherapy can improve survival compared with radiotherapy and chemotherapy alone (Fu et al. 1976; Lo et al. 1976). In addition to the DNA damage inflicted onto cells, radiation exposure also increases apoptosis through accumulating ceramide levels. Radiation therapy has also been proven to inhibit the recovery of the population of cancer cells (Dritschilo et al. 1979).

\subsection{Radiation and Ultrasound Microbubbles}

Radiosensitizers are treatments that enhance tumour cell killing by radiation while maintaining little to no effect to healthy tissues. For example, chemotherapy is generally combined with radiation in cancer treatment (Schrag et al. 2014). 
USmb seems to increase apoptosis within cells by increasing levels of ceramide through physical stress on the cell membrane (Kolesnick et al. 2003). Radiosensitizers can be separated into two different classes based on their relative toxicity. One class called true radiosensitizers, much like the combination of USmb, have non-toxic effects and act merely as an enhancer of radiation. Apparent radiosensitizers still have the effect of enhancing the cytotoxic effect of ionizing radiation however the chemical or treatment itself has toxic properties (Gunderson and Tepper, 2011).

\subsection{Physics of Ultrasound}

Ultrasound, having a frequency higher than human auditory threshold $(20 \mathrm{KHz})$, is a mechanical wave that propagates through media such fluids, soft tissues and solids. Ultrasound within tissues and fluids propagate through longitudinal wave. This means that the oscillating particles travel parallel to the direction of the energy transfer having both points of compression and rarefaction (Cobbold 2007).

The speed of the ultrasound transmittance depends on the compressibility and the stiffness of the medium as well as the temperature and frequency of the wave (Duck, 1990). As the wave propagates the medium will cause attenuation through absorption and scattering. The reflected signal as a results of these processes is what leads the imaging and therapeutic potential of ultrasound. 


\subsubsection{Ultrasound Imaging and Therapy}

Ultrasound imaging is a non-invasive technique used extensively in medicine for the visualization body structures; soft tissue and blood flow in large vessels in particular (Wells 2006). The process takes advantage of the differences in the characteristics of mediums within the body to produce an image. The frequency of the wave also affects the quality of the image where higher frequencies have better resolution but less penetration, and lower frequencies having the opposite effect. In addition to the diagnostic capabilities, ultrasound has therapeutic applications within tissues through thermal and non-thermal mechanisms at certain exposure conditions (Cobbold 2007).

The thermal effect will cause heating of exposed tissues resulting from high intensity ultrasound and can be used for physiotherapy, lithotripsy and tumor removal (O'Brien 2007, Yu et al. 2004). At lower intensities, ultrasound will cause a non-thermal effect, which is useful for drug delivery. The mechanisms that lead to the non-thermal effect consist of radiation pressure and acoustic cavitation. Acoustic cavitation results from the interaction of a mechanical wave (ultrasound) and a gas filled microbubble. Microbubbles can be found naturally in the body within large liquid compartments or artificially by injection of contrast agents (O’Brien 2007).

\subsubsection{Ultrasound Microbubble Imaging and Therapy}

The use of microbubbles for the purpose of imaging has been a common technique, however in recent years the combination of ultrasound and microbubbles has been applied in targeted therapy (Chen et al. 2013). Diagnostically, microbubble contrast agents enhance ultrasound waves by increasing the contrast within the image due to their high echogenicity (Feril \& Kondo, 2004). The ultrasound conditions used clinically are unable to image small blood vessels within 
the circulatory system and tumors (Lindner 2004). The microbubbles exposed to the ultrasound field produce a strong echo increasing the echogenicity of tissues and vessels that are generally poorly detected. These contrast agents are administered intravenously and remain within the blood due to their large size and are therefore ideal for imaging of vessels (Kimmel 2006).

Within therapeutic applications, microbubble contrast agents have been found to improve the efficiency of other types of treatments. Microbubbles can be used to manipulate the delivery of drugs within the body and to cells through different methods. The concentration of the drug in the compartment surrounding the target area can be increased by attaching the drug to the surface of the microbubble or within the inner shell or inside the bubble. Upon exposure to ultrasound, microbubbles will rupture releasing the drug into the immediate location (Ferrara et al. 2007, Unger et al. 2004). Also, by taking advantage of the properties of microbubbles, the delivery of drugs to the intracellular space of cells can be enhanced. USmb treatment has been found to increase the permeability of the cell membrane through sonoporation (Meijering et al. 2009), a form of membrane damage (Okada et al. 2005), by creating pores ranging from $2 \mathrm{~nm}$ to hundreds of nanometers in diameter allowing large molecules accessibility to cells (Taniyama et al. 2002).

\subsection{Ultrasound and Microbubbles}

\subsubsection{Microbubble Composition}

Ultrasound contrast agents used for imaging and therapy generally ranging in size from 1-5 $\mu \mathrm{m}$ in diameter (Qin et al. 2009). These small gas bubbles are very unstable in aqueous solutions and dissolve quickly and therefore require a stabilizing shell; a shell encapsulated gas core. The composition of the shell may consist of surfactants, lipids, albumin, proteins and polymers forming a thin layer 10 to $200 \mathrm{~nm}$ in thickness (Bouakaz and de Jong 2007). The shell is a 
heterogeneous barrier protecting the gas filled core and the outer aqueous environment (Borden et al. 2005). The core determines the echogenicity of the microbubble and can be comprised of air or heavy gases such as perfluorocarbon, nitrogen or sulfur hexafluoride (Bull et al. 2007).

Upon exposure to ultrasound, the microbubbles oscillate and may reflect ultrasound waves or burst under specific conditions. The acoustic response of the microbubbles also depends on its inherent properties such as type of gas, shell and size as well as environmental conditions present during exposure (Chen et al. 2003, de Jong et al. 2002).

\subsubsection{Microbubbles in Ultrasound Fields}

Microbubbles exhibit oscillation around its equilibrium when exposed to an ultrasound field above a certain acoustic threshold and emit and acoustic pressure wave, which depends on microbubble properties and ultrasound exposure (Mayer et al. 2008). At low acoustic pressures microbubbles experience stable liner oscillation and produce ultrasound scattering similar to the transmitted frequency (Hernot \& Klibanov, 2008). Some types of microbubbles only undergo compression under low acoustic pressures and do not expand. Another type of oscillation called non-linear oscillation occurs along with linear oscillations under acoustic pressures higher than those used to cause linear oscillation. Microbubble exhibit maximum oscillation at their resonance frequency also determined by its properties (Ferrara et al. 2007).

Ultrasound activated microbubbles that undergo linear and non-linear oscillations within a liquid can produce microstreaming, shear stress and liquid jets. Microstreaming, a result of both linear and non-linear oscillation, is caused by a radiation force around microbubbles proportional to the amplitude of the microbubble oscillation (VanBavel 2007). Non-linear oscillation also causes liquid jets, which occur as a result of the asymmetrical collapse microbubbles. Both effects cause 
shear stress on the membrane of cells leading to possible pore formation or alterations within the cells.

At much greater acoustic pressures microbubbles experience expansions and contractions that result in destruction of the gas bubble (Chomas et al., 2001). One outcome of disruption occurs during the compression phase when the inner gas diffuses outwards. This single collapsing microbubble may fragment into many smaller microbubbles all cavitation nuclei capable of responding to ultrasound (Postema et al. 2004). Another form of destruction results from the cracking of the outer shell releasing the inner gas bubble. Free-gas bubbles are unstable and may dissolve quickly however respond more violently to ultrasound compared to the encapsulated form (Bevan et al. 2008, Postema et al. 2005).

Microbubbles may also be disrupted through an inertial cavitation mechanism (Atchley et al. 1988). This occurs when a bubble rapidly collapses following a substantial radial expansion. This produces the effects resulting from stable cavitation as well as a few harsher effects. Inertial cavitation causes an increase in temperature and pressure, mechanical shockwaves and free radicals (Kodama and Takayama 1998, Ohl et al. 2006). These effects induce damage to the cell membrane resulting in changes within the cell. The degree of the bio-effects depends on proximity of these events. The impact of the cell greatly depends on the microbubble location and properties including ultrasound parameters. 


\subsubsection{Microbubbles as Carriers}

For the purpose of enhancing delivery of drugs or genes to cells, agents can be loaded into lipid microbubbles (Frenkel et al. 2002). Agents that are generally insoluble or would be destroyed before delivery will be efficiency delivered to the target location with this application (Kang et al. 2010). Drugs can be loaded straight into the microbubble, into the inner layer or on the shell surface (Mukherjee et al. 2000, Lindner 2004). The ability ensures that drugs are released directly in the vicinity of MB disruption, which may enhance drug delivery.

\subsubsection{Sonoporation}

Sonoporation involves the interaction between ultrasound and microbubble contrast agents to temporarily increase the permeability of the cell membrane through the formation of pores (Karshafian et al., 2010; Zhou et al., 2009). It is a reversible process allowing the uptake and the trapping of non-permeable therapeutic compounds. This non-invasive method enhances drug and gene delivery as well as angiogenesis, cardiovascular treatments and treatments across the bloodbrain barrier (Bekeredjian et al. 2005, Hynynen 2008, Mitragotri 2005). This induced sonoporation is advantageous due to the ability to localize the pore formation to one area and therefore controlling the effect of the treatment to a desired location (Szabo 2004). The degree of permeability as a result of sonoporation, which can be altered by changing the conditions of ultrasound, is in direct competition with cell death (Karshafian et al. 2009). 


\subsubsection{Mechanism of Sonoporation}

The biological mechanism currently assumed to be the cause of sonoporation is the formation of transient pores within the cell membrane as a result of the behavior of microbubbles in relation to ultrasound. Pore formation was confirmed by observations from both electron and confocal microscopy with sizes ranging from $2 \mathrm{~nm}$ to hundreds of nanometers in diameter (Karshafian et al., 2010; Zhou et al., 2009). The pores formed due to ultrasound and microbubble significantly increase the permeability of the cell membrane with demonstrated by papers showing that molecules up to 2MDa were of sufficient size for entry within cells (Karshafian et al. 2010). Post exposure, the majority of the pores resealed within a few second but some were shown to have remained up to 24 hours (Zhou et al., 2009).

Based on optical observation, microbubbles have displayed a variety of different responses to ultrasound including oscillation, fragmentation microjetting and microstreaming (Lentacker et al. 2009). The acoustical mechanism responsible for sonoporation were associated with inertial cavitation and stable (non-inertial cavitation) oscillation of microbubbles (Ohl et al. 2006). The combination of the physical effects induce mechanical stress the cell membrane aiding to the formation of the transient pores (Feril \& Kondo, 2004).

The dispersion of pore formation has not been identified or predicted but it has been shown that cells most effected were those in close proximity to the cell membrane (Liang et al., 2009). The close interaction between microbubbles and cells influences the extent of the increase in permeability. The degree of permeability then dictates the extent of delivery within the cell. 


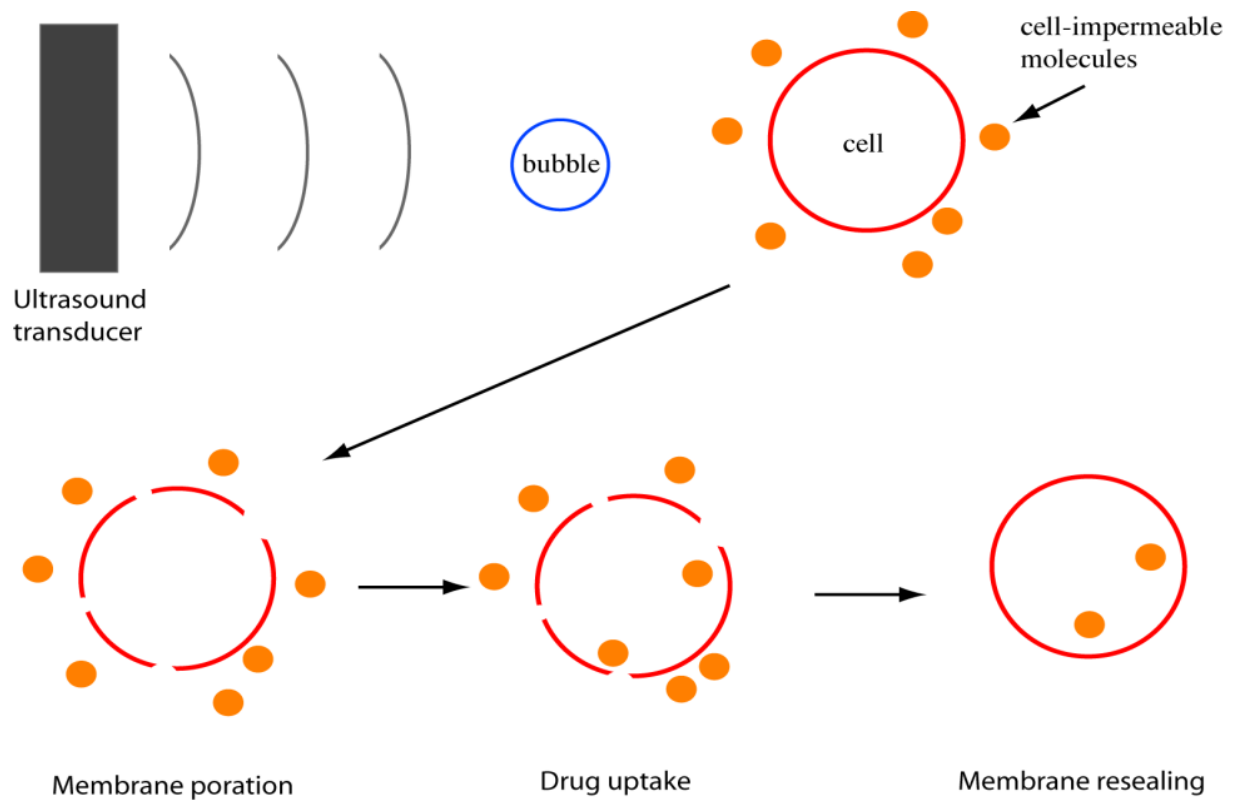

Figure 1.1: Schematic diagram of ultrasound and microbubble induced sonoporation where a microbubbles are placed in an ultrasound field, the microbubbles undergo oscillation causing the phenomenon known as sonoporation allows macromolecules to enter the intracellular matrix (Reprinted from Karshafian et al., 2009)

\section{7 - Hypothesis}

The proposed approach is to improve radiotherapy treatment using ultrasound and microbubble with a chemotherapeutic agent. We have recently observed that ultrasound and microbubble (USmb) can enhance chemotherapy (Goertz et al. 2012) and radiation response in vitro and in vivo (Al-Mahrouki et al.,2012; Czarnota et al., 2012; Karshafian, 2009; Karshafian et al., 2010). This will be the first study done with the combination of all three treatments (USmb+TXT+XRT). The specific objectives are (1) to investigate the effect of the combined treatment of USmb with TXT on therapeutic outcome of radiotherapy (2) to investigate the effect of chemotherapeutic drug treatment time and concentration, and (3) to investigate the effect of microbubble concentration. The enhancement of drug uptake and increased cell sensitivity to radiation therapy may lead to lower required doses that minimize toxic side effects. 


\section{References}

Atchley, A.A., Frizzell, L.A., Apfel, R.E., Holland, C.K., Madanshetty, S., Roy, R.A. (1988). Thresholds for cavitation produced in water by pulsed ultrasound. Ultrasonics 26:280-5.

Al-Mahrouki, A., Karshafian, R., Giles, A., Czarnota, G. (2012). Bioeffects of UltrasoundStimulated Microbubbles on Endothelial Cells: Gene Expression changes associated with radiation enhancement in vitro. Ultrasound in Med \& Biol 38(11), 1958-1969

Barton-Burke, M., Wilkes, G.M., Ingwerson, K. (Eds.). (2001). Cancer Chemotherapy: A Nursing Process Approach Third Edition. Sudbury, MA: Jones and Bartlett Publishers.

Bates, S.E. (2009). Drug Resistance in Cancer Cells. (Mehta, K. \& Siddik, Z.H. Eds.). New York, NY: Springer Science+Business Media.

Bekeredjian R, Grayburn PA, Shohet R.V. (2005). Use of ultrasound contrast agents for gene or drug delivery in cardiovascular medicine. J Am Coll Cardiol 45:329-35.

Bevan, P, Karshafian, R., Burns, P.N. (2008). The Influence of Fragmentation on the Acoustic Response from Shrinking Bubbles. Ultrasound in medicine \& biology 34:1152-62.

Borden, M.A., Kruse, D.E., Caskey, C.F., Zhao, S., Dayton, P.A., Ferrara, K.W. (2005). Influence of lipidshell physicochemical propertiesonultrasound-induced microbubble destruction. IEEE transactions on ultrasonics, ferroelectrics, and frequency control 52:19922002.

Bouakaz, A., de Jong, N. (2007). WFUMB Safety Symposium on Echo-Contrast Agents: nature and types of ultrasound contrast agents. Ultrasound in medicine \& biology 33:187-96.

Brady, L.W., Heilmann, H. -P., Molls, M. (2006). New Technologies in Radiation Oncology. (Schlegel, W.C., Bortfeld, T., Grosu, A. -L.) Berlin, Germany: Springer-Verlag Berlin Heidelberg Schlegel, W.C.,

Bull, J. L. (2007). The application of microbubbles for targeted drug delivery. Expert Opinion on Drug Delivery, 4(5), 475-493. doi:10.1517/17425247.4.5.475 
Bunz, F. (2008). Principles of Cancer Genetics. Baltimore, MD: Springer Science+Business Media.

Chen, W.S., Matula, T.J., Brayman, A.A., Crum, L.A. (2003). A comparison of the fragmentation thresholds and inertial cavitation doses of different ultrasound contrast agents. J Acoust Soc Am 113:643-51.

Chomas, J. E., Dayton, P., Allen, J., Morgan, K., \& Ferrara, K. W. (2001). Mechanisms of contrast agent destruction. IEEE Transactions on Ultrasonics, Ferroelectrics, and Frequency Control, 48(1), 232-248.

Coleman, C.N. (1996). Radiation and chemotherapy sensitizer and protec-tors. In Cancer Chemotherapy: Principles and Practice (B. A. Chab-ner and D. L. Longo, Eds.), pp. 553-584. Lippincott-Raven, Philadelphia.

Cox, J.D., Ang, K.K. (2010). Radiation Oncology Ninth Edition. Philadelphia, PA: Elsevier Inc.

Czarnota, G.J., Karshafian, R., Burns, P.N., Wong, S., Mahrouki, A.A., Lee, J.W., Caissie, A., Tran, W., Kim, C., Furukawa, M., Wong, E., Giles, A. Tumor radiation response enhancement by acoustical stimulation of the vasculature. Proc Natl Acad Sc 109, 2033-2041 (2012)

Datta, B.N. (2004). Textbook of Pathology. New Dehli, India: Jaypee Brothers Medical Publishers Ltd.

De Jong, N., Bouakaz, A., Frinking, P. (2002). Basic acoustic properties of microbubbles. Echocardiography (Mount Kisco, NY)19:229-40.

Dritschilo, A., Piro, A.J., Kelman, A.D. (1979). The effect of cis-platinum on the repair of radiation damage in plateau phase Chinese hamster (V-79) cells. Int J Radiat Oncol Biol Phys $8: 1345-9$.)

Duck, F.A. (1990). Physical properties of tissue. San Diego, CA: Academic Press Limited

Feril, L. B., Jr, \& Kondo, T. (2004). Biological Effects of Low Intensity Ultrasound: The Mechanism Involved, and its Implications on Therapy and on Biosafety of Ultrasound. Journal of Radiation Research, 45(4), 479-489. doi:10.1269/jrr.45.479 
Feril, L. B., Jr, \& Kondo, T. (2004). Biological Effects of Low Intensity Ultrasound: The Mechanism Involved, and its Implications on Therapy and on Biosafety of Ultrasound. Journal of Radiation Research, 45(4), 479-489. doi:10.1269/jrr.45.479

Ferrara, K. (2008). Driving delivery vehicles with ultrasound. Advanced Drug Delivery Reviews 60:1097-102.

Ferrara, K., Pollard, R., Borden, M. (2007). Ultrasound microbubble contrast agents: fundamentals and application to gene and drug delivery. Annual review of biomedical engineering 9: 415- 47.

Foundations of biomedical ultrasound by Richard S.C. Cobbold. Publisher Oxford; Toronto: Oxford University press, (2007).

Frenkel, P. A., Chen, S., Thai, T., Shohet, R. V., \& Grayburn, P. A. (2002). DNA-loaded albumin microbubbles enhance ultrasound-mediated transfection in vitro. Ultrasound in Medicine and Biology, 28(6), 817-822.

Friedberg, E.C., Walker, G.C., Siede, W. (2006). DNA repair and mutagenesis. Ann Arbor, MI: Amer Society for Microbiology.

Fu, K.K., Phillips, T.L., Silverberg, I.J., Jacobs, C., Goffinet, D.R., Chun, C., Friedman, M.A., Kohler, M., McWhirter, K., Carter, S.K. (1987). Combined radiotherapy and chemotherapy with bleomycin and methotrexate for advanced inoperable head and neck cancer: update of a Northern California Oncology Group randomized trial. J Clin Oncol 5:1410-8.

Gunderson, L.L., Tepper, J.E. (2011). Clinical Radiation Oncology, 3rd Edition. Philadelphia: Elsevier Inc.

Hall, E., Giaccia, J. Radiobiology for the Radiobiologist Sixth Edition (2006). Philadelphia, PA: Lippincott Williams \& Wilkins.

Han, W., Yu, K.N. (2010). Ionizing Radiation, DNA Double Strand Break and Mutation. Advances in Genetics Research 4, 1-13. 
Hernot, S., \& Klibanov, A. L. (2008). Microbubbles in ultrasound-triggered drug and gene delivery. Advanced Drug Delivery Reviews, 60(10), 1153-1166. doi:10.1016/j.addr.2008.03.005

Hynynen, K. (2008). Ultrasound for drug and gene delivery to the brain. Advanced Drug Delivery Reviews 60:1209-17.

Karshafian, R., Samac, S., Bevan, P. D., \& Burns, P. N. (2010). Microbubble mediated sonoporation of cells in suspension: Clonogenic viability and influence of molecular size on uptake. Ultrasonics, 50(7), 691-697. doi:10.1016/j.ultras.2010.01.009

Kharisov, B.I., Kharissova, O.V., Mendez, U.O. (2013). Radiation Synthesis of Materials and compounds. Boca Raton, FL: Taylor and Francis Group.

Kimmel, E. (2006). Cavitation bioeffects. Critical Reviews in Biomedical Engineering, 34(2), 105-16.

Kobiler, D., Lustig, S., Shapira, S. (Eds.). (2000). Blood-Brain Barrier: Drug Delivery and Brain Pathology. New York, NY: Kluwer Academic/Plenum Publishers.

Kodama, T., Takayama, K. (1998). Dynamic behavior of bubbles during extracorporeal shockwave lithotripsy. Ultrasound in medicine \& biology 24:723-38.

Kolesnick, R., Fuks, Z. (2003) Radiation and ceramide-induced apoptosis. Oncogene 22, 5897906

Lentacker, I., De Smedt, S. C., \& Sanders, N. N. (2009). Drug loaded microbubble design for ultrasound triggered delivery. Soft Matter, 5(11), 2161-2170.

Leszczynski, D. (Eds.). (2013). Radiation Proteomics: The effects of ionizing and non-ionizing radiation on cells and tissues. Helsinki, Finland: Springer Science+Business Media Dordecht.

Liang, H.-D., Tang, J., Halliwell, M., \& Wells, P. N. T. (2009). Sonoporation, drug delivery, and gene therapy. Proceedings of the Institution of Mechanical Engineers, Part H: Journal of Engineering in Medicine, 224(2), 343-361. doi:10.1243/09544119JEIM565

Lindner, J. R. (2004). Microbubbles in medical imaging: Current applications and future directions. Nature Reviews Drug Discovery, 3(6), 527-532. 
Lindner, J. R. (2004). Microbubbles in medical imaging: Current applications and future directions. Nature Reviews Drug Discovery, 3(6), 527-532.

Liu, G., Franssen, E., Fitch, I., Warner, E. Patient preferences for oral versus intravenous palliative chemotherapy. American Society of Clinical Oncology 15(1) 110-115, (1997)

Lo TC, Wiley AL Jr., Ansfield FJ, Brandenburg JH, Davis HL Jr., Gollin FF, Johnson RO, Ramirez G, Vermund H. (1976). Combined radiation therapy and 5-fluorouracil for advanced squamous cell carcinoma of the oral cavity and oropharynx: a randomized study. Am J Roentgenol 126:229-35.

Mayer, C. R., \& Bekeredjian, R. (2008). Ultrasonic gene and drug delivery to the cardiovascular system. Advanced Drug Delivery Reviews, 60(10), 1177-1192.

Mckay, J., Schacher, T. (2009). The Chemotherapy Survival Guide Third Edition. Oakland, CA: New Harbinger Publications Inc.

Meng, S., Tripathy, D., Shete, S., Ashfaq, R., Haley, B., Perkins, S., Beitsch, P., Khan, A., Euhus, D., Osborne, C., Frenkel, E., Hoover, S., Leitch, M., Clifford, E., Vitetta, E., Morrison, L., Herlyn, D., Terstappen, L. M. M., Fleming, T., Fehn, T., Tucker, T., Lane, N., Wang, J., Uhr, J. (2004). HER-2 gene amplification can be acquired as breast cancer progresses. PNAS 101(25) 9393-9398

Meyn, R. E., Stephens, L. C.,Ang, K. K., Hunter, N. R., Brock, W. A., Milas, L., Peters, L. J. (1993) Heterogeneity in the development of apo-ptosis in irradiated murine tumors of different histologies. Int. J. Radiat. Biol. 64, 563-591

Minev, B.R. (2005). Cancer Management in Man: Chemotherapy, Biological Therapy, Hyperthermia and Supporting Measures. La Jolla, CA: Genelux Corporation. (2011).

Mishra, K.P. Cell membrane oxidative damage induced by gamma-radiation and apoptotic sensitivity. J Environ Pathol Toxicol Oncol 23, 61-6 (2004)

Mitragotri S, Healing sound: the use of ultrasound in drug delivery and other therapeutic applications. Nature reviews Drug discovery 4:255-60. 
Mukherjee, D., Wong, J., Griffin, B., Ellis, S. G., Porter, T., Sen, S., et al. (2000). Ten-fold augmentation of endothelial uptake of vascular endothelial growth factor with ultrasound after systemic administration. Journal of the American College of Cardiology, 35(6), 1678-1686.

Nikolova-Karakasjian MN, Rozenova K (2010) Sphingolipids as Signaling and Regulatory Molecules, eds C Chalfant and M Del Poeta (Landes Bioscience and Springer Science and Business Media, New York), pp 86-107.

Ohl, C., Arora, M., Ikink, R., De Jong, N., Versluis, M., Delius, M., (2006). Sonoporation from jetting cavitation bubbles. Biophysical Journal, 91(11), 4285-4295.

Ohl, C.D., Arora, M., Ikink, R., de Jong, N., Versluis, M., Delius, M., Lohse, D. (2006) Sonoporation from jetting cavitation bubbles. Biophys J 91:4285-95.

Postema, M., Bouakaz, A., Versluis, M., de Jong, N. (2005). Ultrasound-induced gas release from contrast agent microbubbles. IEEE transactions on ultrasonics, ferroelectrics, and frequency control 52:1035-41.

Postema, M., van Wamel, A., Lancée, C.T., de Jong, N. (2004). Ultrasound-induced encapsulated microbubble phenomena. Ultrasound in medicine \& biology 30:827-40.

Qin, S., Caskey, C. F., \& Ferrara, K. W. (2009). Ultrasound contrast microbubbles in imaging and therapy: Physical principles and engineering. Physics in Medicine and Biology, 54(6), R27R57.

Ravanat, J.L., Douki, T., Cadet, J. (2001). Direct and indirect effects of UV radiation on DNA and its components. Journal of Photochemistry and Photobiology B: Biology 63(1-3), 88-102

Schrag, D., Weiser, M.R., Goodman, K.A., Gonen, M., Hollywood, E., Cercek, A., ReidyLagunes, D.L., Gollub, M.J., Shia, J., Guillem, J.G., Temple, L.K.F., Paty, P.B., Saltz, L.B. (2014). Neoadjuvant Chemotherapy Without Routine Use of Radiation Therapy for Patients With Locally Advanced Rectal Cancer: A Pilot Trial. American Society of Clinical Oncology 32(6), 513-518.

Schulte-Frohlinde, D., Von Sonntag, C., Huttermann, J. (1989). Free-Radical and RadiationInduced Damage to DNA, Volume 6. Scotland, UK: Harwood Academic Publishers. 
Shannon, A.M., Bouchier-Hayes, D.J., Condron, C.M., Toorney, D. (2003). Tumour hypoxia, chemotherapeutic resistance and hypoxia-related therapies. Cancer Treatment Reviews 29(4) 297-307.

Spareboom, A., Danesi, R., Ando, Y., Chan, J., Figg, W.D. (2003). Pharmacogenomics of ABC transporters and its role in cancer chemotherapy. Drug Resistance Updates 6(2) 71-84

Szabo, T.L. (2004). Diagnostic ultrasound imaging: inside out. Boston: Elsevier/Academic Press.

Unger, E.C., Hersh, E., Vannan, M., McCreery, T. (2001). Gene Delivery Using Ultrasound Contrast Agents. Echocardiography 18:355-61.

Unger, E.C., Porter, T., Culp, W., Labell, R., Matsunaga, T., Zutshi, R. (2004). Therapeutic applications of lipid- coated microbubbles. Adv Drug Deliv Rev 56:1291-314.

Zhou, Y., Kumon, R. E., Cui, J., \& Deng, C. X. (2009). The Size of Sonoporation Pores on the Cell Membrane. Umb, 35(10), 1756-1760. doi:10.1016/j.ultrasmedbio.2009.05.012 


\title{
Chapter 2 IN VITRO STUDY
}

This chapter will be submitted to a peer-reviewed journal and includes an abstract and introduction.

\begin{abstract}
Purpose: The application of ultrasound and microbubbles (USmb) has been shown to enhance the therapeutic effect of chemotherapy (TXT) and radiotherapy (XRT). Ultrasonically-stimulated microbubbles at therapeutic conditions can increase the permeability of biological membranes and enhance the passage of therapeutic agents across blood vessels and cell membranes. Furthermore, chemotherapeutic agents such as taxotere have been studied in combination with radiation as a radiosensitizer with favourable results. This work investigated the potential of USmb combined with chemotherapy to enhance the efficacy of ionizing radiation in prostate cancer cells.
\end{abstract}

Prostate cancer (PC3) cells in suspension were treated with combined treatment of USmb, chemotherapy and radiotherapy. Cells were treated with ultrasound and microbubbles at 500 $\mathrm{kHz}$ pulse centre frequency, $580 \mathrm{kPa}$ peak negative pressure, $10 \mu \mathrm{s}$ pulse duration, $60 \mathrm{~s}$ insonation time and $2 \%$ Definity microbubbles (v/v), radiotherapy at $2 \mathrm{~Gy}$, and chemotherapy using Taxotere (TXT) concentrations from 0.001 to $0.1 \mathrm{nmol} / \mathrm{ml}$ for 5 and 120 minutes. Following treatment, cell viability was assessed using clonogenic assay. Ultrasound and microbubbles combined with chemotherapy improved treatment response of radiotherapy in PC3 cells by $\sim 28$-folds. Cell viability of $2 \%$ was achieved with TXT+USmb+XRT compared with XRT alone (57\%) for 120 minutes treatment with taxotere. USmb improved radiotherapy by 
$\sim 2.5$ folds (USmb+XRT=22\%) compared with radiotherapy alone (57\%), and chemotherapy by $\sim 1.5$ fold decrease $(\mathrm{TXT}+\mathrm{USmb}=58 \%)$ compared with chemotherapy alone $(76 \%)$. In addition, USmb (74\%) improved TXT+XRT (37\%) by 19-folds compared with TXT+USmb+XRT (2\%). This effect depended on chemotherapy treatment duration. The results indicate that the combined treatment of chemotherapy and ultrasound-microbubbles with radiotherapy induced a synergistic enhancement in cell death. Furthermore, ultrasound and microbubbles improved the treatment response of both chemotherapy and radiotherapy.

Keywords: chemotherapy, Ultrasound therapy, Sonoporation, ultrasound \& microbubble, radiotherapy, radio-enhancement 


\subsection{Introduction}

Recently, ultrasound (US) in combination with microbubbles (MB) has been shown to enhance cell death together with radiotherapy (XRT) (Czarnota et al. 2012; Lee et al. 2012) and chemotherapy (Yu et al. 2006). In addition, it has been shown that chemotherapy enhances radiotherapy by making cancer cells more susceptible to radiation treatment (Takizawa et al. 2000). The delivery of TXT is achieved through passive diffusion and increased permeability with USmb leads to increased drug uptake and enhanced cell sensitivity to radiation (Choijamts et al. 2011;Tran et al. 2012). The therapeutic effect of TXT on cell viability depends on treatment duration (Li et al. 2004) and concentration (Le et al. 2013).

TXT a member of the taxane family, is used clinically for cancer treatment (Gravis et al. 2003). As a result of the hydrophobic nature of both TXT and the semi-permeable membrane, the small TXT molecule can diffuse across the membrane with no expense to the cell (Steffansen et al. 2010). Studies have shown that through increasing concentration of the drug and duration of treatment lead to increased cell death, compliant with the diffusion mechanism. Once in the cell, TXT is shown to cause cell cycle arrest in the G2/M phase by inhibiting the breakdown and stabilizing tubulin thus interfering with mitotic function (Balcer-Kubiczek et al 2008). TXT has also been shown to cause alterations in gene expression within the cell, particularily decreasing expression of a protein related to the control of ceramide levels.

TXT has been investigated as a radiosensitizer due to the changes it inflicts on cells. It is understood that the effect of radiotherapy on cells is predominately determined by the phase at which the cell is developing in its cycle ( $\mathrm{Li}$ et al. 2004). Cells appear to be radiosensitive in the G2/M phase as opposed to any other point such as S phase, the least sensitive phase (Pawlik et 
al. 2004). This characteristic makes taxotere a candidate for enhancing radiation therapy due to its intrinsic ability to halt cells in the G2/M phase.

The success of cancer therapy with radiation and chemotherapy is limited by their inability to localize treatments leading to undesired side effects, such as toxicity to healthy tissue (Geers et al. 2010; Mothersill et al. 2003). The application of ultrasound can be localized non-invasively and treat tissues with great precision (Rifai et al. 2010; Rapoport et al. 2009). Microbubbles, used clinically as contrast agents, are used to enhance targeted drug delivery in response to acoustic waves (Yudina et al. 2010). Upon exposure to ultrasonic waves, gas-filled microbubbles will oscillate through a series of compressed and expanded states and under particular intensities will cause microbubble fragmentation (Tlaxca et al. 2010; Rapoport et al. 2007). The collapse of microbubbles, known as cavitation, results in a significant energy release and the production of micro jets that shear the membrane of cells causing physical changes such as poration and improved endocytosis, thus increasing cell membrane permeability (Meijering et al. 2009; Chen et al. 2011).

Another advantage of ultrasound and microbubble treatment is its effectiveness in drug delivery, enhancing the effect of drugs by momentarily increasing cell membrane permeability (Choijamts et al. 2011; Rapoport et al. 2009). A study examining the effect of doxorubicin and taxotere revealed that USmb treatment synergistically enhanced cancer cell death (Ghoshal et al.2012); Das et al.2011). It has been reported that the cavitation of microbubbles allowed drugs to effectively enter cells and exert their function (Zhao et al. 2008). Evidence suggests that USmb acts as a chemo-sensitizer creating cells that are vulnerable to chemotherapy drugs such as taxotere (Yu et al. 2006). 
Ultrasound-activated microbubbles have also been shown to enhance the effect of XRT by activating the apoptosis pathway within cells (Karshafian et al. 2009; Czarnota et al. 2012). Studies have shown that USmb induced biochemical death of cells such as prostate cancer and endothelial cells triggering the production of ceramide, suggested to be a main inducer of apoptosis (Nikolova-Karakashian et al.2010; Lee et al.2012). Cells that produce ceramide are susceptible to apoptosis and as a result these cells are increasingly sensitive to radiotherapy (Liu et al.2006). In addition, aside from the direct action of radiotherapy (DNA damage), XRT will also cause membrane damage through interactions with molecules within the cells increasing levels of ceramide and therefore enhancing cell death (Sathishkumar et al. 2005; Kolesnick et al. 2003).

This research will take advantage of the ultrasound and microbubble application to enhance the localized delivery of TXT to irradiated cells thereby increasing tumour cell death. Moreover, results from in vitro and in vivo experiments have shown strong correlations between overall cell death and treatments combining USmb with radiation treatment (Al-Mahrouki et al. 2012; Czarnota et al. 2012; Karshafian 2009; Karshafian et al. 2010).

The effects of combining USmb, XRT and chemotherapy treatments on prostate cancer cells (PC3) will be investigated. The hypothesis guiding the research is that ultrasound and microbubbles combined with TXT can enhance radiotherapy. The specific objectives are to determine the effect of TXT concentration and duration as well as MB concentration on cell viability. 


\section{2 - Materials and Methods: In vitro cell suspension}

Cells in suspension were treated with chemotherapy, radiotherapy, ultrasound and microbubbles at various chemotherapy durations, chemotherapy dose, microbubble concentrations and order of the treatments. The viability of the cells was quantified using clonogenic assay

\subsubsection{In Vitro Cell Model:}

Human prostate cancer cell line PC-3 was obtained from the (ATCC, MD, USA) .The cell line was maintained in RPMI-1640 medium (GIBCO) supplemented with 10\% (vol/vol) fetal bovine serum $(\mathrm{FBS})$ at $37^{\circ} \mathrm{C}$ in a humidified atmosphere of $5 \% \mathrm{CO}_{2}$ and $95 \%$ air and harvested during exponential growth by trypsinization. Cells were suspended in growth media at a concentration of $1 \times 10^{6}$ cells $/ \mathrm{mL}$ and a volume of $3 \mathrm{~mL}$.

\subsubsection{Chemotherapy Drug:}

Cells were treated with taxotere (Taxotere, Aventis Pharmaceuticals, Inc.) at concentrations of 0.001, 0.01 and $0.1 \mathrm{nM}$, for either 5 minutes or two hours in a water bath at $37^{\circ} \mathrm{C}$. Following the treatment cells were washed three times with 9 mL RPMI 1640 cell media containing $10 \%$ FBS at room temperature.

\subsubsection{Ionizing Radiation Exposure}

Cells in complete RPMI growth medium were placed in $35 \mathrm{~mm}$ culture dishes and exposed to ionizing radiation in $2 \mathrm{~Gy}$ single fraction using $160 \mathrm{kVp} \mathrm{X-rays} \mathrm{at} \mathrm{200cGy/min} \mathrm{dose} \mathrm{rate}$ (Faxitron X-ray Corporation, Lincolnshire, IL, USA). 


\subsubsection{Ultrasound and Microbubble Treatment}

Cells were placed into an acoustic chamber which contained an immersible magnetic stirrer and exposed to ultrasound and microbubbles. The ultrasound system exposure consisted of a single element transducer 500 kHz centre frequency (IL0509HP, Valpey Fisher Inc., Hopkinton, MA), a waveform generator (AWG520, Tektronix Inc, Beaverton, OR) and a power amplifier (RPR4000, Ritec Inc, Warwick, RI). The cells' exposure condition was $500 \mathrm{kHz}$ pulse center frequency, $32 \mu$ s pulse duration $3 \mathrm{kHz}$ pulse repetition frequency (PRF) at $580 \mathrm{kPa}$ peak negative pressure amplitude for 60 second in the presence of microbubbles. These parameters were chosen based on previous experiments (Karshafian, 2009) (Figure 2.1).

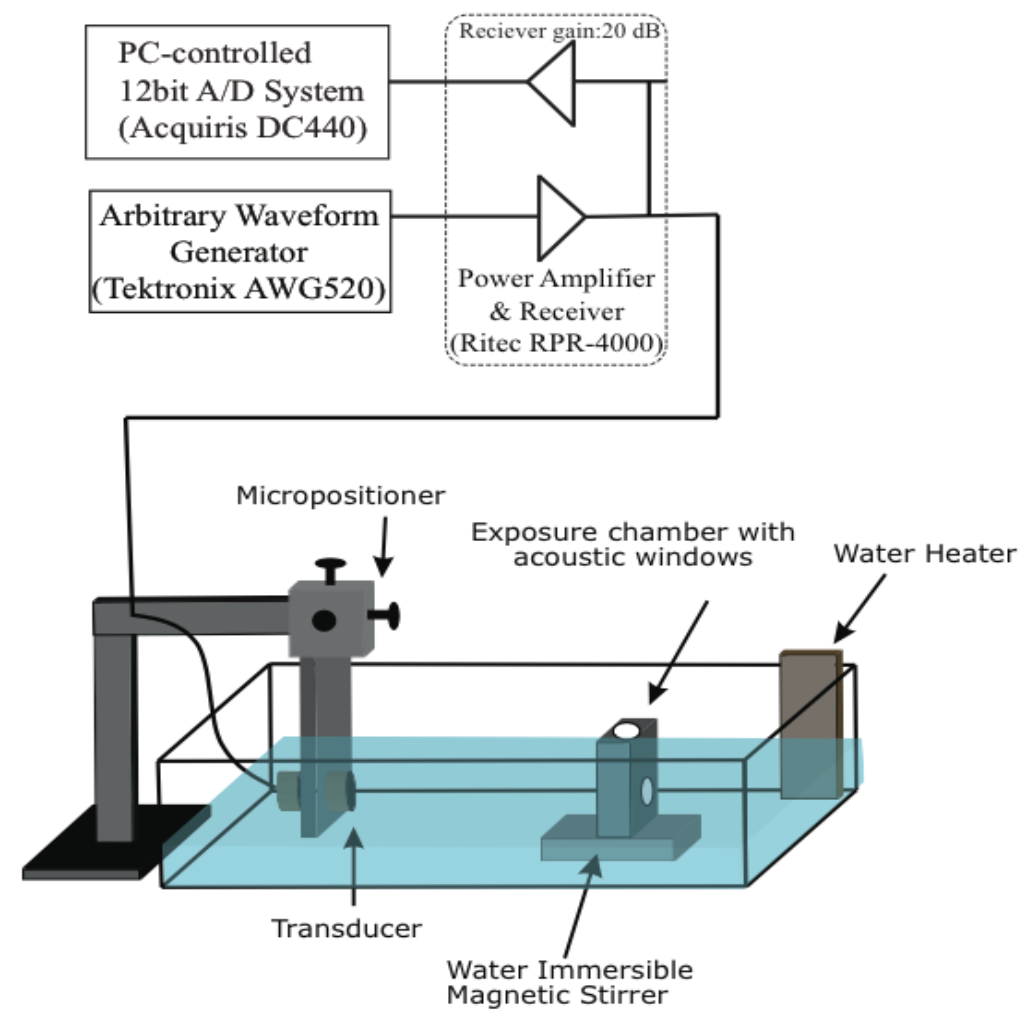

Figure 2.1: A schematic diagram of the ultrasound exposure apparatus. Cells are placed within the chamber and exposed to set acoustic conditions (Reprinted from Karshafian et al., 2009) 
The microbubble contrast agent used in these experiments was Definity® microbubbles (Lantheus Medical Imaging, Inc., North Billerica, MA, USA), which is clinically approved agent. The microbubbles were prepared by activating the Definity® vial using a Vialmix ${ }^{\circledR}$ (Lantheus Medical Imaging, Inc., North Billerica, MA, USA) for 45 seconds. The microbubbles were warmed to room temperature prior to activation.

Microbubbles were used at different volume concentrations of 2, 1, 0.5, $0.1 \% \mathrm{v} / \mathrm{v}$. A volume of $60 \mu \mathrm{L}$ of diluted microbubble agent, equivalent to $15 \mu \mathrm{L}$ of undiluted agent, corresponding to a $0.5 \% \mathrm{v} / \mathrm{v}$ (volume concentration) was added to the cell suspension. Cells were exposed to ultrasound pulses immediately following the addition of microbubbles. In the combined treatment case, taxotere agent was added immediately before exposing the cells to ultrasound microbubbles.

\subsubsection{Experimental Conditions}

Each experimental condition involving the various combinations of TXT, USmb and XRT was performed in triplicates. TXT was placed inside the sample for either 5 minutes or 2 hours and were washed 3 times with media (RPMI) following the completion of each treatment. During treatments with USmb and TXT, samples were treated to USmb simultaneously with the addition of TXT. When treating samples with XRT in combination with USmb or TXT, samples were treated with XRT 2 minutes post exposure to USmb or TXT. The experimental condition for the combination of all three treatment types was achieved by simultaneously treating samples with USmb and TXT, then with XRT 2 minutes thereafter. 
Experiment conditions:

Table 2.1: Experimental conditions of TXT duration experiment

TXT duration experiment conditions: $\left(\mathrm{TXT}_{2 \mathrm{hr}} 0.1 \mathrm{nmol} / \mathrm{ml}, \mathrm{USmb} 2 \%\right.$ \& XRT 2 Gy Fixed)

\begin{tabular}{|l|l|l|l|}
\hline $\mathrm{TXT}_{5 \text { Min }}$ & TXT $_{5 \text { Min }}+$ USmb & TXT $_{5 \text { Min }}+$ XRT & TXT $_{5 \text { Min }}+$ USmb+XRT \\
\hline TXT $_{2 \mathrm{hr}}$ & TXT $_{2 \mathrm{hr}}+$ USmb & TXT $_{2 \mathrm{hr}}+\mathrm{XRT}$ & TXT $_{2 \mathrm{hr}}+\mathrm{USmb}+\mathrm{XRT}$ \\
\hline
\end{tabular}

Table 2.2: Experimental conditions of TXT concentration experiment

\begin{tabular}{|c|c|c|c|}
\hline $\mathrm{TXT}_{2 \mathrm{hr}}(0 \mathrm{nmol} / \mathrm{ml})$ & $\mathrm{TXT}_{2 \mathrm{hr}}(0 \mathrm{nmol} / \mathrm{ml})+\mathrm{USmb}$ & $\mathrm{TXT}_{2 \mathrm{hr}}(0 \mathrm{nmol} / \mathrm{ml})+\mathrm{XRT}$ & $\mathrm{TXT}_{2 \mathrm{hr}}(0 \mathrm{nmol} / \mathrm{ml})+\mathrm{USmb}+\mathrm{XRT}$ \\
\hline $\operatorname{TXT}_{2 \text { hr }}(0.001 \mathrm{nmol} / \mathrm{ml})$ & $\mathrm{TXT}_{2 \mathrm{hr}}(0.001 \mathrm{nmol} / \mathrm{ml})+\mathrm{USmb}$ & $\mathrm{TXT}_{2 \mathrm{hr}}(0.001 \mathrm{nmol} / \mathrm{ml})+\mathrm{XRT}$ & $\mathrm{TXT}_{2 \mathrm{hr}}(0.001 \mathrm{nmol} / \mathrm{ml})++\mathrm{USmb}+\mathrm{XRT}$ \\
\hline $\mathrm{TXT}_{2 \mathrm{hr}}(0.01 \mathrm{nmol} / \mathrm{ml})$ & $\mathrm{TXT}_{2 \mathrm{hr}}(0.01 \mathrm{nmol} / \mathrm{ml})+\mathrm{USmb}$ & $\mathrm{TXT}_{2 \mathrm{hr}}(0.01 \mathrm{nmol} / \mathrm{ml})+\mathrm{XRT}$ & $\mathrm{TXT}_{2 \mathrm{hr}}(0.01 \mathrm{nmol} / \mathrm{ml})+\mathrm{USmb}+\mathrm{XRT}$ \\
\hline $\mathrm{TXT}_{2 \mathrm{hr}}(0.1 \mathrm{nmol} / \mathrm{ml})$ & $\mathrm{TXT}_{2 \mathrm{hr}}(0.1 \mathrm{nmol} / \mathrm{ml})+\mathrm{USmb}$ & $\mathrm{TXT}_{2 \mathrm{hr}}(0.1 \mathrm{nmol} / \mathrm{ml})+\mathrm{XRT}$ & $\mathrm{TXT}_{2 \mathrm{hr}}(0.1 \mathrm{nmol} / \mathrm{ml})+\mathrm{USmb}+\mathrm{XRT}$ \\
\hline
\end{tabular}

Table 2.3: Experimental conditions of microbubblue concentration experiment

\begin{tabular}{|l|l|l|l|}
\hline \multicolumn{3}{|l|}{ Microbubblue concentration experiment conditions: (TXT ${ }_{2 \mathrm{hr}} 0.1 \mathrm{nmol} / \mathrm{ml} \&$ XRT 2 Gy Fixed) } \\
\hline US(mb 0\%) & $\mathrm{TXT}_{2 \mathrm{hr}+} \mathrm{US}(\mathrm{mb} 0 \%)$ & $\mathrm{US}(\mathrm{mb} 0 \%)+\mathrm{XRT}$ & $\mathrm{TXT}_{2 \mathrm{hr}}+\mathrm{US}(\mathrm{mb} 0 \%)+\mathrm{XRT}$ \\
\hline US(mb 0.1\%) & $\mathrm{TXT}_{2 \mathrm{hr}+} \mathrm{US}(\mathrm{mb} 0.1 \%)$ & $\mathrm{US}(\mathrm{mb} 0.1 \%)+\mathrm{XRT}$ & $\mathrm{TXT}_{2 \mathrm{hr}}+\mathrm{US}(\mathrm{mb} 0.1 \%)+\mathrm{XRT}$ \\
\hline US(mb 0.5 \%) & $\mathrm{TXT}_{2 \mathrm{hr}}+\mathrm{US}(\mathrm{mb} 0.5 \%)$ & $\mathrm{US}(\mathrm{mb} 0.5 \%)+\mathrm{XRT}$ & $\mathrm{TXT}_{2 \mathrm{hr}}+\mathrm{US}(\mathrm{mb} 0.5 \%)+\mathrm{XRT}$ \\
\hline US(mb 1\%) & $\mathrm{TXT}_{2 \mathrm{hr}}+\mathrm{US}(\mathrm{mb} 1 \%)$ & $\mathrm{US}(\mathrm{mb} 1 \%)+\mathrm{XRT}$ & $\mathrm{TXT}_{2 \mathrm{hr}}+\mathrm{US}(\mathrm{mb} 1 \%)+\mathrm{XRT}$ \\
\hline US(mb 2\%) & $\mathrm{TXT}_{2 \mathrm{hr}}+\mathrm{US}(\mathrm{mb} 2 \%)$ & $\mathrm{US}(\mathrm{mb} 2 \%)+\mathrm{XRT}$ & $\mathrm{TXT}_{2 \mathrm{hr}}+\mathrm{US}(\mathrm{mb} 2 \%)+\mathrm{XRT}$ \\
\hline
\end{tabular}




\subsubsection{Clonogenic Assay}

Following the treatment, cell viability was assessed through their ability to proliferate and form a colony. Cells (100 cells $/ \mathrm{mL}$ at $1 \mathrm{~mL}$ volume) were plated in $50 \mathrm{~mm}$ Petri dishes containing $4 \mathrm{~mL}$

cell media culture and incubated for 14 days. The cells were stained with Methylene blue (1\% w/v, VWR International, Ontario, Canada) and counted using a microscope. Each experiment was repeated three times with five samples per condition. The effect of chemotherapy and microbubbles concentration were determined by the viability ratio $\left(V_{R}\right)$ which was defined by the number of colonies formed $\left(\mathrm{V}_{\mathrm{C}}\right)$ normalized with respect to untreated control cells. The data was presented as mean \pm SD and statistical significant differences were assessed using student t-test.

\subsubsection{Analysis of Synergism}

Synergism of the combined treatment was assessed using the Bliss independence model (Meletiadis et al., 2003). The additive cell viability $\left(\mathrm{V}_{\mathrm{A}}\right)$ was calculated and compared to experimental values $\left(\mathrm{V}_{\mathrm{C}}\right)$ for each treatment. $\mathrm{V}_{\mathrm{A}}$ was determined by the following equation: $\mathrm{V}_{\mathrm{A}=} \mathrm{V}_{\mathrm{C} 1} \times \mathrm{V}_{\mathrm{C} 2} \times \mathrm{V}_{\mathrm{C} 3}$ where $\mathrm{V}_{\mathrm{C} 1}, \mathrm{~V}_{\mathrm{C} 2}$ and $\mathrm{V}_{\mathrm{C} 3}$ represent cell viabilities of single treatments. The combined treatment was considered synergistic when cell viability was statistically lower than the expected additive effect calculated value. 


\subsection{Results}

Ultrasound and microbubbles (USmb) improved the therapeutic outcome of chemotherapy (TXT) and radiotherapy (XRT). Cell viability of the combined treatment (TXT ${ }_{2 h}+\mathrm{XRT}+\mathrm{USmb}$ $=2 \%)$ in PC3 cells decreased by $\sim 28$-folds, $\sim 19$-folds and $\sim 11$-folds compared to XRT alone (57\%), TXT $_{2 \mathrm{~h}}+\mathrm{XRT}(37 \%)$ and USmb+XRT (22\%) respectively (Fig2.2). The therapeutic efficiency of the combined treatment depended on chemotherapy duration and concentration as well as MB concentration.

\subsubsection{Chemotherapy Duration and Combined Treatment}

Clonogenic viability of cells treated with USmb and XRT with or without TXT, for both $5 \mathrm{~min}$ and $2 \mathrm{hr}$, are shown in Figure 2.1. Cells treated with $\mathrm{TXT}+\mathrm{USmb}+\mathrm{XRT}$ at both $2 \mathrm{~h}\left(\mathrm{~V}_{\mathrm{c}}=2 \%\right)$ and 5 min $\left(\mathrm{V}_{\mathrm{c}}=8 \%\right)$ synergistically reduced cell viability by $\sim 11$ and $\sim 3$ folds respectively in relation to $\mathrm{USmb}+\mathrm{XRT}\left(\mathrm{V}_{\mathrm{c}}=22 \%\right)$ treatment. A statistically significant difference was also observed between the treatment durations in all conditions $(\mathrm{P}<0.05)$. On average, a decrease of $10 \%$ in cell viability was observed in the comparison between $\mathrm{TXT}_{2 \mathrm{hr}}+\mathrm{XRT}\left(\mathrm{V}_{\mathrm{c}}=37 \%\right)$ and $\mathrm{TXT}_{5 \min }+\mathrm{XRT}\left(\mathrm{V}_{\mathrm{c}}=49 \%\right)$. Similar decreases were also obtained within TXT+USmb and TXT alone treatments amongst both durations. In addition, the TXT alone treatment displayed $25 \%$ \& $15 \%$ decrease in cell viability, relative to the untreated control, for both $2 \mathrm{hrs}$ and $5 \mathrm{~min}$ respectively.

Results also showed that TXT treatment duration played an important role in enhancing XRT effect on cell viability. Cell viability decreased in the $\mathrm{TXT}_{2 h r}+\mathrm{XRT}\left(\mathrm{V}_{\mathrm{c}}=37 \%\right)$ treatment by $20 \%$ whereas $\mathrm{TXT}_{5 \min }+\mathrm{XRT}\left(\mathrm{V}_{\mathrm{c}}=49 \%\right)$ decreased by $8 \%$ compared to $\mathrm{XRT}\left(\mathrm{V}_{\mathrm{c}}=57 \%\right)$ alone. 
The addition of the USmb treatment also improved the therapeutic response of both XRT and TXT treatment. A $\sim 3$ fold decrease in cell viability was found in the USmb+XRT $\left(\mathrm{V}_{\mathrm{c}}=22 \%\right)$ treatment compared to XRT $\left(\mathrm{V}_{\mathrm{c}}=57 \%\right)$ alone. Furthermore, an average decrease of $20 \%$ in cell viability was observed when treating cells with TXT+USmb compared to TXT alone for both durations Figure (2.1a).The effect of the combination of TXT+USmb+XRT on cell death was significant at both treatment durations in regards to the viability ratio $\left(\mathrm{V}_{\mathrm{R}}\right)$ (Figure $\left.2.2 \mathrm{~b}\right)$. 


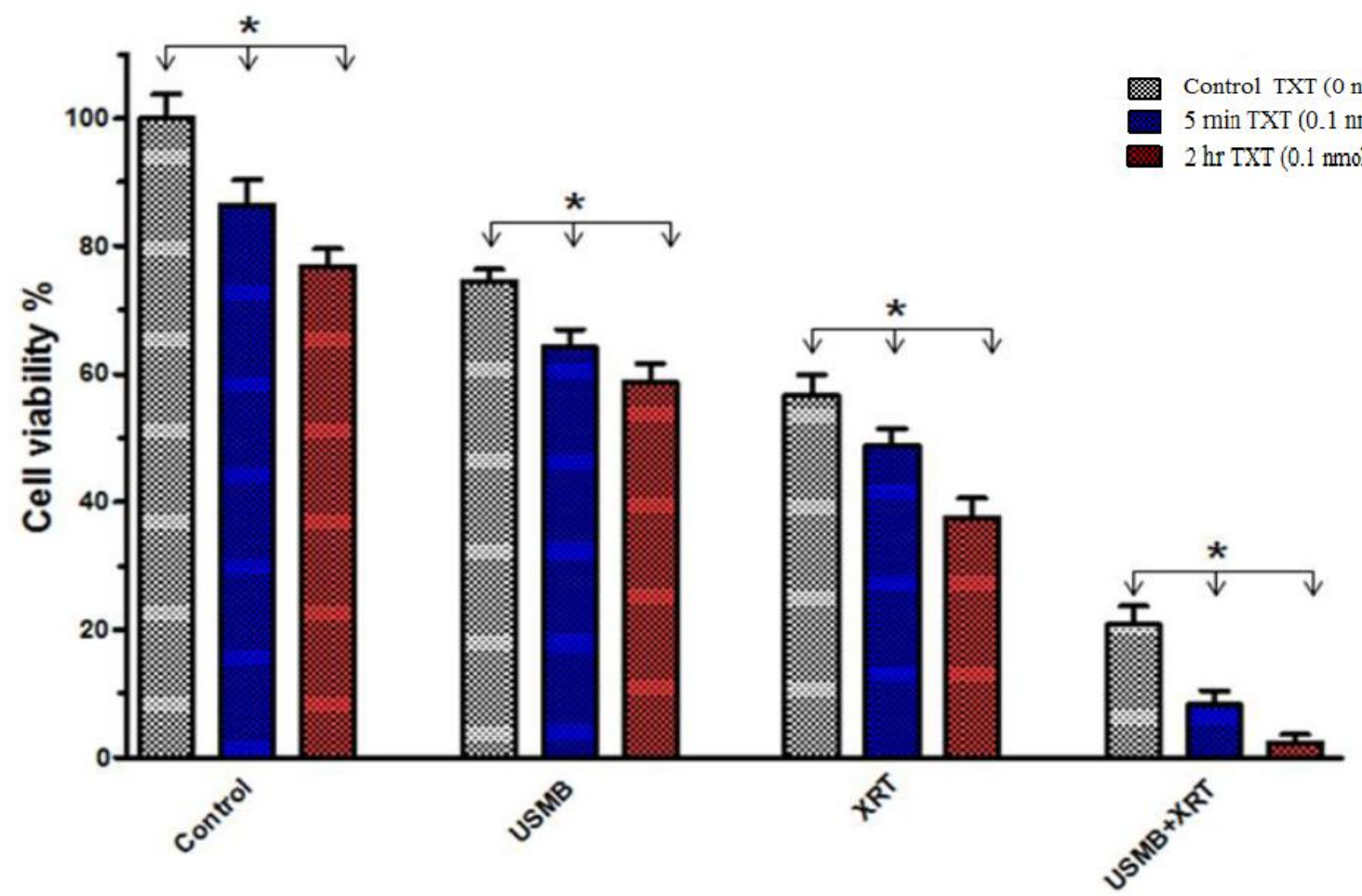

Figure 2.2: (a) PC3 clonogenic viability exposed to $0.1 \mathrm{nM}$ TXT at two different treatment exposure times (5 minutes blue bars \& $2 \mathrm{hr}$ red bars) cell viability was normalized to the control. USmb fixed at $0.5 \mathrm{MHz}$ frequency pulses with $580 \mathrm{kPa}$ negative peak pressure and $2 \%(\mathrm{v} / \mathrm{v})$ microbubbles, and a $160 \mathrm{kVp} 2 \mathrm{~Gy}$ single radiation dose and their combinations are shown.

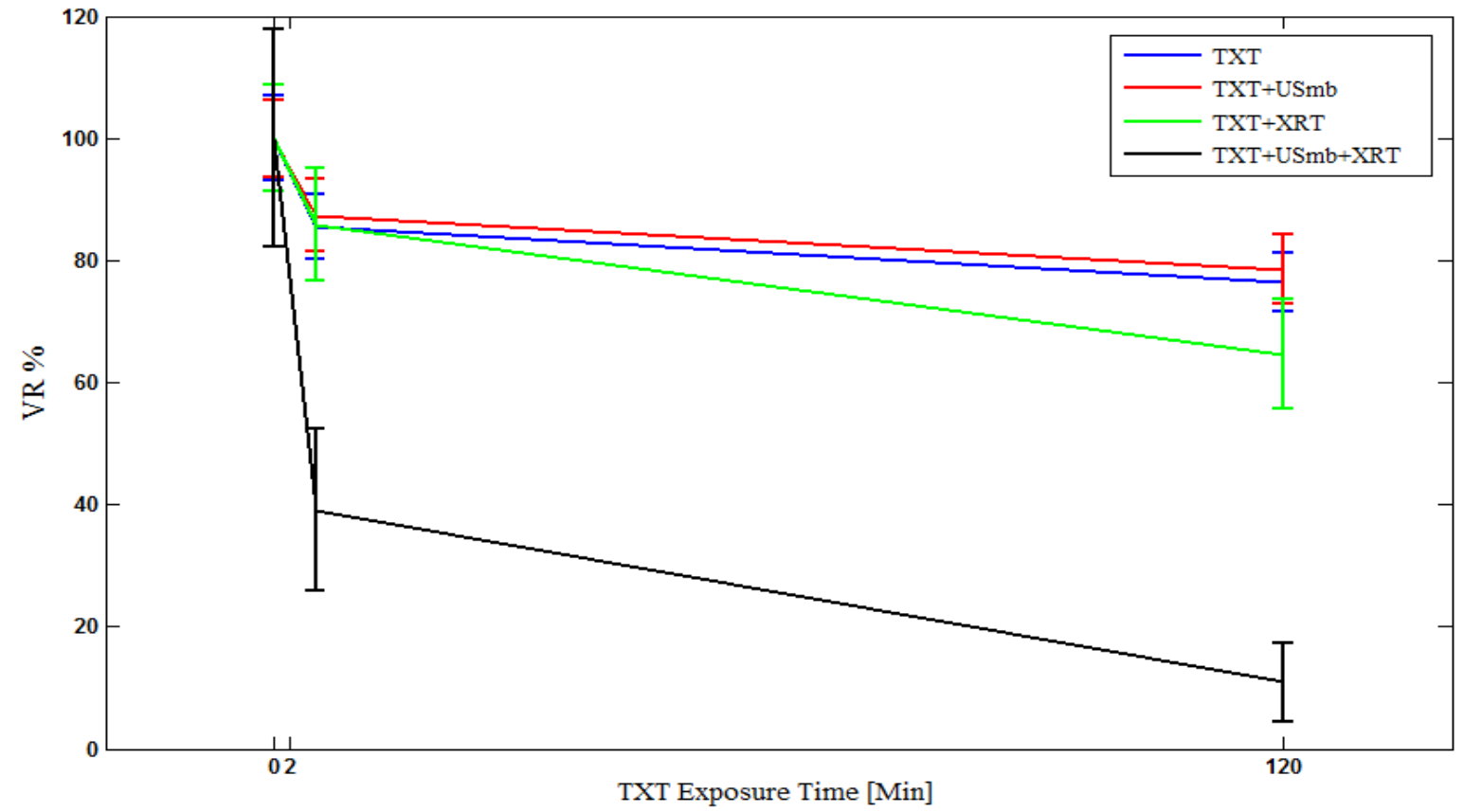

Figure 2.2: (b) Represents the viability ratio (VR\%) were samples normalized to zero $\mathrm{nmol} / \mathrm{mL}$ TXT for each combined treatment. These samples were centrifuged, removing TXT within the sample before irradiation and plating in dishes. $\mathrm{N}=24$ from 4 independent experiments. 


\subsubsection{Study of Synergism for Combined Treatments at Different Chemotherapy Durations}

The therapeutic effect (synergism) of all three treatments (TXT, USmb and XRT) was calculated using Bliss independence criterion for both chemotherapy durations (Meletiadis et al., 2003) (Figures $2.3 \mathrm{a} \& \mathrm{~b})$.

The combined treatment of $\mathrm{TXT}+\mathrm{USmb}+\mathrm{XRT}\left(\mathrm{V}_{\mathrm{c}}=2 \%, 8 \%\right.$ for $2 \mathrm{hr}$ and $5 \mathrm{~min}$ respectively) synergistically stimulated cell death at both chemotherapy durations. The experimental cell viability $\left(\mathrm{V}_{\mathrm{c}}\right)$ values were statistically different compared with calculated cell viabilities $\left(\mathrm{V}_{\mathrm{A}}=32 \%, \mathrm{~V}_{\mathrm{A}}=35 \%\right.$ for $2 \mathrm{hr}$ and $5 \mathrm{~min}$ respectively) based on single experimental treatment. $\mathrm{USmb}+\mathrm{XRT}\left(\mathrm{V}_{\mathrm{c}}=22 \%\right)$ combined treatment also induced a synergistic effect compared to the calculated cell viability $\left(\mathrm{V}_{\mathrm{A}}=42 \%\right)$ based on values from single treatments $\left(\mathrm{V}_{\mathrm{c}}=76 \%\right.$ \& $57 \%$ for USmb and XRT).

The effect of TXT+XRT and TXT+USmb was additive for both treatment durations (2hr \& 5 min). The additive calculated cell viabilities $\left(\mathrm{V}_{\mathrm{A}}=43 \%, 56 \%\right.$ respectively) for the $2 \mathrm{hr}$ Chemo treatment was statistically comparable to experimentally measured cell viabilities $\left(\mathrm{V}_{\mathrm{c}}=37 \%, 58 \%\right.$ respectively) indicating additive effects. For the short treatment time (5min), the additive calculated cell viability $\left(\mathrm{V}_{\mathrm{A}}=48 \%, 63 \%\right.$ respectively) was also comparable to the experimental cell viability value $\left(\mathrm{V}_{\mathrm{c}}=49 \%, 65 \%\right.$ respectively) for each treatment. 
(a)

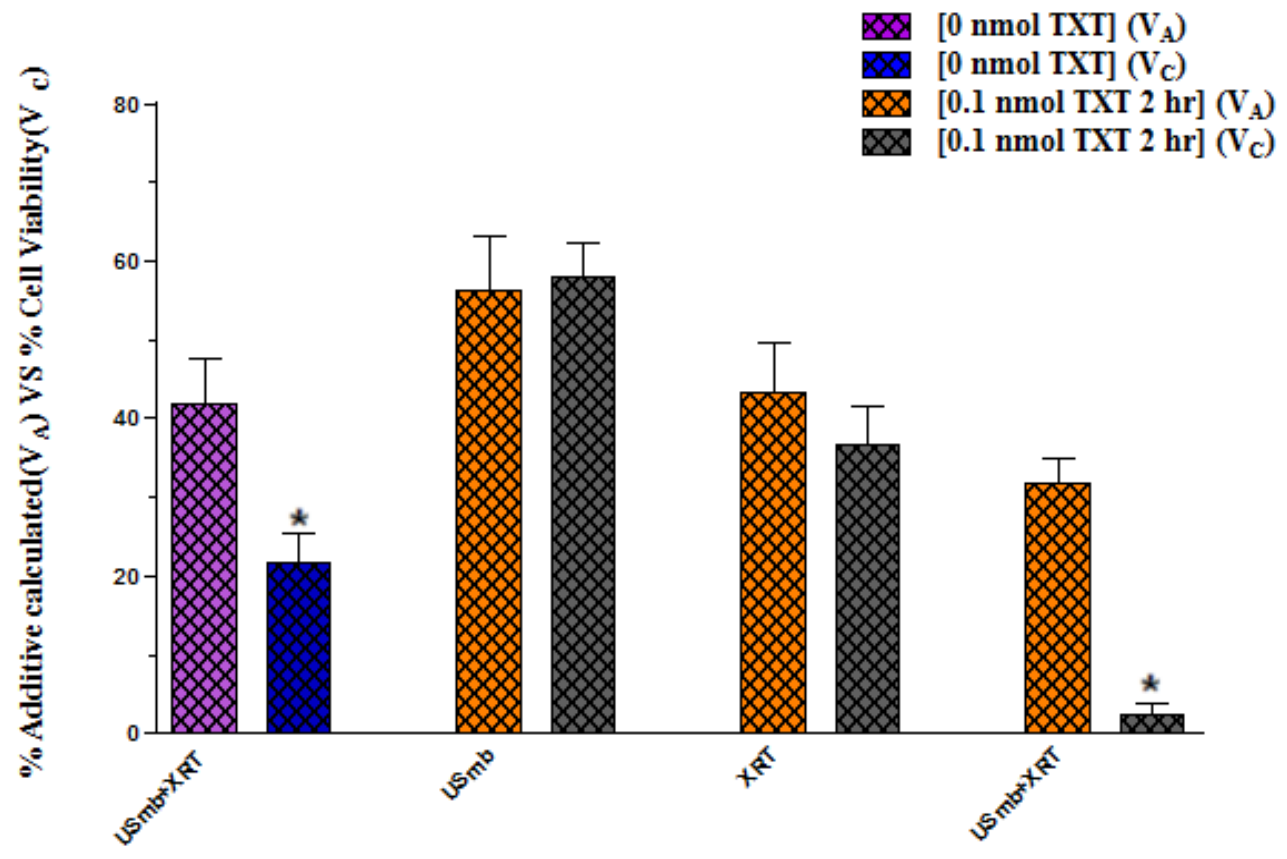

(b)

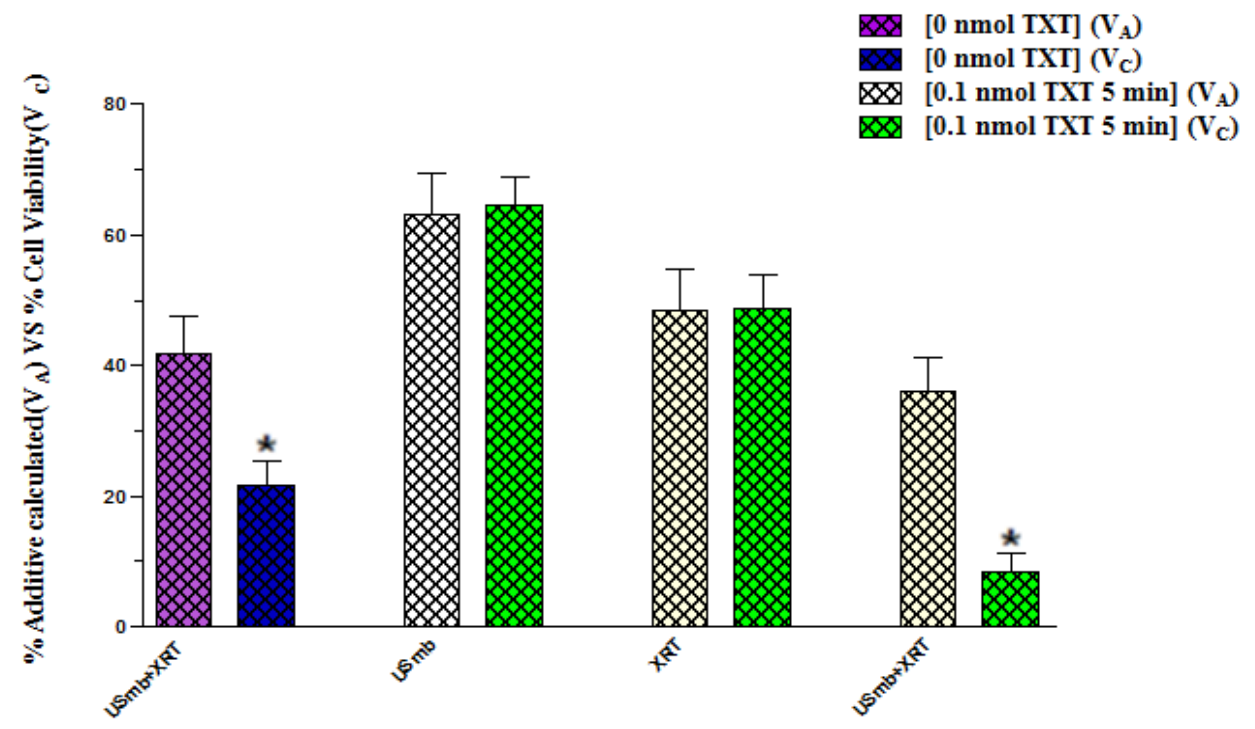

Figure 2.3: The calculated additive effect $\left(\mathrm{V}_{\mathrm{A}}\right)$ of $\mathrm{TXT}, \mathrm{USmb}$, and XRT compared to cell viability $\left(\mathrm{V}_{\mathrm{C}}\right)$ for (a) 5 minutes TXT and (b) Two hr TXT. The asterisks identify the treatments that have a statistically significant $\mathrm{V}_{\mathrm{C}}<\mathrm{V}_{\mathrm{A}}$ with $\mathrm{P}<0.05$. 
The different permutations of TXT+USmb+XRT at $2 \mathrm{hr}\left(\mathrm{V}_{\mathrm{C}}=2 \%\right)$ and $5 \mathrm{~min}\left(\mathrm{~V}_{\mathrm{C}}=8 \%\right)$ were investigated to determine the possible synergistic mechanism, by comparing the experimental cell viability to the calculated additive value. The additive calculated cell viabilities $(\mathrm{TXT}+\mathrm{USmb})+\mathrm{XRT}\left(\mathrm{V}_{\mathrm{A}}=16 \%, 18 \%\right),(\mathrm{TXT}+\mathrm{XRT})+\mathrm{USmb}\left(\mathrm{V}_{\mathrm{A}}=33 \%, 37 \%\right)$ and $\mathrm{TXT}+$ $(\mathrm{USmb}+\mathrm{XRT})\left(\mathrm{V}_{\mathrm{A}}=27 \%, 36 \%\right)$ at both $2 \mathrm{hr}$ and $5 \mathrm{~min}$ respectively, were synergistic at both durations. (Figure2.3).

(a)

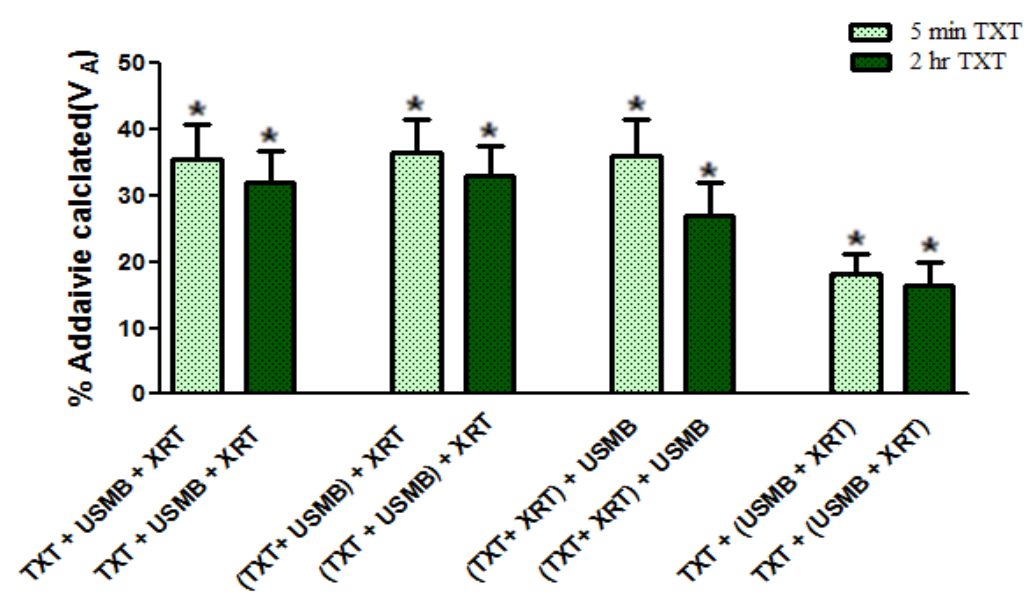

(b)

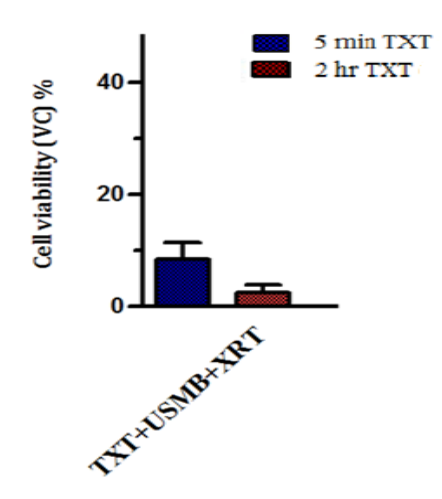

Figure 2.4: (a) The calculated additive effect $\left(\mathrm{V}_{\mathrm{A}}\right)$ of different permutations of TXT+USmb+XRT 5 minutes \& $2 \mathrm{hr}$ exposure time. (b) Experimental cell viability $\left(\mathrm{V}_{\mathrm{C}}\right)$ for $\mathrm{TXT}+\mathrm{USmb}+\mathrm{XRT}$. The asterisks identify the treatments that have a statistically significant $\mathrm{V}_{\mathrm{C}}<\mathrm{V}_{\mathrm{A}}$ with $\mathrm{P}<0.05$. 


\subsubsection{Investigate Chemotherapy Drug Concentration Dose}

The effect of TXT was determined by obtaining the cell viability ratio (VR) for all treatments (Figure $2.5 \mathrm{a} \& \mathrm{~b}$ ). The effect of the combination of TXT+USmb+XRT on cell death was substantial at $0.1 \mathrm{nmol} / \mathrm{ml}$ and $0.01 \mathrm{nmol} / \mathrm{ml}$ TXT concentrations. Changing TXT concentration within TXT alone $(91 \%, 87 \%, 76 \%)$, TXT + USmb $(94 \%, 86 \%, 75 \%)$ and TXT+XRT $(94 \%$, $77 \%, 67 \%)$ treatments also had additive effects with no statistical significant differences amongst any of the concentrations $(0.001,0.01$ and $0.1 \mathrm{nmol} / \mathrm{ml})$ respectively. In these three treatments, increasing the chemotherapy dosage caused a linear decrease in cell viability. TXT in combination with ultrasound and microbubbles improved the therapeutic response of radiotherapy at concentrations beyond $0.001 \mathrm{nmol} / \mathrm{ml}$. VR decreased by $\sim 3$ folds within the TXT+USmb+XRT treatment when relatively comparing TXT concentrations within the treatment.

The combined TXT+USmb+XRT treatment had a profound effect on cell viability at TXT concentrations of $0.1 \mathrm{nmol} / \mathrm{ml}(\mathrm{VR}=12 \%)$ and $0.01 \mathrm{nmol} / \mathrm{ml}(\mathrm{VR}=31 \%)$ when compared to TXT alone $(\mathrm{VR}=76 \%, 87 \%), \mathrm{TXT}+\mathrm{USmb}(\mathrm{VR}=75 \%, 86 \%)$ and $\mathrm{TXT}+\mathrm{XRT}(\mathrm{VR}=67 \%, 77 \%)$ respectively. However, when analyzing the VR at $0.001 \mathrm{nmol} / \mathrm{ml}$, the effects of the combined treatment were additive: $\mathrm{TXT}+\mathrm{USmb}+\mathrm{XRT} \quad(\mathrm{VR}=93 \%)$ to Chemo alone (VR=91\%), $\mathrm{TXT}+\mathrm{USmb}(\mathrm{VR}=94 \%)$ and TXT+XRT (VR=94\%) (Figure $2.5 \mathrm{~b})$.

Moreover, the point obtained on the graph at $0 \mathrm{nmol} / \mathrm{ml}$ was still noteworthy. Though the $\mathrm{VR}=100 \%$, the cell viability for USmb, XRT, and USmb+XRT at $0 \mathrm{nmol} / \mathrm{ml}$ were $75 \%, 55 \%$ and $19 \%$ for the three treatments respectively (Figure 2.5 a). 
(a)

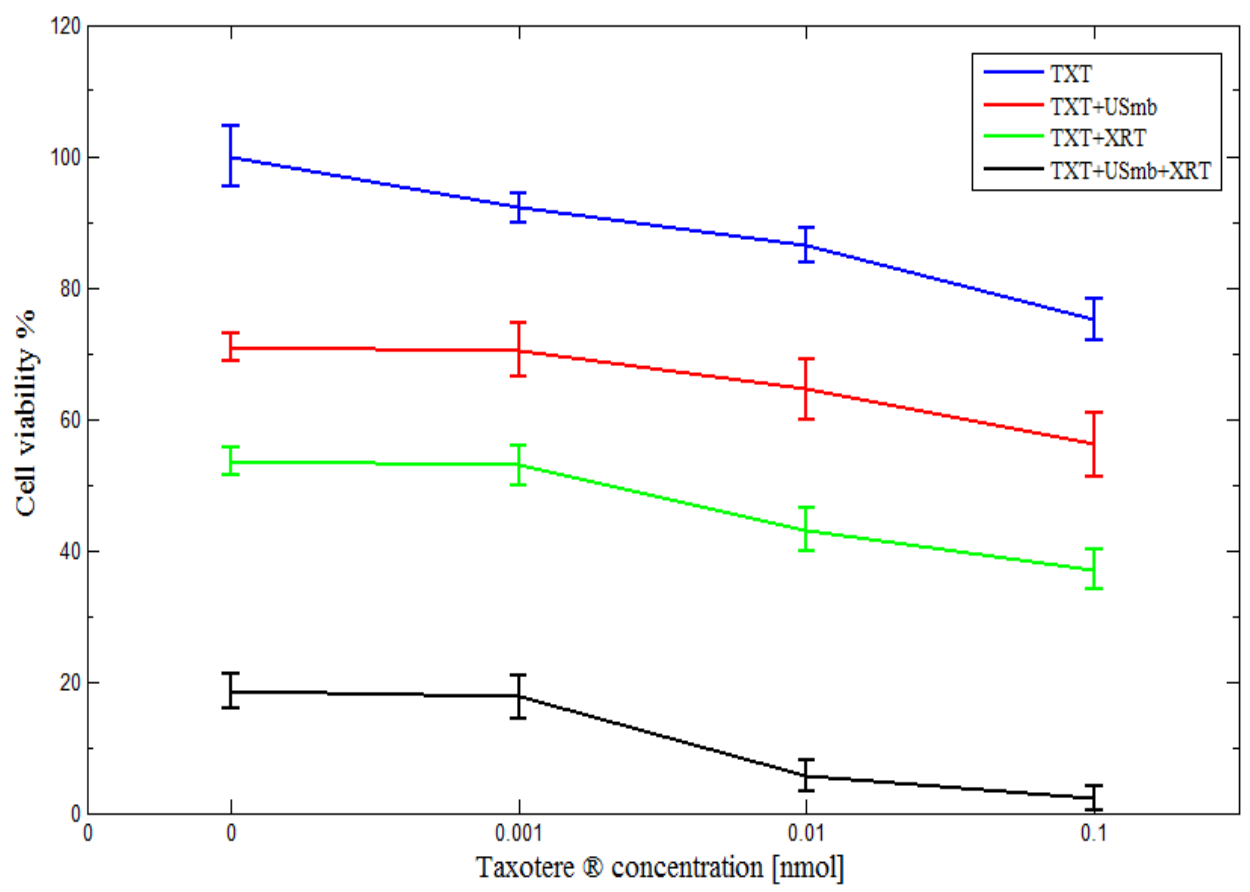

(b)

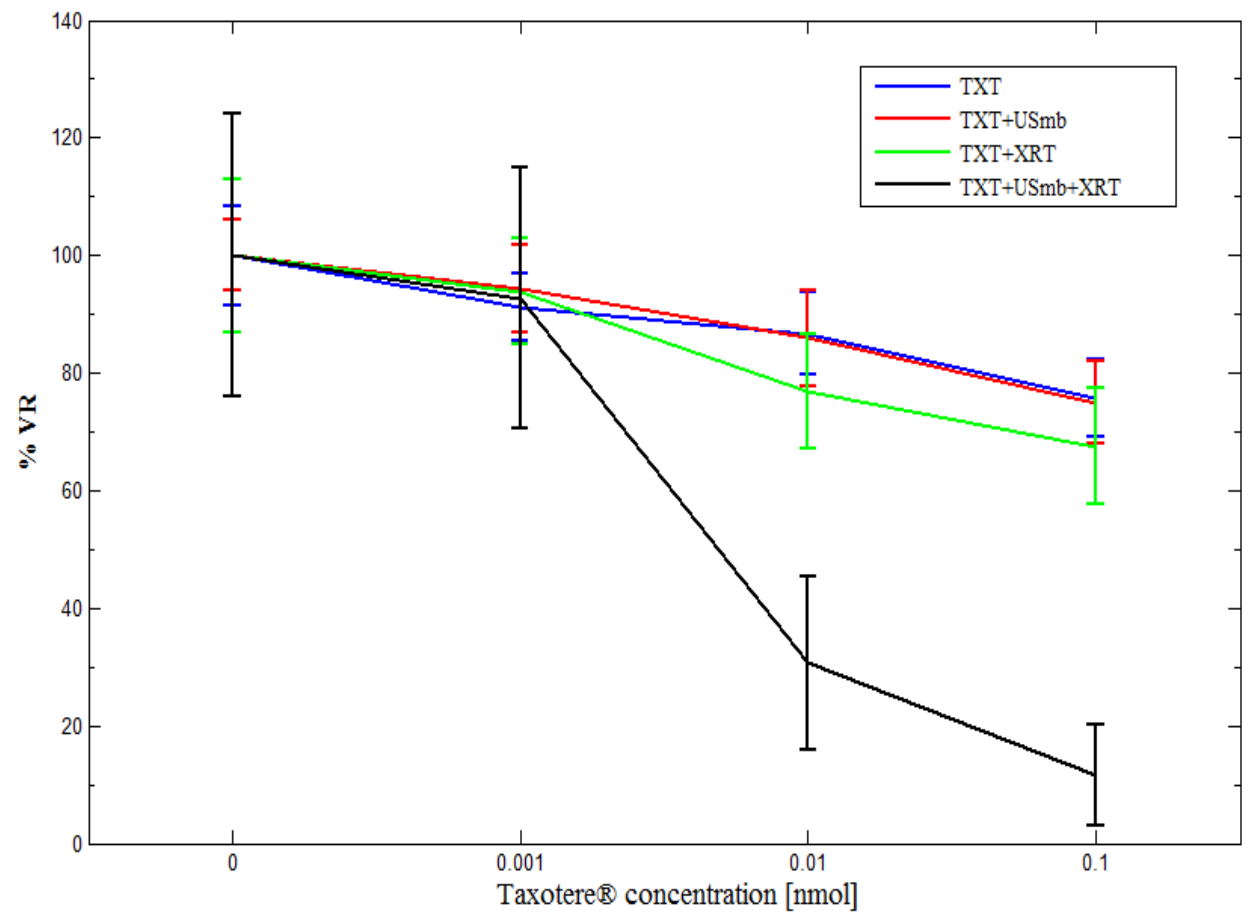

Figure 2.5: (a) PC3 clonogenic viability exposed to a different TXT concentrations $(0.001,0.01,0.1 \mathrm{nmol} / \mathrm{ml})$ at 2 $\mathrm{hr}$ treatment exposure cell viability, fixed $2 \%$ (v/v) microbubbles, and $160 \mathrm{kVp} 2 \mathrm{~Gy}$ single radiation dose and their combinations , cell viability was normalized to the control. cell viability was normalized to the control. USmb fixed at $0.5 \mathrm{MHz}$ frequency pulses with $580 \mathrm{kPa}$ negative peak pressure. (b) Represents the viability ratio (VR\%) were samples normalized to zero $\mathrm{nmol} / \mathrm{ml}$ TXT for each combined treatment. These samples were centrifuged, removing TXT within the sample before irradiation and plating in dishes. $\mathrm{N}=24$ from three independent experiments. 


\subsubsection{Study of Synergism for Combined Treatments in the Chemotherapy Dose}

The additive effect for the combined treatment of TXT, USmb and XRT were calculated using Bliss independence criterion for three TXT concentrations $(0.001,0.01$ and $0.1 \mathrm{nmol} / \mathrm{ml})$ at $2 \mathrm{hr}$ treatment duration (Meletiadis et al. 2003) (Figure 2.6a).

Synergistic effects were induced by the combined treatment of TXT + USmb + XRT at all TXT concentrations. The effect was determined by comparing experimental cell viability values $\left(\mathrm{V}_{\mathrm{c}}=2 \%, 8 \%, 18 \%\right.$ for $0.1,0.01$ and $0.001 \mathrm{nmol} / \mathrm{ml}$ respectively) of the combined treatment to the calculated cell viability $\left(\mathrm{V}_{\mathrm{A}}=31 \%, 36 \%, 38 \%\right.$ for $0.1,0.01$ and $0.001 \mathrm{nmol} / \mathrm{ml}$ respectively) observed from the experimental value for each single treatment. The values were statistically different with $\mathrm{V}_{\mathrm{C}}<\mathrm{V}_{\mathrm{A}}$ suggesting synergistic effects.

The effect of TXT+XRT and TXT+USmb was additive for the three TXT concentrations $(0.1$, $0.01,0.001 \mathrm{nmol} / \mathrm{ml})$. The additive calculated cell viabilities $\left(\mathrm{V}_{\mathrm{A}}=42 \%, 48 \%, 50 \%\right.$ respectively $)$ pertaining to the TXT+XRT treatment were statistically comparable to the experimentally measured cell viabilities ( $\mathrm{V}_{\mathrm{c}}=37 \%, 43 \%, 52 \%$ respectively) indicating additive effects. Similarly, the TXT+USmb treatment also resulted in cell viabilities $\left(\mathrm{V}_{\mathrm{c}}=56 \%, 64 \%, 70 \%\right)$ that were analogous to calculated values $\left(\mathrm{V}_{\mathrm{A}}=57 \%, 65 \%, 68 \%\right)$.

The different permutations of the combined treatment of TXT+USmb+XRT were investigated to determine the possible synergistic mechanism by comparing the experimental cell viability to the calculated additive value. Permutations were statistically different but additive at all TXT concentrations $(0.001 \mathrm{nmol} / \mathrm{ml}, 0.01 \mathrm{nmol} / \mathrm{ml}, 0.1 \mathrm{nmol} / \mathrm{ml})$ for $(\mathrm{TXT}+\mathrm{USmb})+\mathrm{XRT}\left(\mathrm{V}_{\mathrm{A}}=38 \%\right.$, $35 \%, 30 \%)$ and $(\mathrm{TXT}+\mathrm{XRT})+\mathrm{USmb}\left(\mathrm{V}_{\mathrm{A}}=38 \%, 31 \%, 26 \%\right)$. However, synergism was achieved 
with the $\mathrm{TXT}+(\mathrm{XRT}+\mathrm{USmb})$ combination at $(0.01,0.1 \mathrm{nmol} / \mathrm{ml})$ and additive at $(0.001$ $\mathrm{nmol} / \mathrm{ml}$ ) (Figure 2.6b).

(a)

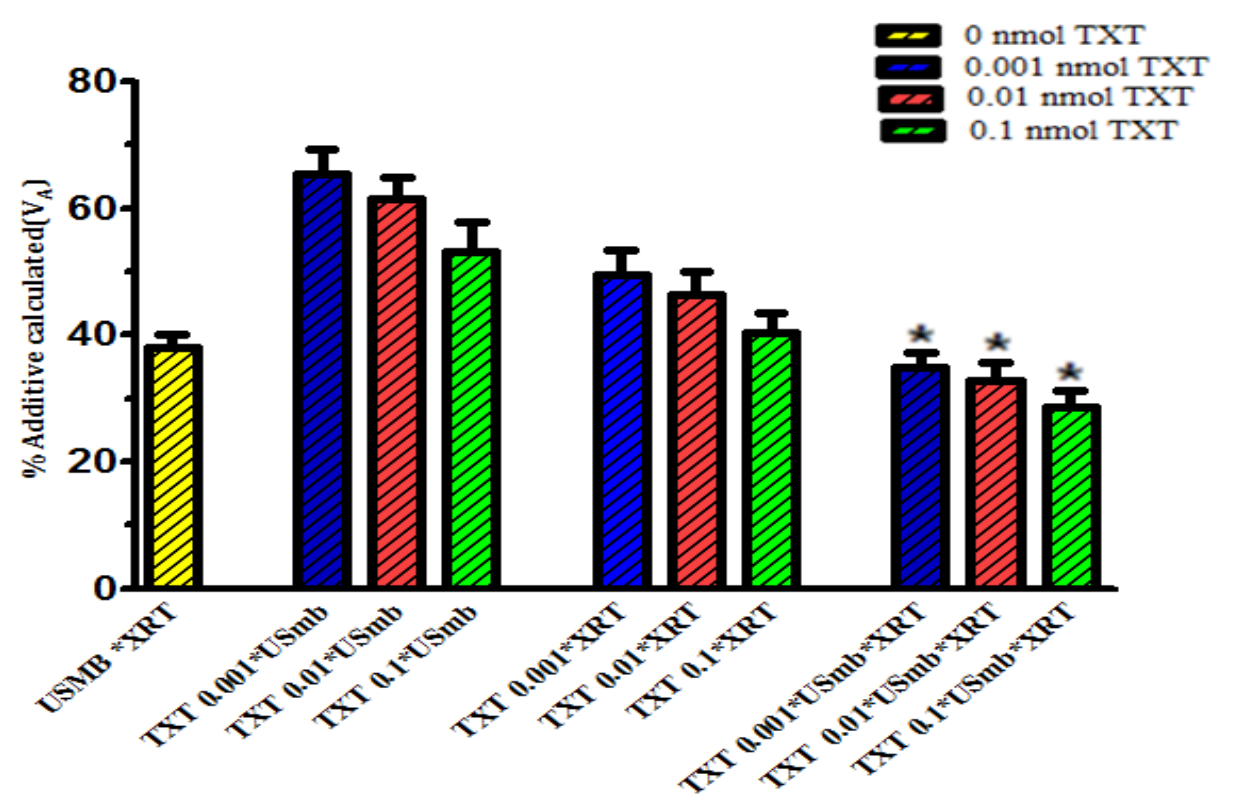

(b)

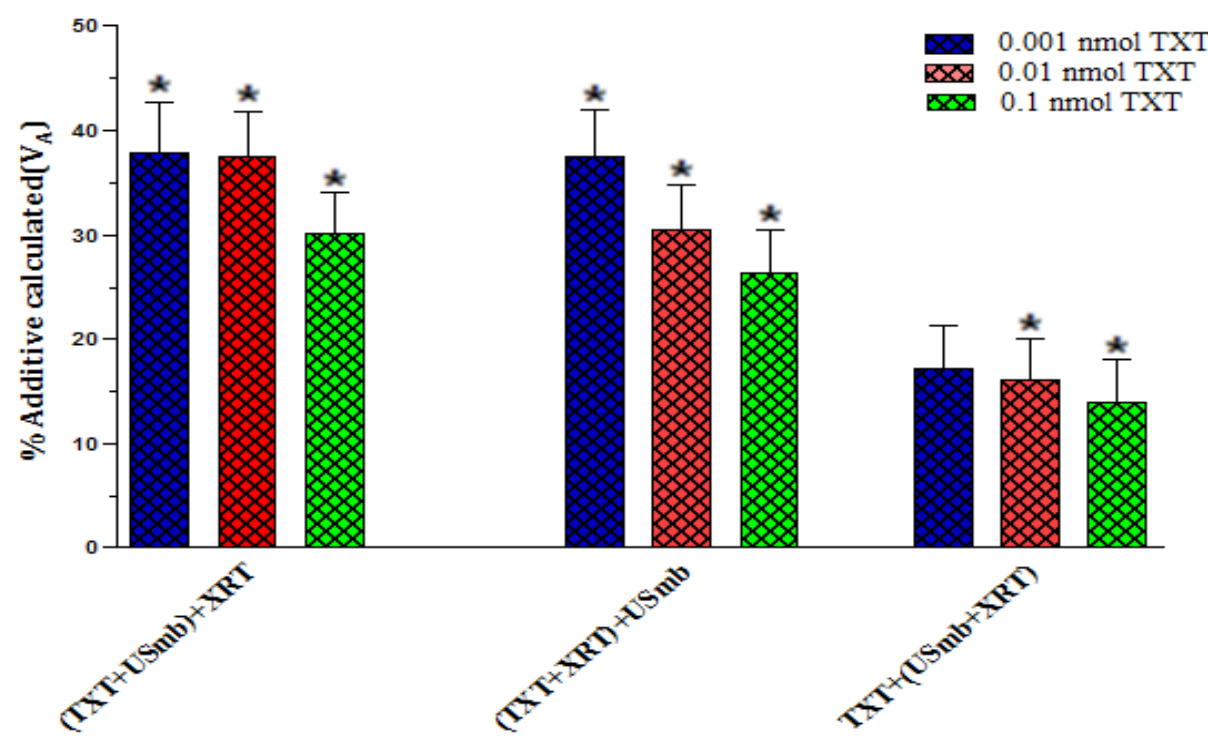

Figure 2.6: (a) The calculated additive effect $\left(\mathrm{V}_{\mathrm{A}}\right)$ compared to the experimental cell viability $\left(\mathrm{V}_{\mathrm{C}}\right)$ in Fig2.4 (a) for the different treatment combination at $(0.001,0.001,0.1 \mathrm{nmol} / \mathrm{ml})$ TXT doses. The asterisks identify the treatments that have a statistically significant compared to $\mathrm{V}_{\mathrm{C}}$ (b) The calculated additive effect $\left(\mathrm{V}_{\mathrm{A}}\right)$ of different permutations of TXT+USmb+XRT a statistically significant $\mathrm{V}_{\mathrm{C}}<\mathrm{V}_{\mathrm{A}}$ with $\mathrm{P}<0.05$. Figure 2.6(b) 


\subsubsection{Investigate Microbubble (MB) Concentration}

Microbubble concentration was another parameter that influenced the overall cell viability. The effect was observed by obtaining cell viabilities for each treatment (USmb, USmb+XRT, USmb+TXT and TXT+USmb+XRT) and normalizing it to its corresponding to control (0\% $\mathrm{MB})$. Thus, the data collected was cell viability ratio (VR) providing relative proficiency of each treatment. (Figure $2.7 \mathrm{a} \& \mathrm{~b})$.

The combined treatment of TXT+USmb+XRT, which proved to be the most effective treatment, was synergistic at all microbubble concentrations $(0.1 \%, 0.5 \%, 1 \%$ and $2 \%)$ selected for this experiment. The VR at each concentration $(\mathrm{VR}=27 \%, 23 \%, 15 \%$ and $5 \%$ respectively) decreased subsequently as the microbubbles concentration was increased, while each differed significantly from the control (VR=100\%). The USmb+XRT treatment was another that showed synergistic effects at microbubble concentrations of $1 \%(\mathrm{VR}=56 \%)$ and $2 \%(\mathrm{VR}=41 \%)$.The results also show that VR for USmb+TXT+XRT was significantly different even at $0.1 \% \mathrm{MB}$ concentration $(\mathrm{VR}=27 \%)$ compared to the VR for the USmb alone, USmb + TXT and USmb+XRT Figure 2.7 (b). 
(a)

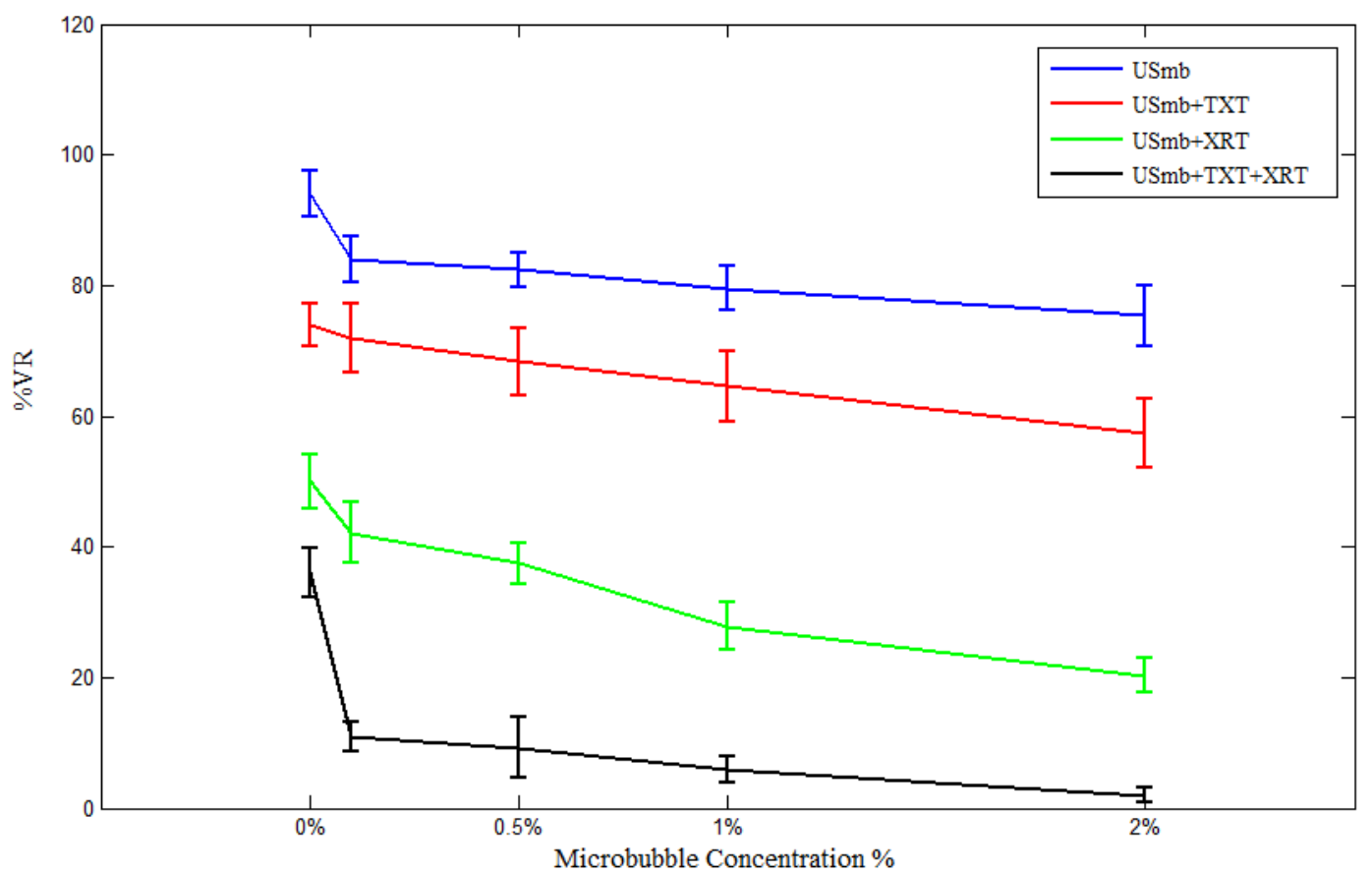

(b)

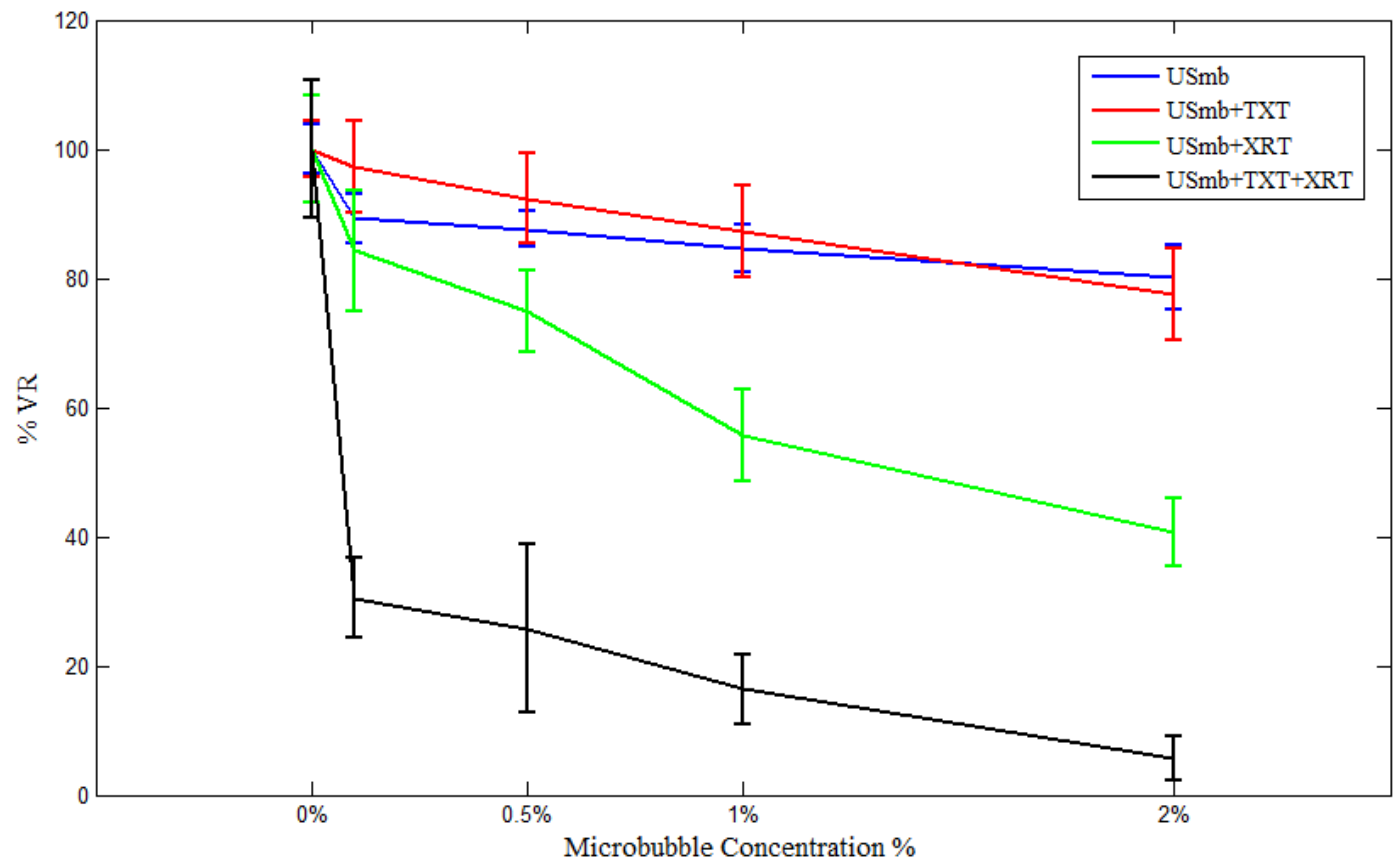

Figure2.7: (a) PC3 clonogenic viability exposed to a different MB concentrations $(0.1,0.5,1,2 \%$ (v/v)) microbubbles concentrations, and fixed $2 \mathrm{hr}$ TXT treatment exposure and and a $160 \mathrm{kVp} 2 \mathrm{~Gy}$ single radiation dose and their combinations ,cell viability was normalized to the control. USmb fixed at $0.5 \mathrm{MHz}$ frequency pulses with $580 \mathrm{kPa}$ negative peak pressure (b) represents the viability ratio were samples normalized to zero $\mathrm{nmol} / \mathrm{ml} \mathrm{TXT}$ for each combined treatment. These samples were centrifuged, removing TXT within the sample before irradiation and plating in dishes. $\mathrm{N}=24$ from three independent experiments. 


\section{Ultrasound without Microbubble Graph}

Additive effect achieved in the combined treatment US+TXT+XRT with cell viability of $\left(\mathrm{V}_{\mathrm{c}}=\right.$ $36 \%)$. Cell viability was decreased $\sim 18$ fold when $\mathrm{MB}$ were added $\left(\mathrm{V}_{\mathrm{c}}=2 \%\right.$ ) (Figure 2.7 (a)) In the US + XRT, the $\mathrm{V}_{c}$ decreased to $50 \%$ whereas the addition of MB decreased $\mathrm{V}_{\mathrm{c}}$ to $21 \%$. Ultrasound and microbubbles also decreased Vc in US+TXT and US alone treatments by $~ 6 \%$ and $\sim 19 \%$ respectively with $2 \% \mathrm{v} / \mathrm{v}$ microbubble concentration (Figure 2.8 ).

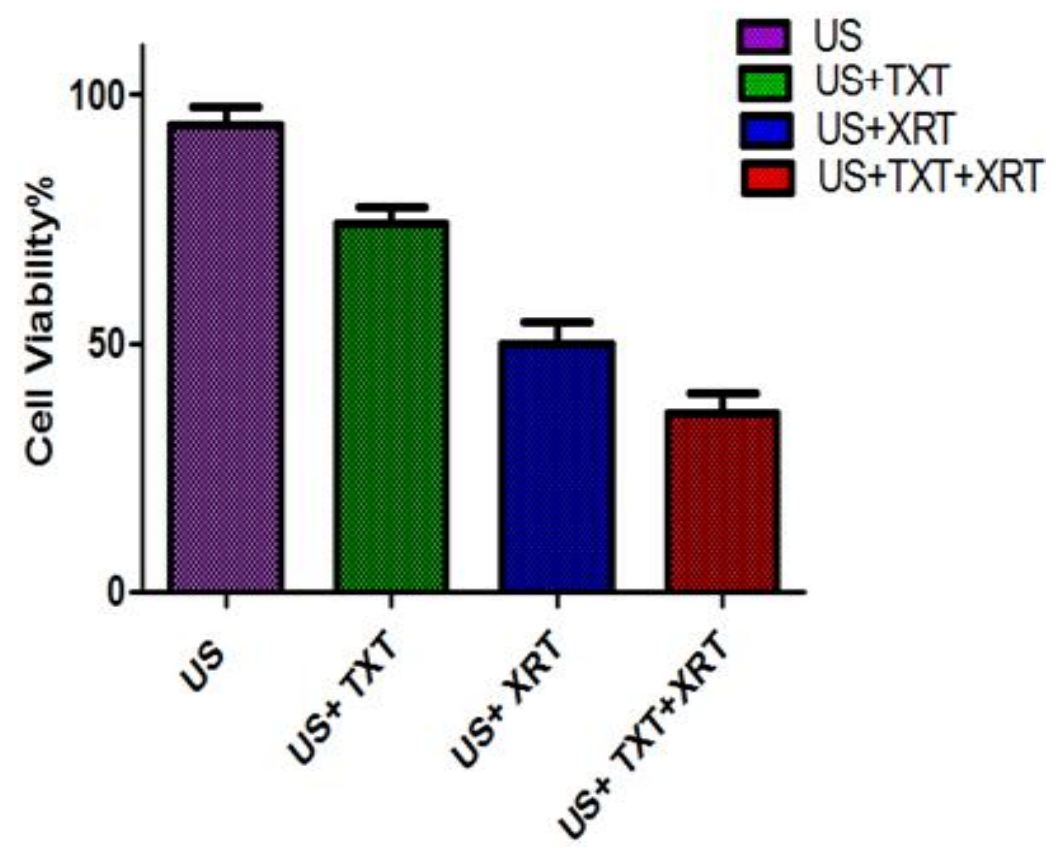

Figure 2.8.Cell viability at (Zero \%) MB With different treatment combination 


\subsubsection{Study of Synergism for Combined Treatments for Microbubble Concentration}

The additive effect was calculated for all microbubble concentrations $(0.1 \%, 0.5 \%, 1 \%, 2 \%$ (v/v\%)) for the combined treatment TXT, USmb and XRT (Figure 2.9 a).Synergistic effects were induced by the combined treatment of TXT + USmb + XRT at all four microbubble concentrations. The effect was determined by comparing experimental cell viability values $\left(\mathrm{V}_{\mathrm{c}}=2 \%, 6 \%, 9 \%, 11 \%\right)$ of the combined treatment to the calculated cell viability $\left(\mathrm{V}_{\mathrm{A}}=37 \%\right.$, $36 \%, 35 \%, 33 \%$ respectively) observed from the experimental value for $2 \%, 1 \%, 0.5 \%$ and $0.1 \%$ (v/v \%) respectively. The values were statistically different with $\mathrm{V}_{\mathrm{C}}<\mathrm{V}_{\mathrm{A}}$ suggesting synergistic effects. Synergastic effect achieved with USmb+XRT for $(2 \%, 1 \%(\mathrm{v} / \mathrm{v} \%))$ and additive effect with $(0.5 \%, 0.1 \%(\mathrm{v} / \mathrm{v} \%)$. USmb+TXT calculated additive were statistically comparable to the experimentally measured at the four-microbbbule concentrations achving an additive effect. 
(a)

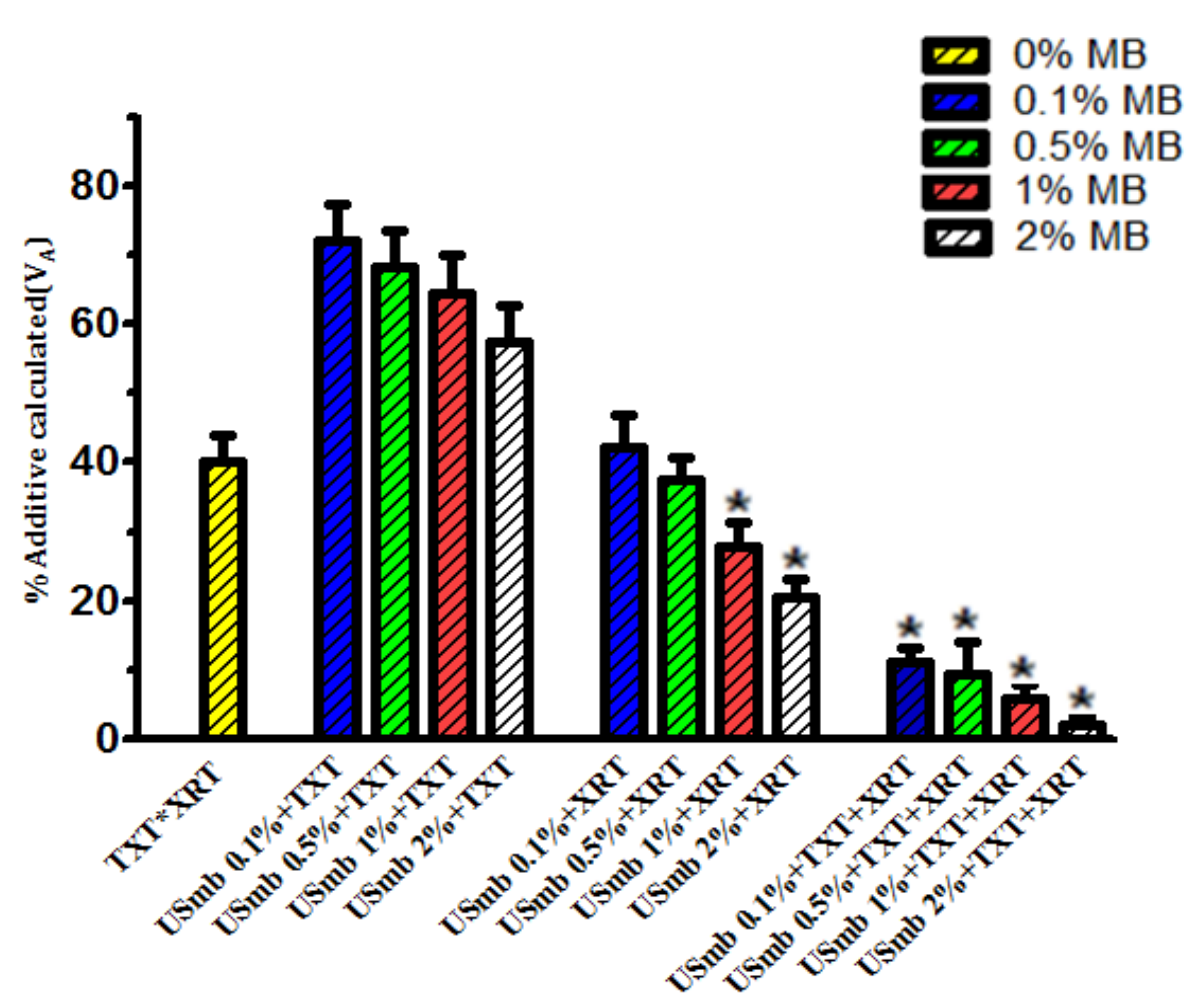

(b)

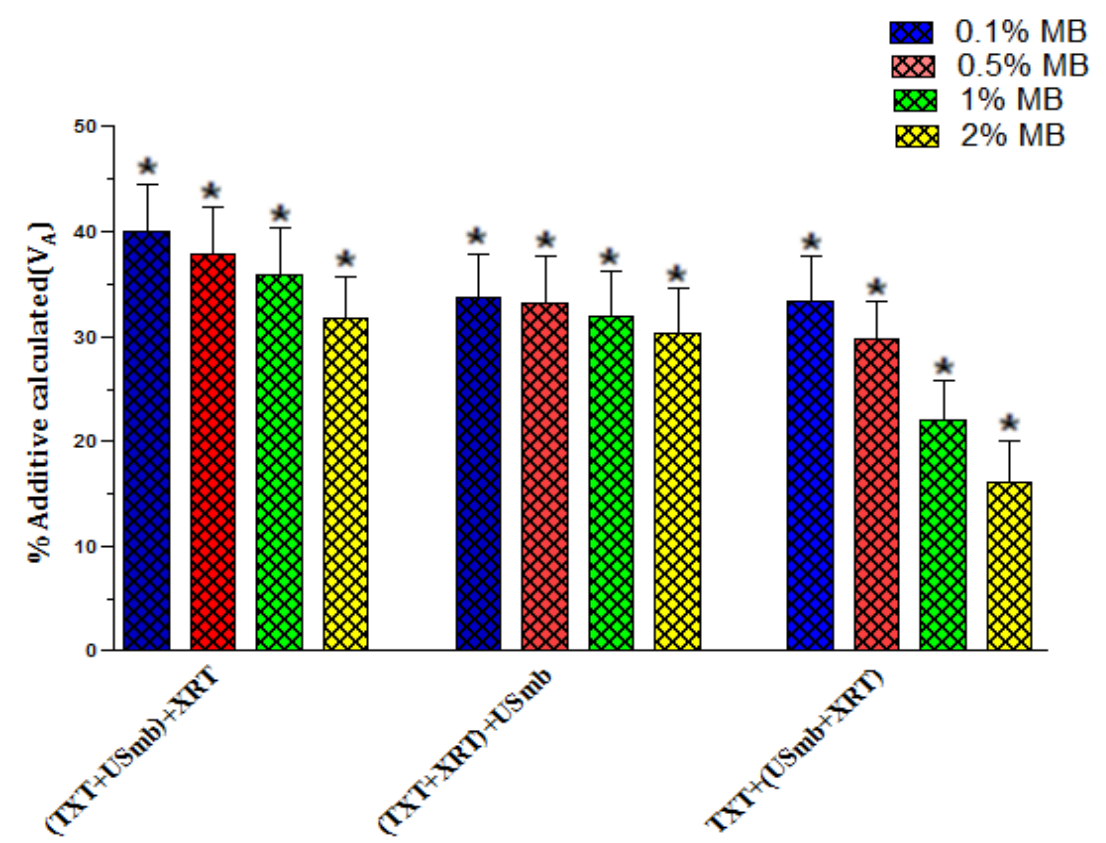

Figure 2.9: (a) The calculated additive effect (VA) compared to the experimental cell viability (VC) in Fig2.9 (a) for the different treatment combination at $(0.1,0.5,1,2 \%(\mathrm{v} / \mathrm{v}))$ microbubbles concentrations. The asterisks identify the treatments that have a statistically significant compared to $\mathrm{V}_{\mathrm{c}}(\mathbf{b})$ The calculated additive effect (VA) of different permutations of TXT+USmb+XRT a statistically significant VC $<$ VA with $\mathrm{P}<0.05$. Figure 2.9(b) 


\subsection{Discussion}

The effect of the combined $\left(\mathrm{TXT}_{2 \mathrm{hr}}+\mathrm{USmb}+\mathrm{XRT}\right)$ treatment resulted in a cell viability of $\sim 2 \%$, $\sim 4$-folds less than that of the shorter duration $\left(\mathrm{TXT}_{5 \min }+\mathrm{USmb}+\mathrm{XRT}\right)$. The cell viability of the combined treatment $\left(\mathrm{TXT}_{2 \mathrm{hr}}+\mathrm{USmb}+\mathrm{XRT}\right)$ resulted in a $\sim 9$-folds and $\sim 3$-folds decrease at $0.1 \mathrm{nM}$ TXT concentration compared to $0.001 \mathrm{nmol} / \mathrm{mL}$ and $0.01 \mathrm{nmol} / \mathrm{ml} / \mathrm{mL}$ respectively. Every aspect of the combination of all three treatments resulted synergistical cell death. From our knowledge, there are no papers at this time that have focused on the combination of all three treatments except for one study completed by Mu et al. 2012 that treated cells with HIFU, TXT and XRT. This paper was able to produce significant results showing a $\sim 3.5$ fold decrease in tumour size between the control treatments and the combined treatments, however, the combined treatment was additive.

When comparing cell viability results from TXT alone treatments of $5 \mathrm{~min}$ and $2 \mathrm{hr}$, cell viability decreased by $\sim 1.1$ folds. A paper studying the effects of the same treatment observed similar results, wherein the decrease in cell viability was achieved with lower doses of TXT and longer treatment times compared to higher durations with shorter treatment times (Le et al. 2013). Previous studies have shown significant decreases in cell viability while increasing TXT treatment duration (Li et al. 2004; Freitas et al. 2011). Cell viability was also effected as concentration was increased with $\sim 92 \%$ viability at $0.001 \mathrm{nM}$ and $\sim 75 \%$ at $0.1 \mathrm{nM}$. This concentration dependent effect has been shown in previous studies where cell viability in endothelial cells decreased while increasing TXT concentration (Grant et al. 2003).

More specific to prostate cancer cells, a paper showed comparable cell viability values at 0.001nM ( 96\%) and 0.1nM ( 83\%) (Karshafian et al.2010). Furthermore, Li et al. 2004 showed 
that PC-3 cells were less able to recover when subjected to higher TXT concentrations (4nM) as opposed to lower concentrations ( $1 \mathrm{nM})$.

The USmb+TXT condition had an additive effect when considering TXT dose at concentrations (0.001 nM, 0.01nM) lower than $0.1 \mathrm{nM}$ and $\mathrm{MB}$ concentrations $(0.1 \%, 0.5 \%, 1 \%)$ lower than $2 \%$ with an average decrease in cell viability of $\sim 20 \%$ for both. Results also showed that cell viability decreased, by the same fraction as the TXT alone treatments, in regards to increasing duration ( 1.1 folds difference). However, given USmb enhanced the permeability of the cell membrane, the effect of USmb and TXT treatment from this paper was additive and not synergistic as previously shown in other papers (Goshal et al 2012; Goertz et al. 2012). Doxorubicin in vitro has been shown to cause synergistic effects at a concentration $10 \mu \mathrm{M}$, significantly higher than the amount used in this study. Though Goertz et al. 2012 performed the experiment in vivo, the results were synergistic with at a higher ultrasound pressure (1.65 $\mathrm{MPa})$ and transducer frequency $(1 \mathrm{Mhz})$. This suggests that a minimum concentration of TXT and ultrasound exposure is required to elicit a synergistic response.

When observing the effects of combining USmb+XRT, cell viability was measured in response to changes in MB concentration. Synergistic effects were observed at MB concentrations of $1 \%$ and $2 \%$, but were additive at $0.5 \%$ and $0.1 \%$ with $2 \mathrm{~Gy}$ radiation dose. A study pertaining to $\mathrm{USmb}+\mathrm{XRT}$ treatments also reported synergy at MB concentrations above $1 \%$ with PC-3 cells in vitro and in vivo as well as leukemia cells (AML) (Karshafian 2009). Synergism was also observed in vitro at $1 \% \mathrm{MB}$ concentration with a radiation dose of $3 \mathrm{~Gy}$ and a peak negative pressure of $580 \mathrm{kPa}$ (same pressure used in this study) (Karshafian et al. 2010). Two other papers studying in vitro AML cells and in vivo bladder cancer showed radiosensitivity in cells increase with $\mathrm{MB}$ concentration (cell death beginning to peak at 1\%) and synergistic decrease of 
vasculature (1\% and 3\%) respectively (Karshafian et al. 2009; Tran et al. 2012). Kim et al. 2012 also showed synergy at $1 \%$ MB concentration with $59 \%$ cell death, but in addition showed synergistic cell death even at $0.01 \%$, where the ultrasound peak negative was pressures $(750 \mathrm{kPa})$, compared to $(580 \mathrm{kPa})$ in this study.

Being a radiosensitizer, TXT treatment in combination with radiotherapy produced significant but additive cell death at all chemotherapy concentrations and durations with maximum cell death at $0.1 \mathrm{nM}$ and the $2 \mathrm{hr}$ treatments respectively. Similar to previous paper that showed a significant decrease in cell viability when cells were subjected to TXT and radiation together (Pradier et al. 2001; Lee et al. 2012). Studies also achieved synergy with TXT+XRT treatment in HeLa cells and feline and canine cancer cell lines due to higher drug concentrations (30nM) and radiation dose (10Gy) used in the studies (Balkman et al. 2012). Though significant, this suggests that the concentration of drug present in the solution was a limiting factor to synergistically cause cell death (Balkman et al. 2012). 


\section{Possible Enhancements Mechanism(s):}

TXT+ USmb+XRT caused a synergistic decrease in cell viability as a result of the effects of ultrasound and microbubbles, primarily enhancing cell membrane permeability as well as stimulating apoptosis through increase ceramide production.

Owing to the hydrophobic properties of TXT, the drug is capable of passively diffusing across cell membranes. Since passive diffusion depends on the concentration gradient drugs across the membrane, among other factors such as temperature and surface area, the increased concentration of drug results in an increased rate of diffusion (Steffansen et al. 2010). Increasing exposure provided the drug with further time to diffuse across the cell membrane therefore increasing the number of TXT molecules found within the cell (Hacker et al. 2009). Moreover, though rate of diffusion decreased over time, TXT would continue to flow across the membrane until its equilibrium explaining how cell viability was inversely proportional with time (Hacker et al. 2009). The recovery time of cells is also effected at higher concentrations suggesting TXT may inhibit cell growth along with enhancing cell death.

At optimal ultrasound conditions, microbubbles undergo a process called cavitation generating high amounts of energy causing increased cell membrane permeability and endocytosis (Chen et al. 2011). The increase of cell membrane permeability by USmb may have led to an increase in the initial rate of passive diffusion (Menter et al. 2012). According to Guzman et al. 2002, it was demonstrated after USmb treatment, cells were capable of taking up molecules as small as 623Da and up to $464 \mathrm{kDa}$ and larger, corresponding to the size of TXT ( 807 Da). In an additional paper concerning the maximum size of molecules adequate enough to flow through the pores, showed that the cut-off weight was above 2MDa in size (Karshafian et al. 2010; Sathishkumar et al. 2005). The majority of pores reseal within a few seconds however some 
pores have been shown to remain open up to 24 hours post USmb treatment (Zhao et al. 2008). This observation suggests that there was an ongoing period of sensitivity on the cell membrane even after cavitation of microbubbles. It is not clear whether this period after ultrasound exposure has a significant effect on permeability however it may be a factor enhancing diffusion.

One of the stimuli investigated in this paper, among many such as duration and acoustic pressure, was influencing the efficiency of drug uptake through changes in MB concentration (Walker et al. 1997; Tsai et al. 2009). A recent paper suggested that microbubbles within a homogenous solution follow a Poisson distribution explaining that each pore was generated by one bubble (Zhou et al. 2009). It has also been shown that the efficacy of drug delivery depended on the proximity of microbubbles to the membrane (Guzman et al. 2003). In addition, the full extent of sonoporation appears to be directly related to the bubble-to-cell ratio (Zhao et al. 2008). The results from these paper show that increasing MB concentration enhances sonoporation by increasing the likelihood of a microbubble located near the membrane surface and the number of pores formed.

When cells are subjected to TXT and are then exposed to XRT, there is a significant decrease in cell viability. The mechanism of action involves TXT causing a cell cycle stop in the most radiosensitive G2/M phase (Balcer-Kubiczek et al. 2008; Pawlik et al.2004). TXT is also involved in down regulating the SphK-1 gene related to ceramide metabolism, which indirectly increased the level of the signalling molecule that triggers apoptosis ( $\mathrm{Li}$ et al. 2004; Bassoy et al. 2012). Also, the increased effect may be due to the fact that cells have the biggest surface area and contain the most DNA during the G2 phase of the cell cycle relative to any point in time within the cell; both targets of radiotherapy. In addition, the repair mechanisms in place during 
the G2 phase are not as effective and elaborate in comparison to other phases, so substantial amount of damage to DNA will be less likely to become repaired (Parshad et al. 1985)

Synergism was observed within the USmb and radiotherapy treatment combination. Recent studies have reported that in both in vitro and in vivo studies the effect of radiation was increased following USmb treatment (Tran et al. 2012; Karshafian et al. 2007). Aside from the increased permeability employed by USmb, there were numerous bio-effects that promoted apoptosis, one of which was the increase in ceramide molecule as a result of cause cell membrane damage and DNA damage (Nikolova-Karakashian et al. 2010). The level at which ceramide was produced appeared to be linked to MB concentration as well as radiation dose (Czarnota et al. 2012). The rate of converting membrane bound sphingomyelinases to ceramide increases when cells are exposed to raditation (Mahrouki et al. 2012). The combined levels of USmb and radiation appear to elevate the level of ceramide considerably above a certain threshold resulting in significant cell death. The combined action also has a high impact on cell viability as it inhibits recovery as a result of treatment (Dritschilo et al. 1979).

The identified treatment modalities compliment one another in such a way to induce a synergistic effect on PC-3 cells. The combination of all three treatments triggered irreversible biological alterations within cells. Though it was shown that TXT in combination with any one treatment was unable to produce a synergistic response due to its low concentration, it was compensated by USmb and radiation within the combined condition. 


\subsection{4 - Limitations}

The in vitro cell PC3 suspension model used in the experiments allowed considerable control of environmental, biological, and exposure parameters. Other studies have also used similar designs for experiments (Karshafian et al., 2010; Ward et al., 2000). However, because PC-3 cells are an adherent cell line there may be differences in their responses. Also the results from a cell suspension study might not be comparable results from an in vivo model, another limitation of using the current model.

In addition, the effectiveness of the treatments was measured by cell viability, but the changes within the cell can be further analyzed. Future work will focus on measuring ceramide levels in the cell to appropriately determine its effect on apoptosis. Other work will identify the different changes in the cell at low and high TXT concentrations to understand its range of effects. 


\section{5 - Conclusions}

The combined treatment of Taxotere, ultrasound and microbubbles, and radiation is synergistic in PC3 cells in vitro. Cell viability decreased by $\sim 28$ fold with the combined treatment compared to XRT alone. The synergistic effects depended on drug concentration, treatment duration and the microbubble concentration. Cell viability of the combined treatment $\mathrm{TXT}_{2 \mathrm{hr}}+\mathrm{USmb}+\mathrm{XRT}$ is significantly lower compared to $\mathrm{TXT}_{5 \min }+\mathrm{USmb}+\mathrm{XRT}$. Combined treatment was synergistic at TXT concentration above $0.001 \mathrm{nmol} / \mathrm{ml}$ dose, and at $0.1 \%(\mathrm{v} / \mathrm{v})$ microbubble concentration. Ultrasound and microbubbles also induced a synergistic enhancement with ionizing radiation at $1 \%(\mathrm{v} / \mathrm{v})$ microbubble concentration. TXT and radiation treatments decreased cell viability more than radiation alone, but only achieved this effect additively. This study indicates that USmb+TXT+XRT may significantly enhance the desired effect of radiotherapy and potentially minimize toxic side effects by lowering the TXT dosage amounts. 


\section{References}

Balcer-Kubiczek, E.K., Attarpour, M., Wang, J.Z., Regine, W.F. The Effect of Docetaxel (Taxotere ${ }^{\circledR}$ ) on Human Gastric Cancer Cells Exhibiting Low-Dose Radiation Hypersensitivity. Clin Med Oncol 2, 301-311 (2008)

Balkman, C.E., Gieger, T.L., Zgola, M.M., Lewis, L.D., McEntee, M.C. In Vitro Characterization of Docetaxel as a Radiosensitizer in Canine and Feline Cancer Cell Lines. Open Journal of Veterinary Medicine

Bassoy, E.Y., Baran, Y. Bioactive sphingolipids in docetaxel-induced apoptosis in human prostate cancer cells. Biomedicine and Pharmacotherapy 66, 103-110 (2012)

Bhangal G., Halford S., Wang J., Roylance R., Shah R., Waxman J. (2000) Expression of the multidrug resistance gene in human prostate cancer. Urol Oncol 5: 118-121.

Chen, H., Brayman, A.A., Kreider, W., Bailey, W.R., Matula, T.J. Observations of translation and jetting of ultrasound-activated microbubbles in mesenteric microvessels. Ultrasound Med Biol 372, 2139-2148 (2011)

Choijamts, B., Naganuma, Y., Nakajima, K., Kawarabayashi, T., Miyamoto, S., Tachibana, K., Emoto, M. Metronomic irinotecan chemotherapy combined with ultrasound irradiation for a human uterine sarcoma xenograft. Cancer Science 102, 452-459 (2011)

Cussler, E. Diffusion Barriers. Journal for the Basic Principles of Diffusion Theory, Experiment and Application 6, 72.1- 72.12 (2007)

Czarnota, G.J., Karshafian, R., Burns, P.N., Wong, S., Mahrouki, A.A., Lee, J.W., Caissie, A., Tran, W., Kim, C., Furukawa, M., Wong, E., Giles, A. Tumor radiation response enhancement by acoustical stimulation of the vasculature. Proc Natl Acad Sc 109, 2033-2041 (2012)

Das, A., Salloum, F.N., Kukreja, R.C. The Role of PDE-5 Inhibitors in Prostate Cancer. Prostate Cancer- Diagnostic and Therapeutic Advances, Chapter 13 (2011)

Duan, H., Zhang, HJ., Yang, JQ., Oberley, LW., Futscher, BW., Domann, FE. MnSOD upregulates maspin tumor suppressor gene expression in human breast and prostate cancer cells. Antioxid Redox Signal 5, 677-88 (2003) 
Geers, B., Lentacker, I., Cool, S., Demeester, J., De Smedt. S.C., Sanders, N.N. Ultrasound responsive doxorubicin-loaded microbubbles; towards an easy applicable drug delivery platform. J Control Release 148, 59-60 (2010)

Ghoshal, G., Swat, S., Oelze, M.L. Synergistic Effects of Ultrasound-Activated Microbubbles and Doxorubicin on Short-Term Survival of Mouse Mammary Tumor Cells. ULTRASONIC IMAGING 34, 15- 22 (2012)

Grant, D.S., Williams, T.L., Zahaczewsk, M., Dicker, A.P. (2003). Comparison of antiangiogenic activities using paclitaxel (taxol) and docetaxel (taxotere). Int J Cancer 104, 121129

Gravis, G., Bladou, F., Salem, N., Macquart-Moulin, G., Serment, G., Camerlo, J., Genre, D., Bardou, V., Maraninchi, D., Viens, P. Weekly Administration of Docetaxel for Symptomatic Metastatic Hormone-Refractory Prostate Carcinoma. Cancer 98, 1627-34 (2003)

Guzman HR, McNamara AJ, Nguyen DX, Prausnitz MR. Bioeffects caused by changes in acoustic cavitation bubble density and cell concentration: A unified explanation based on cell-tobubble ratio and blast radius. Ultrasound Med Biol 29, 1211-1222 (2003)

Guzmán, H.R., Nguyen, D.X., McNamara, A.J., Prausnitz, M.R. Equilibrium loading of cells with macromolecules by ultrasound: effects of molecular size and acoustic energy, Journal of pharmaceutical sciences 91 7,1693-1701(2002)

Haber, A.H., Rothstein, B.E. Radiosensitivity and Rate of Cell Division: "Law of Bergonie and Tribondeau". Science 163, 1338-1339 (1969)

Hacker, M., Bachmann, K., Messer, W. (2009). Pharmacology: Principles and Practice. Burlington, MA: Academic Press.

Karshafian R, Giles A, Burns PN, Czarnota GJ. Ultrasound microbubble potentiated sensitization of cells and tumors to radiotherapy. Radio- ther Oncol 2007. 84S2, S27

Karshafian, R., Giles, A., Burns, P., Czarnota, G.J. Ultrasound-activated Microbubbles as Novel Enhancers of Radiotherapy in Leukemia Cells in Vitro. IEEE International Ultrasonics Symposium Proceedings (2009) 
Karshafian, R., Samac, S., Bevan, P.D., Burns, P.N. Microbubble mediated sonoporation of cells in suspension: Clonogenic viability and influence of molecular size on uptake. Ultrasonics 50, 691-697 (2010)

Kawai K., Sakurai M., Sakai T., Misaki M., Kusano I., Shiraishi T., et al. (2000) Demonstration of MDR1 P-glycoprotein isoform expression in benign and malignant human prostate cells by isoform-specific monoclonal antibodies. Cancer Lett 150: 147-153.

Kolesnick, R., Fuks, Z. Radiation and ceramide-induced apoptosis. Oncogene 22, 5897-906 (2003)

Lee, J., Karshafian, R., Papanicolau, N., Giles, A., Kolios, M.C., Czarnota, G.J. Quantitative ultrasound for the monitoring of novel microbubble and ultrasound radiosensitization. Ultrasound in Med and Biol 38, 1212-1221 (2012)

Li, Y., Li, X., Hussain, M., Sarkar, F.H. Regulation of Microtubule, Apoptosis, and Cell CycleRelated Genes by Taxotere in Prostate Cancer Cells Analyzed by Microarray. Neoplasia 6,158 $167,(2004)$

Mehier-Humbert, S., Bettinger, T., Yan, F., \& Guy, R. H. (2005). Plasma membrane poration induced by ultrasound exposure: implication for drug delivery. Journal of controlled release : official journal of the Controlled Release Society, 104(1), 213-22. doi:10.1016/j.jconrel.2005.01.007

Meijering, B.D., Juffermans, L.J., van Wamel, A., Henning, R.H., Zuhorn, I.S., Emmer, M., Versteilen, A.M., Paulus, W.J., van Gilst, W.H., Kooiman, K., de Jong, N., Musters, R.J., Deelman, L.E., Kamp, O. Ultrasound and microbubble-targeted delivery of macromolecules is regulated by induction of endocytosis and pore formation. Circ Res 104, 679-87 (2009)

Menter DG, Ramsauer VP, Harirforoosh S, Chakraborty K, Yang P, et al. (2011) Differential Effects of Pravastatin and Simvastatin on the Growth of Tumor Cells from Different Organ Sites. PLoS ONE 6(12): e28813. doi:10.1371/journal.pone.0028813

Mishra, K.P. Cell membrane oxidative damage induced by gamma-radiation and apoptotic sensitivity. J Environ Pathol Toxicol Oncol 23, 61-6 (2004) 
Mothersill, C., Seymour, C. Radiation-induced bystander effects, carcinogenesis and models. Oncogene 22, 7028-33 (2003)

Mu, Z., Ma, C-M., Chen, X., Cvetkovic, D., Pollack, A., Chen, L. (2012). MR-guided pulsed high intensity focused ultrasound enhancement of docetaxel combined with radiotherapy for prostate cancer treatment. Physics in Medicine and Biology 57, 535-545

Nikolova-Karakasjian MN, Rozenova K (2010) Sphingolipids as Signaling and Regulatory Molecules, eds C Chalfant and M Del Poeta (Landes Bioscience and Springer Science and Business Media, New York), pp 86-107.

O'Donnell, R.T., DeNardo, S.J., Miers, L.A., Lamborn, K.R., Kukis, D.L., DeNardo, G.L., Meyers, F.J. Combined modality radioimmunotherapy for human prostate cancer xenografts with taxanes and 90yttrium-DOTA-peptide-ChL6. Prostate 50, 27-37 (2002)

Okada, K., Kudo, N., Niwa, K., Yamamoto, K. A basic study on sonoporation with microbubbles exposed to pulsed ultrasound. J Med Ultrasonics 32, 3-11 (2005)

Parshad, R., Sanford, K.K., Jones, G.M. Chromosomal radiosensitivity during the G2 cell-cycle period of skin fibroblasts from individuals with familial cancer. Cell Biology 82, 5400-5403

Pawlik, T.M., Keyomarsi, K. Role of cell cycle in mediating sensitivity to radiotherapy. Int J Radiat Oncol Biol Phys 59, 928-42 (2004)

Pressler H, Sissung TM, Venzon D, Price DK, Figg WD (2011) Expression of OATP Family Members in Hormone-Related Cancers: Potential Markers of Progression. PLoS ONE 6(5): e20372. doi:10.1371/journal.pone.0020372

Rapoport, N., Gao, Z., Kennedy, A. Multifunctional nanoparticles for combining ultrasonic tumor imaging and targeted chemotherapy. J Natl Cancer Inst 99, 1095-106 (2007)

Rapoport, N.Y., Kennedy, A.M., Shea, J.E., Scaife, C.L., Nam, K. Controlled and targeted tumor chemotherapy by ultrasound-activated nanoemulsions/microbubbles. J Control Release 138, 268276 (2009) 
Rifai, B., Arvanitis, C.D., Bazan-Peregrino, M., Coussios, C.C. Cavitation-enhanced delivery of macromolecules into an obstructed vessel. J Acoust Soc Am 128, 310-15 (2010)

Sathishkumar, S., Boyanosky, B., Karakashian, A.A., Rozenova, K., Giltiay, N.V., Kudrimoti, M., Mohiuddin, M., Ahmed, M.M., Nikolova-Karakashian, M. Elevated sphingomyelinase activity and ceramide concentration in serum of patients undergoing high dose spatially fractionated radiation treatment: implications forendothelial apoptosis. Cancer Biol Ther 4, 97989 (2005)

Simões-Wüst, A.P., Schürpf, T., Hall, J., Stahel, R.A., Zangemeister-Wittke, U. Bcl-2/bcl-xL bispecific antisense treatment sensitizes breast carcinoma cells to doxorubicin, paclitaxel and cyclophosphamide. Breast Cancer Research and Treatment 76, 157-166 (2002)

Steffanson, B., Brodin, B., Neilson, C.U. (Eds.). (2010). Molecular Biopharmaceutics. Grayslake, IL: Pharmaceutical Press.

Takizawa, M., Fukudu, S., Yokohama, M., Miyatake, Y., Inuyama, Y. An experimental study of the combined effect of radiotherapy and chemotherapy on head and neck squamous cell carcinoma cell line. Aurus Nasus Larynx 28, 83-86 (2001)

Ting, H.J., Hsu, J., Bao, B.Y., Lee, Y.F. Docetaxel-induced growth inhibition and apoptosis in androgen independent prostate cancer cells are enhanced by 1a,25-dihydroxyvitamin D3. Cancer Letters 247, 122-129 (2007)

Tlaxca' J.L., Anderson, C.R., Klibanov, A.L., Lowrey, B., Hossack, J.A., Alexander, J.S., Lawrence, M.B., Rychak, J.J. Analysis of in vitro Transfection by Sonoporation Using Cationic and Neutral Microbubbles. Ultrasound in Medicine \& Biology 36, 1907-1918 (2010)

Tran, W.T., Iradji, S., Sofroni, E., Giles, A., Eddy, D., Czarnota, C.J. Microbubble and ultrasound radioenhancement of bladder cancer. British Journal of Cancer 107, 469-476 Tsai KC, Liao ZK, Yang SJ, Lin WL, Shieh MJ, Hwang LH, Chen WS. Differences in gene expression between sonoporation in tumor and in muscle. J Gene Med 11, 933-940 (2009)

Verweij, J., Clavel, M., Chevalier, B. Paclitaxel (Taxol ${ }^{\mathrm{TM}}$ ) and docetaxel (Taxotere ${ }^{\mathrm{TM}}$ ): Not simply two of a kind. Annals of Oncology 5, 495-505 (1994) 
Walker KW, Pantely GA, Sahn DJ. Ultrasound-mediated destruction of contrast agents. Effect of ultrasound intensity, exposure, and frequency. Invest Radiol 327, 28-734 (1997)

Ward, M., Wu, J., \& Chiu, J. F. (2000). Experimental study of the effects of Optison concentration on sonoporation in vitro. Umb, 26(7), 1169-1175.

Yoon, I., Han, S., Choi, Y.H., Kang, H.E., Cho, H.J., Kim, J.S., Shim, C.K., Chung, S.J., Chong, S., Kim, D.D. Saturable sinusoidal uptake is rate-determining process in hepatic elimination of docetaxel in rats. Xenobiotica 42, 1110-1119 (2012)

Yudina, et al., Ultrasound-mediated intracellular drug delivery using microbubbles and temperature-sensitive liposomes, J. Control. Release (2011), doi:10.1016/j.jconrel.2011.06.006

Zhao, Y. Z., Luo, Y. K., Lu, C. T., Xu, J. F., Tang, J., Zhang, M., Zhang, Y., and Liang, H. D. Phospholipids-based microbubbles sonoporation pore size and reseal of cell membrane cultured in vitro. J. Drug Targeting, 2008, 16(1), 18-25.

Zhao, Y. Z., Luo, Y. K., Lu, C. T., Xu, J. F., Tang, J., Zhang, M., Zhang, Y., and Liang, H. D. Phospholipids-based microbubbles sonoporation pore size and reseal of cell membrane cultured in vitro. J. Drug Targeting, 2008, 16(1), 18-25.

Zhou, Y., Kumon, R.E., Cui, J., Deng, C.X. The size of sonoporation pores on the cell membrane. Ultrasound Med Biol 35, 1756-1760 (2009) 


\section{Chapter 3}

\section{SUMMARY \& FUTURE WORK}

\section{1 - Summary}

Chemotherapy and radiotherapy are the most common cancer treatment methods; however, both are limited by the dose applied due to toxicity. In this study, ultrasound and microbubble treatment was used to increase TXT uptake by the phenomenon known as sonoporation, as well causing a synergistic cell death in combination with radiation due to increased radiosensitivity.

Chemotherapy treatment duration, dose applied and microbubble concentration are factors, which play a significant role in the effectiveness of each treatment. A cell suspension model was exposed to combinations of TXT+USmb+XRT and was measured with clonogenic assay. The clonogenic viability data suggest that the combined treatment of TXT+ USmb+XRT with $2 \mathrm{hr}$ exposure of $0.1 \mathrm{nmol} / \mathrm{mL}$ TXT dose and $2 \%(\mathrm{v} / \mathrm{v}) \mathrm{MB}$ concentration produced the greatest cell death with $\sim 2 \%$ cell viability.

Prostate cancer cells were able to uptake more chemotherapy drug in the two hour treatment duration compared to 5 minute duration, with $\sim 4$ fold decrease in cell viability in the $\mathrm{TXT}_{2 \mathrm{hr}}+$ USmb+XRT compare to $\mathrm{TXT}_{5 \mathrm{~min}}+\mathrm{USmb}+\mathrm{XRT}$. The passive diffusion of the drug suggests that the longer durations and higher concentration of chemotherapy drug around the cell will lead to more drug crossing the cell membrane relative to shorter durations and smaller concentrations. Synergism was achieved with the combined treatment $\mathrm{TXT}_{2 \mathrm{hr}}+\mathrm{USmb}+\mathrm{XRT}$ among all threechemotherapy dose $(0.001,0.01,0.1 \mathrm{nmol} / \mathrm{ml} / \mathrm{mL})$ with a $\sim 3$-fold decrease between each dose. In addition, the presence of microbubbles is significant to achieving a synergistic effect in the $\mathrm{TXT}_{2 \mathrm{hr}}+\mathrm{USmb}+\mathrm{XRT}$. 
The use of ultrasound and microbubble induced increased cell membrane permeability and radiosensitivity. Since the significantly low TXT concentrations and durations as well as microbubble concentrations obtained such significant cell death, the combination of all three treatments has the potential for clinical applications. The three-treatment combination TXT+USmb+XRT applied in this project demonstrated, for the first time, a synergistic increase in cell death.

\section{2 - Future work}

The combined treatments were applied in vitro under different conditions to investigate synergism and a possible insight of the mechanism behind cell death. This was done in vitro in order to control and manipulate the environment as to put focus on specific treatment parameters. It also gives us the choice for large number of samples due to the lower cost and shorter experimental time relative to in vivo studies; around 600 dishes were used for a statistically significant sample size to only 80 mice. Although large numbers of in vitro experiments can be performed, the limiting factor for this experiment is treating cells outside their normal environment (no surrounding tissues, no blood supply, no normal supply of nutrients) making it difficult to compare to in vivo experiments. Applying the chemotherapy, radiotherapy and USmb treatments in an animal model can provide an understanding of the mechanisms, as well help confirm the synergistic effects achieved within in vitro studies as shown in the previous chapter. 


\subsection{1 - In vivo Investigation of TXT, USmb and XRT}

\section{Materials and Methods}

Prostate cancer cells (PC3) were xenografted on the hind leg of severe combined immunodeficient (SCID) mice and treated with combinations of TXT+USmb+XRT. Low and higher frequency ultrasound images were obtained with RF signal data and power Doppler for the detection of blood within the tumour before and $24 \mathrm{hr}$ after the treatment. The mice were euthanized and its tumour was extracted for histology 24 hours after the treatment. 4 mice were used for each condition, with a total of 80 mice used for entire study.

Cancer cell: Human prostate cancer cell line (PC-3) (American Type Culture Collection, Manassas, VA, USA) were cultured using RPMI-1640 growth medium (Wisent, St Bruno, QC, Canada), which was supplemented with $1 \%$ penicillin/streptomycin (Gibco, Life Technologies, Burlington, ON, Canada) and 10\% fetal bovine serum (Thermo Scientific Hyclone, Logan, UT, USA). Cells were collected for injection using $0.05 \%$ Trypsin EDTA (Gibco).

In vivo animal model: The right hind legs of severe combined immunodeficient (SCID) male mice (Charles River Laboratory International Inc. Canada), 6 wk of age and $20-30 \mathrm{~g}$ in mass, were injected subcutaneously with $50 \mu \mathrm{L}$ of suspended PC3 cells and treated with different combinations of Chemo, USmb and XRT. Tumours approximately 6-11 $\mathrm{mm}$ diameter formed after 5-6 weeks, at which point the mice were ready for experimentation.

Chemotherapy drug (TXT): Taxotere (Taxotere®; MW $807.9 \mathrm{~g} / \mathrm{mol}$ ) was obtained through Sunnybrook Health Sciences Center from Aventis Pharmaceuticals, a member of sanofi -aventis Group (Bridgewater, NJ,U.S.A). A $100 \mu \mathrm{L}$ dilution of taxotere was prepared at a concentration of 1.25 Dilution/Volume and administered through a tail-vein catheter, then flushed with saline solution. 
Ultrasound and microbubble treatment: element ultrasound transducer with a $500 \mathrm{kHz}$ center-frequency (IL0509HP, Valpey Fisher Inc., Hopkinton, MA). A waveform generator (AWG520, Tektronix Inc., Beaverton, OR) and a power amplifier (RPR4000, Ritec Inc., Warwick, RI) were used to amplify the signal to the transducer. The mice were exposed to ultrasound for duration of 2 minutes to 16 cycles of $32 \mu$ s pulse duration, $50 \mathrm{~ms}$ sequence duration, 10 seconds sequence repetition period, $3 \mathrm{kHz}$ pulse repetition frequency, and $350 \mathrm{kPa}$ and $580 \mathrm{kPa}$ peak negative pressures of ultrasound using a calibrated ultrasound transducer,. Two ultrasound pressure were used hypothesizing that the lower ultrasound pressure $(350 \mathrm{kPa})$ increases sonoporation effects and a higher pressure $(580 \mathrm{kPa})$ increase cell sensitivity for radiation by more damage on the cell membrane, with 5 minutes between the two ultrasound treatments.

Definity® microbubbles $(100 \mu \mathrm{L})$ were used at a concentration of $0.5 \% \mathrm{v} / \mathrm{v}$ (volume concentration) (Lantheus Medical Imaging, Inc., North Billerica, MA, USA) activated using a Vialmix device (Lantheus Medical Imaging) and injected through a tail-vein catheter followed by a $100 \mu \mathrm{L}$ saline flush.

Radiotherapy (XRT): Tumours were exposed to an 8Gy single fraction dose at 160kVp and 200cGy/min dose rate (Faxitron Xray Corporation, Lincolnshire, IL, USA). The mouse body except for the tumour was covered with a 3-mm-thick lead sheet. Mice were treated with radiation after the combination of chemotherapy and/or USmb treatments as well as radiation alone. 
Growth delay: The tumours (from all the treatment conditions) were measured three times a week with a calliper until the tumour inhibited mice mobility. The mice were then sacrificed by means of cervical dislocation. Tumour volume was determined using $(1 \times \mathrm{w} \times \mathrm{h} \times \pi) / 6$ to account for its spherical shape.

Histology: Tumour samples were fixed for 24 hours in $1 \%$ parformaldehyde, and embedded in paraffin blocks. Sections were cut from distal to proximal ends of the tumour. Slices were then cytospinned at 2000G and fixed for 30 minutes, followed by hermatoxylin and eosin staining, Tunel or CD31 staining. The selection of apoptotic cells done manually for the tunnel staining using Imagej manually, the tunnel positive area divided by the total area to find the death percentage.

Ultrasound imaging: A VEVO 770 (Visualsonics, Toronto, Canada) imaging/scanning system was used in B-mode, power Doppler, and RF signal data 24 hours pre- and post-treatment to obtain data. The scan began from the upper leg of the mouse and moved towards the foot. Power Doppler mode was used with an RMV707b transducer at $20 \mathrm{MHz}$ central frequency with a step size of $0.2 \mathrm{~mm}$, a wall filter of $2.0 \mathrm{~mm} / \mathrm{s}$, and a scan speed of $2.0 \mathrm{~mm} / \mathrm{s}$. RF data was acquired collecting $250 \mathrm{RF}$ lines per image. The RF data analyzed with the difference in $\mathrm{dB}$ that increase in backscatter caused by increase in the isolate apoptotic cell. 


\section{Results \& Discussion}

Histology images: Terminal deoxynucleotidyl transferase dUTP nick end labeling (TUNEL) is a common method of cell staining used to detect apoptotic cells. This technique detects apoptotic cells by labelling fragmented DNA. Samples are stained by immunoperoxidase and then visualized using bright field microscopy. The staining used at University Health Network (UHN) was a homemade kit, similar to the "Apoptag Kit" sold by EMD Millipore. Drug induced DNA damage is not indicated by TUNEL assay analysis, unless the drug has apoptotic effects. So there is another way to assess cell death by TUNEL assay highlights fragmented DNA by binding to the free 3'OH end of the fragments that have modified nucleotides. This type of TUNEL analysis is useful because it detects apoptosis early on, before nuclei undergo significant morphological changes. The more labelling of fragmented DNA (the darker the area) the more cell death. The size of the labelling area correlated with the increase in treatments. A significant increase in sparse tissue is observed with TXT+USmb+XRT compared with TXT+XRT and TXT+XRT, and each treatment alone. This promotes and emphasizes the potential of the combined treatment of TXT+USmb+XRT (Figuer 3.1)

Hematoxylin and Eosin (H\&E) Staining is a technique used to identify various regions of cells such as the cytoplasm, nucleus and connective tissue, as well as the overall structure of a cell or tissues.

A CD31 stain is used to indicate regions of endothelial cells, and in this case to highlight regions of malignant vascular tumours. CD31 plays an important role in angiogenesis, and is expressed by all human pulmonary endothelial cells. Because tumours have intricate and excessive vasculature, stains for CD31 can indicate areas of dense vasculature and therefore a possible tumour. The areas in the images indicate the tumour region (Figure 3.1). 
Further analysis will be done on selected conditions via The Ki-67 protein, a cellular marker for proliferation. ${ }^{[5]}$ It is strictly associated with cell proliferation. During interphase, the Ki67 antigen can be exclusively detected within the cell nucleus, whereas in mitosis most of the protein is relocated to the surface of the chromosomes. Ki-67 protein is present during all active phases of the cell cycle $\left(G_{1}, S, G_{2}\right.$, and mitosis), but is absent from resting cells $\left(G_{0}\right)$. 


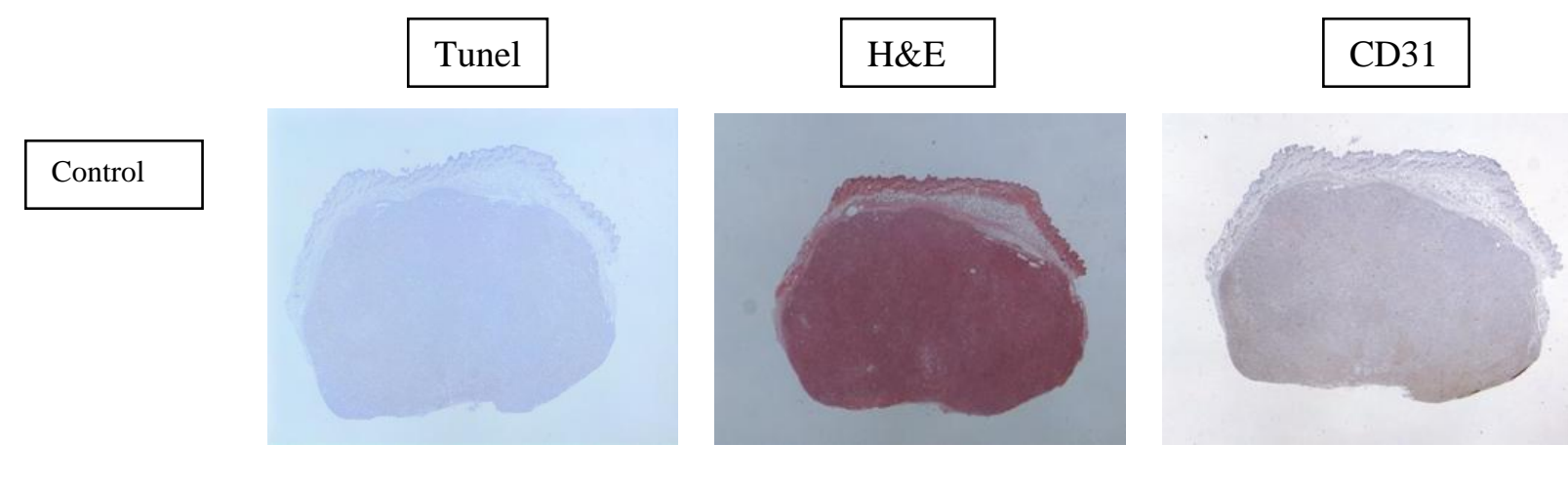

USmb $350 \mathrm{kPa}$
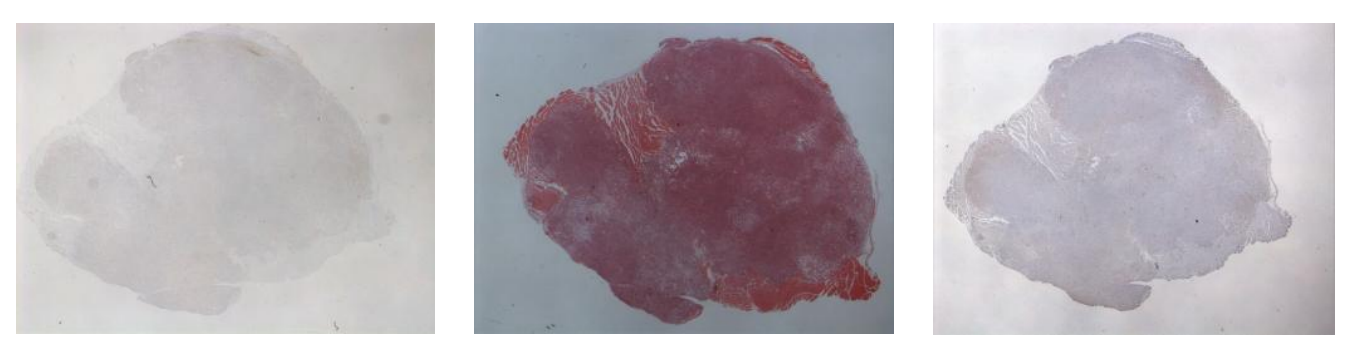

USmb $580 \mathrm{kPa}$
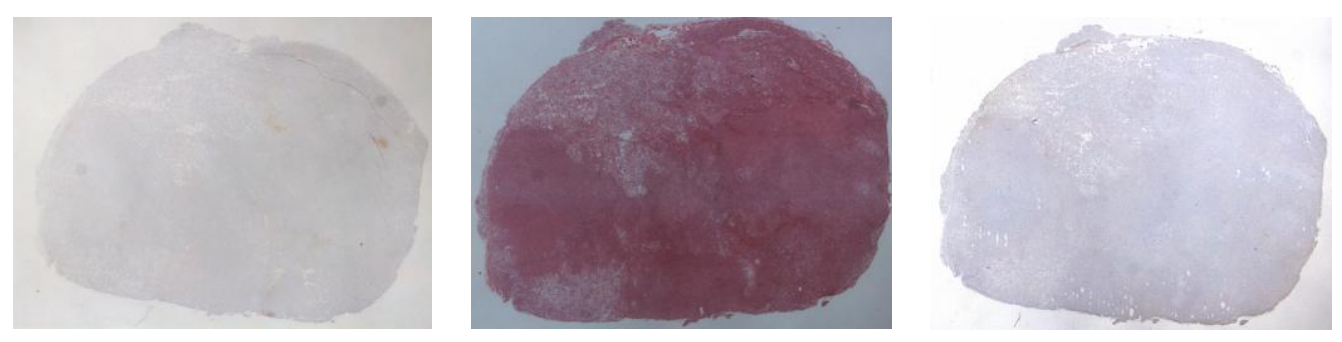

\section{USmb $350 \mathrm{kPa}+$}

USmb580 kPa
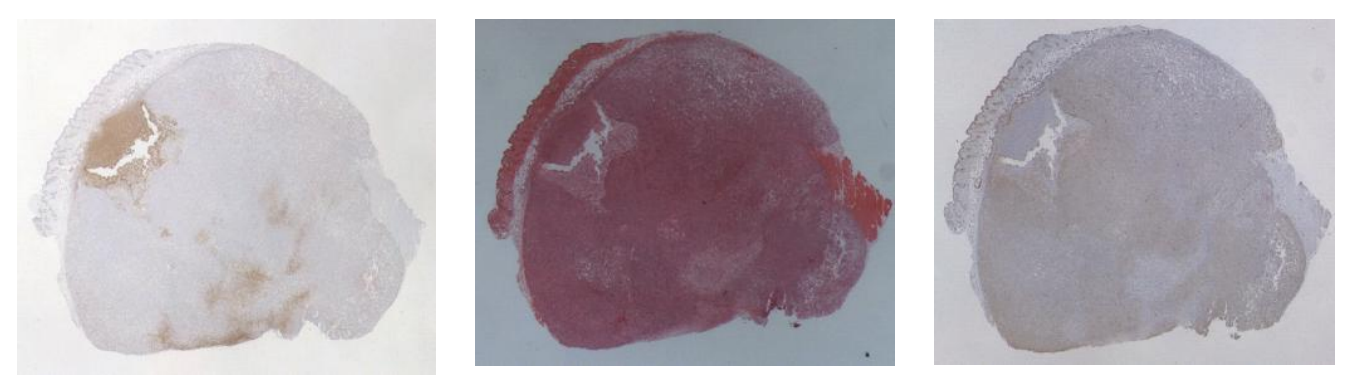

TXT
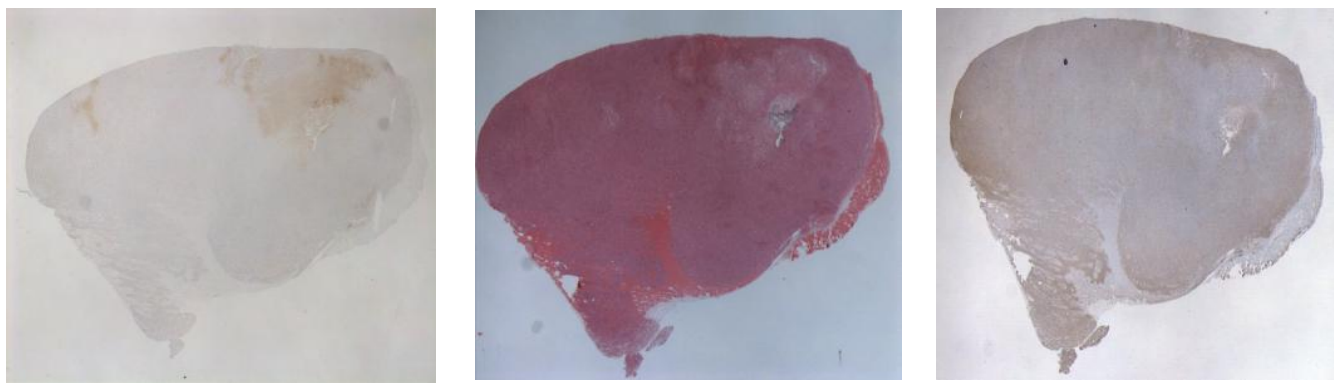

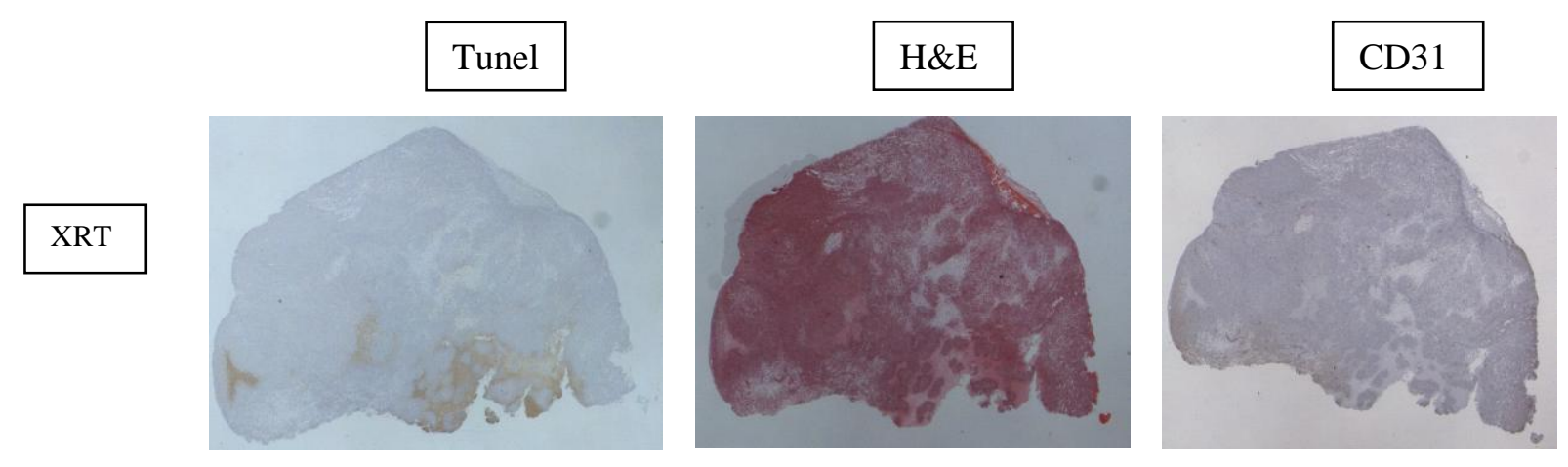

TXT+USmb580 $\mathrm{kPa}$

TXT+ USmb $350 \mathrm{kPa}+$

USmb580 $\mathrm{kPa}$

USmb 350+ USmb $580 \mathrm{kPa}+\mathrm{XRT}$
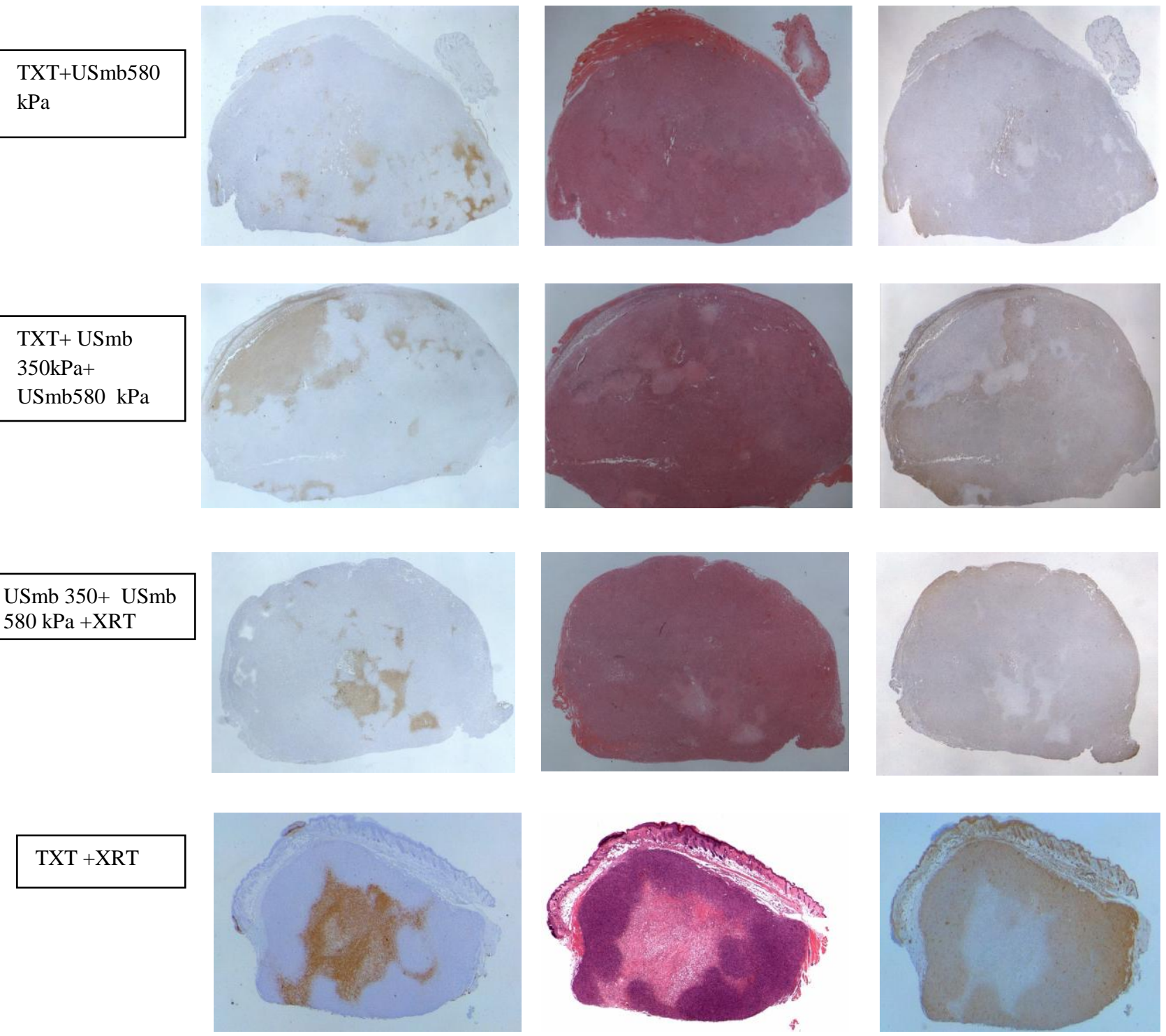


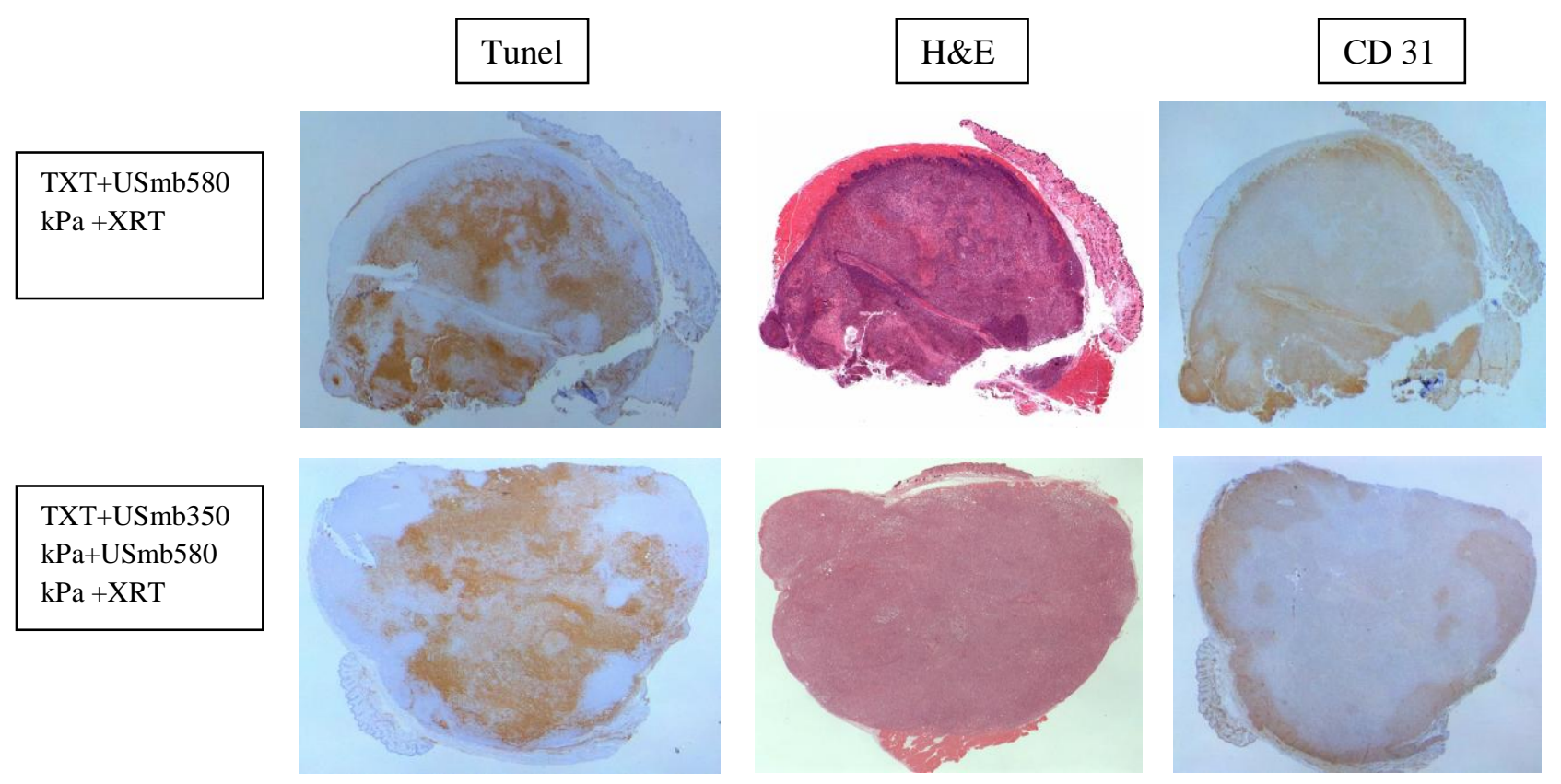

Figure 3.1: Representative Tunel, hematoxylin and eosin (H\&E), and CD31 stains for the untreated control, USmb 350 kpa, USmb 580 kPa, USmb 350 kPa+ USmb 580 kPa, TXT, XRT, TXT+USmb 580 $\mathrm{kPa}$, TXT+ USmb 350 +USmb580 kPa, USmb 350+USmb580 kPa +XRT, TXT +XRT, TXT+USmb580 $\mathrm{kPa}+\mathrm{XRT}$, and TXT+USmb 350nUSmb580 $\mathrm{kPa}+\mathrm{XRT}$. Images were taken at $1 \mathrm{x}$ magnification with a light microscope. 
Tunel positive cells: The area of Tunel positive cells was selected in each Tunel image consisting of four images for each condition. Based on these results, there appears to be a linear increase in the area of Tunel positive cells until a maximum of $\sim 70 \%$ of cell death area with the combination of all treatments.

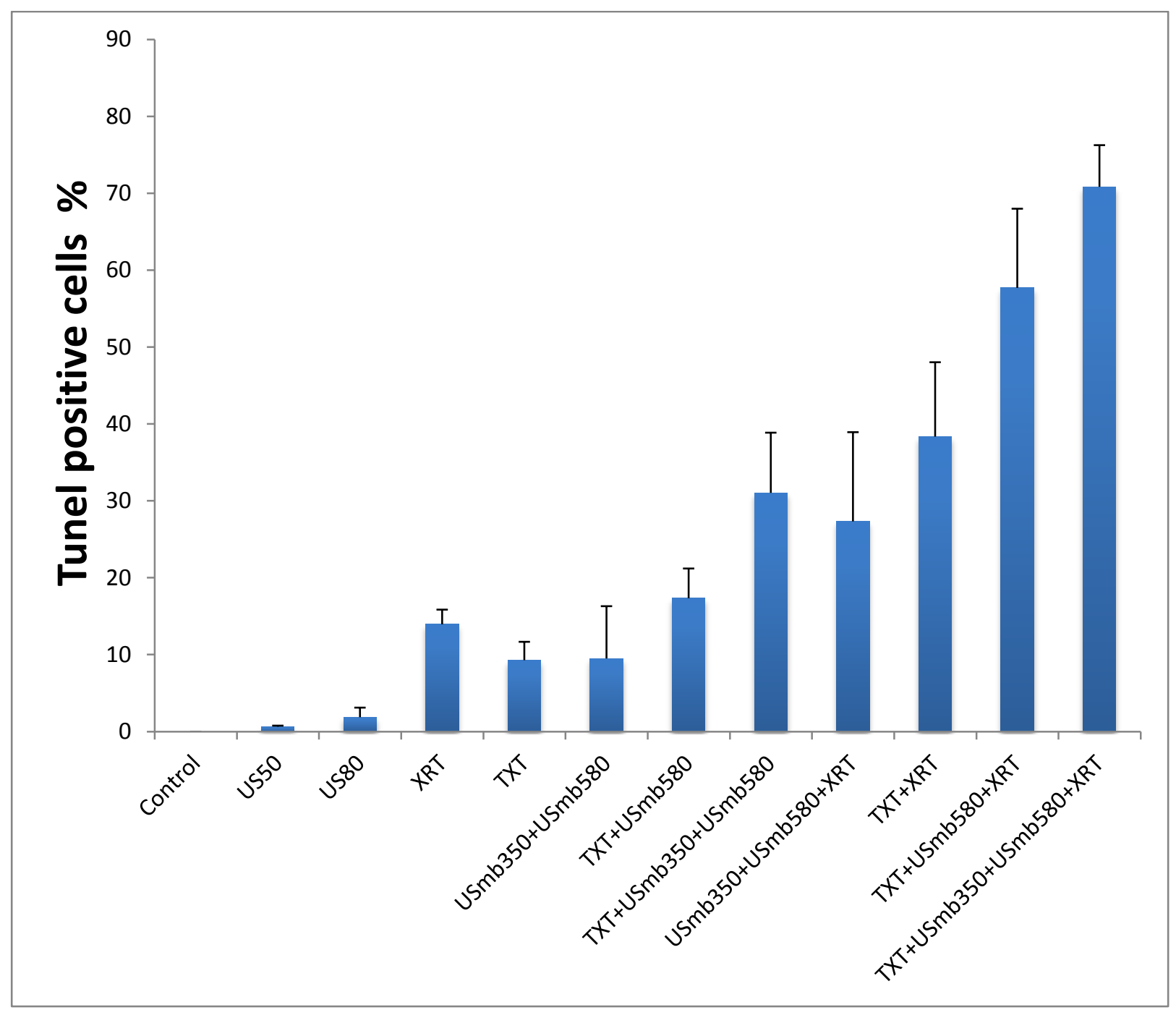

Figure 3.2: Tunel- positive apoptotic cells exposed to different treatments conditions. Four animals per condition were used to calculate the means and SD of the Tunel- postive cells. Significant difference between the $\mathrm{TXT}+\mathrm{USmb} 350 \mathrm{kPa}+\mathrm{USmb} 580 \mathrm{kPa}+\mathrm{XRT}$ and any other treatment condition $\mathrm{P}<0.05$. 
RF data analysis: High frequency ultrasound imaging of the tumour as used to detect cell death. There was a gradual increase in Midband fit beginning from control, which continued to increase to $9 \mathrm{~dB}$ when exposed to TXT+USmb350+USmb580+XRT. Change in cell nuclear material and the cell membrane during apoptosis led to the increase in scattering.

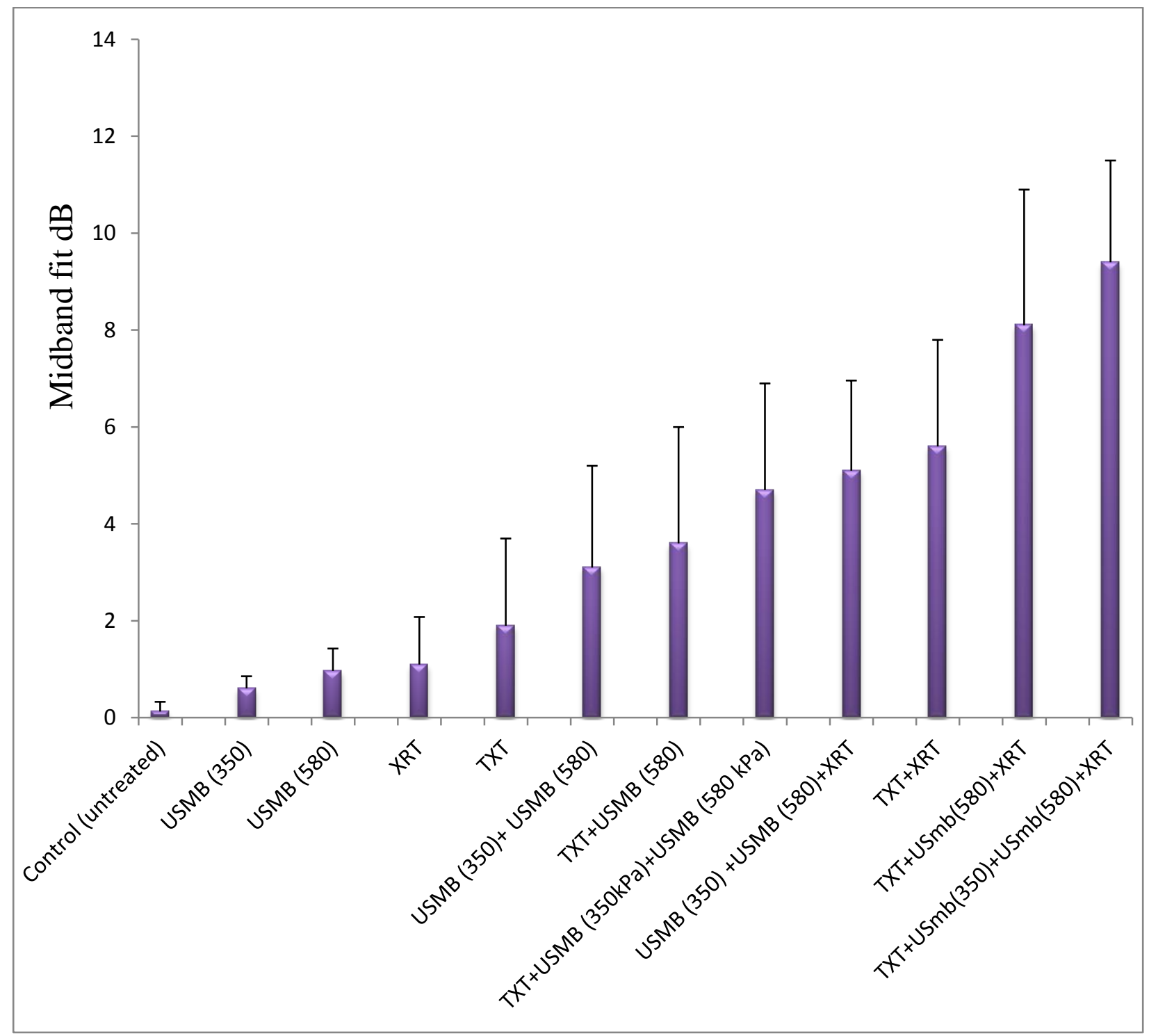

Figure 3.3: High frequency ultrasound imaging for the PC3 tumour. The RF readings obtained are the difference in the backscatter pre and post treatment for all the conditions. $\mathrm{N}=4$ for each condition. The bars represent SD. 
Growth delay: A growth delay study was performed for five different treatment conditions. Four mice were used per condition with a total of twenty mice used over 42 days of study Figure 3.4.The control group of mice significantly increased in tumour size through time after 28 days. The mice group exposed to XRT had inhibition in tumour volume and tumour recovery within the first 16 days. After 16 days, tumour size increased at a rate slower than control group and survival was longer ( $\sim 30$ days). TXT+XRT and USmb+XRT demonstrated similar growth curve. Both curves suggest a prolonged inhibition of recovery compared to XRT alone, however there is more animal survive with the TXT+XRT (Figure 3.5). The tumours treated with TXT+USmb(350+580)+XRT exhibited a significantly longer period or inhibition, reduced tumour size and prolonger survival beyond any other treatment group. Mice within this was sacrificed at the end of the study, which was 42 days long.

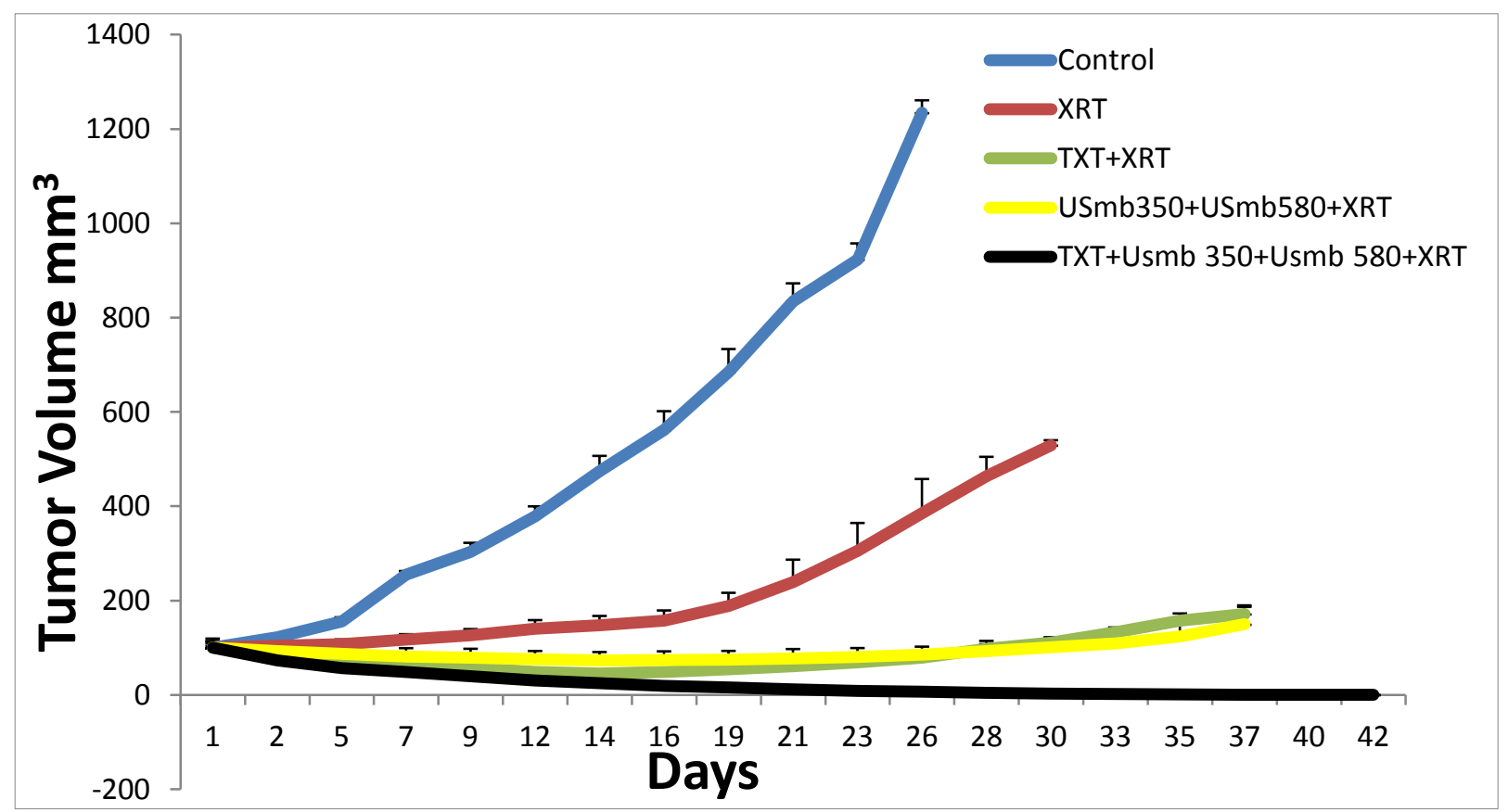

Figure 3.4:Growth delay curve of tumour growth post treatments normalized with untreated control $(\mathrm{n}=4)$. All microbubble treatments were done with $2.5 \%(\mathrm{v} / \mathrm{v})$, with a TXT dose of $1.25 \mathrm{mg} / \mathrm{ml}$ and $8 \mathrm{~Gy}$ X-ray radiation. 
Survival curve: The addition of TXT demonstrates postponed growth in tumours with both TXT+XRT and TXT+USmb+XRT. USmb (350 kPa)+ USmb (580 Kpa) +XRT also delayed tumour growth. The TXT USmb (350 kPa)+ USmb (580 Kpa) +XRT treatment caused a significant decrease in tumour size compared to all other treatment conditions, and it was undetectable through sight and touch by the end of the study (42 days). Tunel, H\&E and CD31 stains indicated that TXT USmb (350 $\mathrm{kPa})+$ USmb $(580 \mathrm{Kpa})+$ XRT produced a significant larger area of tumour cell death relative to all other treatment conditions. The combination of the three treatments in this study (TXT,USmb and XRT) led to a synergistic effect both In Vitro \& In Vivo. Further analysis should be done using power Doppler and high and low frequency Bmode images, as well as to detect blood within the tumour before and 24 hours after treatment.

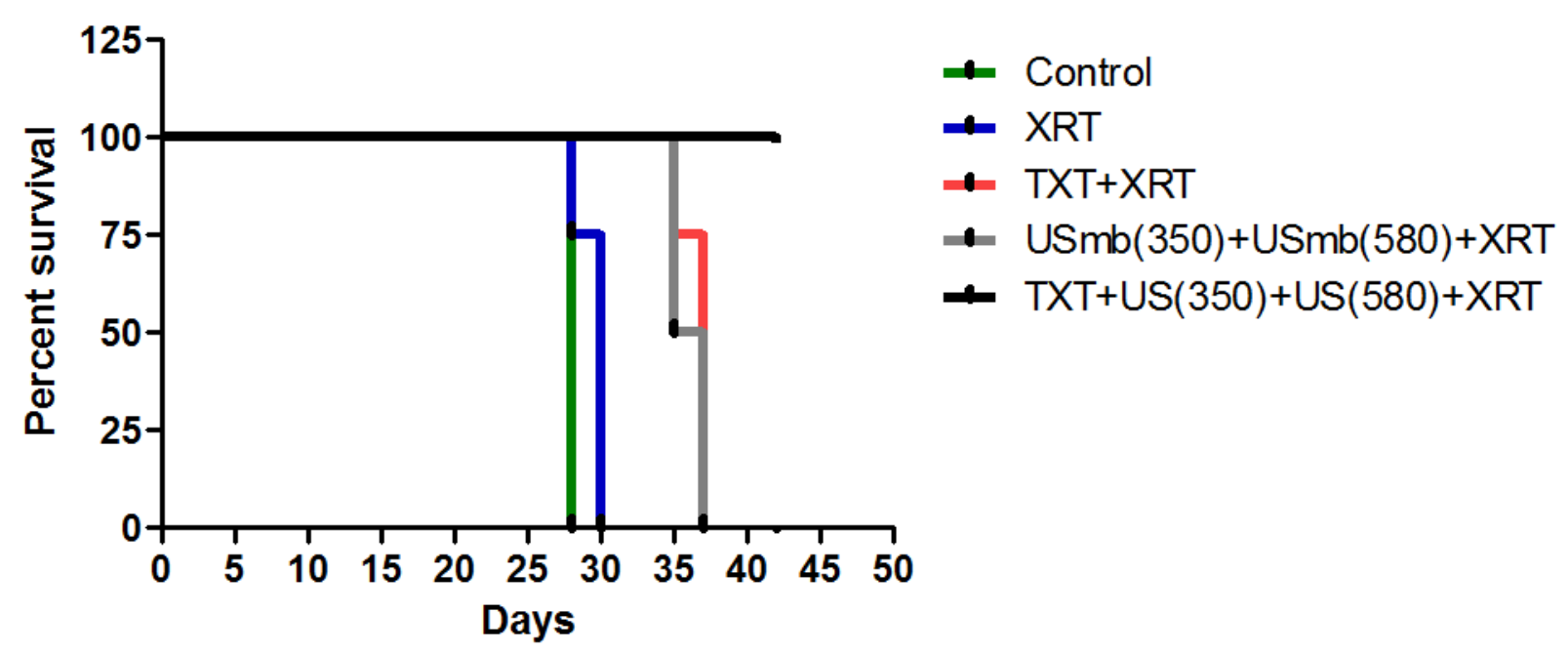

Figure 3.5: Survival proportions: Survival curves for tumour mice $n=4$. Control (the green line), treated by XRT only (the blue line) and treated by TXT following XRT treatment (the red line). Injection of MB and treated with US ( $350 \mathrm{kPa}$ ) with delays of 5 minutes for the next US (580 kPa) MB treatment following by XRT (the grey line). The combination of all three treatments are represented by the black line. 


\section{References}

Negoescu, A., Guillermet, C., Lorimier, P. Brambilla, E., Labat-Moleur, F. (1998). Importance of DNA fragmentation in apoptosis with regard to TUNEL specificity. Biomedicine \& Pharmacotherapy 52(6), 252-258.

Fenton, B.M. , Paoni, S.F., Lee, J., Koch, C.J., Lord, E.M.(1999).Quantification of tumour vasculature and hypoxia by immunohistochemical staining and $\mathrm{HbO}_{2}$ saturation measurements. British Journal of Cancer 79, 464-471.

Fischer, A.H., Jacobson, K.A., Rose, J., Zeller, R. (2006). Basic Methods in Microscopy: Hematoxylin and Eosin Staining of Tissue and Cell Sections. Cold Spring Harbor, NY: Cold Spring Harb Protoc. 